\title{
Die Verbreitungsweise der Diphtherie mit specieller Berücksichtigung des Verhaltens der Diphtherie in Breslau 1886--1890.
}

Eine epidemiologische Stadie.

Von

Professor C. Flügge

in Breslau.

(Hierzu Taf. IV-IX.)

Bis vor wenigen Jahren waren wir bezüglich der Erkenntniss der Diphtherieverbreitung lediglich auf ärztliche Beobachtungen und statistischepidemiologische Untersuchungen angewiesen. Erstere lehrten uns die directe Uebertragbarkeit der Krankheit auf Personen, welche sich in nächster Nähe des Kranken aufhalten und vielfältigen Berührungen mit diesem ausgesetzt sind; ferner erfuhren wir aus einigen besonders prägnanten Fällen Genaueres über die Incubatiouszeit, welche zwischen Ansteckung und Ausbruch der Krankheit liegt. Die epidemiologischen Untersuchungen leisteten rergleichsweise weniger, insofern sie zu widersprechenden und unsicheren Ergebnissen führten. Es war schwierig, zuverlässiges statistisches Material über Diphtherieerkrankungen oder Diphtherietodesfälle in grösserem Umfange zu erhalten und dasselbe dann so zu gruppiren, dass die natürlichen Schwankungen in der Verbreitungsweise der Krankheit mit den verschiedenen möglicherweise einflussreichen Factoren verglichen werden konnten. Trotz dieser Schwierigkeiten, die von den Statistikern mehrfach dargelegt sind, blieb aber nichts anderes übrig, als immer von neuem epidemiologisehe Beobachtungen anzustellen, weil wir damals schlechterdings kein anderes Mittel besassen, um über die Verbreitungsweise der Diphtherie Klarheit zu gewinnen.

Zeitschr. 1. Hygiene. XVII. 
Diese Sachlage hat sich wesentlich geändert seit der Entdeckung des Diphtheriebacillus durch Löffler (1). Nachdem die Löffler'schen Resultate durch Roux und Yersin (2), Babès (3), v. Hofmann (4), Kolisko und Paltauf (5) u. A. vollauf bestätigt sind, und nachdem fortgesetzte Studien uns über die Lebensbedingungen und Absterbebedingungen der Erreger, ihr Verhalten im Thierkörper, den Infectionsmodus, die Empfänglich keit bezw. Unempfänglichkeit der Versuchsthiere gegenüber den Bacillen unter verschiedenen Bedingungen, kurz über das gesammte biologische Verhalten der Bacillen belehrt haben, sind uns dadurch bestimmte Directiven für unsere Anschauungen über die Verbreitungsweise der Diphtherie gegeben. Nun ist allerdings der Einwand zulässig, dass vielleicht doch die natürliche Verbreitungsweise der Krankheit und namentlich ihr Auftreten als Epidemie von Factoren beeinflusst wird, denen wir bei unseren Laboratoriumsversuchen gar nicht Rechnung tragen können. Wenn daher wirklich die epidemiologische Forschung in einwandfreier Beweisführung Eigenthümlichkeiten in der Verbreitung aufdeckt, welche sich nicht mit demjenigen Ausbreitungsmodus vereinigen lassen, den wir aus den biologischen Eigenschaften des Bacillus uns ableiten müssen, dann bleibt eigentlich nichts übrig, als dass wir die Unzulänglichkeit unserer Laboratoriumsversuche eingestehen und die epidemiologischen Ergebnisse als ausschlaggebend für unsere Auffassung ansehen. Aber es ist andererseits sehr wohl zu bedenken, dass die statistisch-epidemiologischen Untersuchungen stets voller Fehlerquellen sind, die sich kaum jemals vollständig eliminiren lassen, und bereits sehr oft zu Täuschungen und Irrthümern geführt haben. Statistiker von Fach pflegen deshalb solchen Untersuchungen so viel als möglich fern zu bleiben und haben ihrer berechtigten Skepsis wiederholt scharfen Ausdruck gegeben (Engel, Knapp, v. Fircks u. A.). Die Laboratoriumsexperimente bewegen sich auf ungleich festerer Basis, sind leichter $\mathrm{zu}$ controliren und $\mathrm{zu}$ deuten. Es wird daher im Allgemeinen für unsere Erkenntniss förderlicher sein, wenn wir von dieser festen Basis ausgehen, und von ihr aus bestimmte Anschauungen über die Verbreitungsart der Diphtherie ableiten; dann aber mit diesen die Resultate der epidemiologischen Forschungen in Vergleich setzen. Decken letztere gewisse Eigenthümlichkeiten der Verbreitung auf, die mit den Eigenschaften der Erreger nicht harmoniren, so werden wir zunächst die betreffenden epidemiologischen Daten; denen so leicht Fehlerquellen anhaften, genauer auf ihre Beweiskraft prüfen müssen. Vielleicht führt dann eine nach bestimmten Gesichtspunkten vorgenommene Kritik bezw. eine nach richtigerer Methode ausgeführte Controluntersuchung $\mathrm{zu}$ anderen, unseren Laboratoriumsergebnissen sich besser anschliessenden Resultaten, so dass wir nicht nöthig haben, geheimnissvolle Momente $x, y$ oder $z$ 
anzunehmen, welche bei der natürlichen Verbreitung der Erreger im Gegensatz zu den experimentellen Uebertragungen mitwirken und welche geeignet sind, die eben klar gelegten Wege wieder von neuem zu verdunkeln.

A. Welche Verbreitungsweise der Diphtherie ergiebt sich aus den biologischen Eigenschaften der Diphtherieerreger?

Auf Grund der heute vorliegenden experimentellen Untersuchungen über den Diphtheriebacillus müssen wir uns folgende Vorstellungen über die Verbreitungsweise der Diphtherio bilden:

Die Diphtheriebacillen sind nachgewiesen im diphtherischen Belag der Erkrankten, in deren Auswurf und Mundsecret; sie sind oft noch mehrere Wochen nach Ablauf der Krankheit in lebendem und infectionstüchtigem Zustand im Munde und im Auswurf nachgewiesen. Ferner beherbergen erwiesener Maassen manche Erwachsene und ebenso unempfängliche Kinder virulente Diphtheriebacillen im Munde ohne andere Symptome als die einer leichten Angina, zuweilen selbst ohne alle Krankheitssymptome. Die Bacillen können durch Auswurf oder Mundsecret an die Hände gelangen oder an Taschentücher, Kleidung, Bettwäsche und verschiedenste Sachen, die mit dem Kranken in Berührung sind, auch auf den Fussboden und die Wände in der Nähe des Bettes; ferner-werden sie sicher von der Infectionsstelle aus auf das Ess- und Trinkgeschirr übertragen werden.

Die vom Kranken, Reconvalescenten oder leicht Erkrankten auf Wäsche, Ess- und Trinkgeschirr, Spielsachen u. s. w. übertragenen Erreger kōnnen unter günstigen Verhältnissen 4 bis 6 Wochen lebendig bleiben. Sind sie vor dem vollständigen Austrocknen, vor Belichtung und vor der Ueberwucherung durch Saprophyten geschützt, dann können sie 7 bis 9 Monate, vielleicht noch länger, am Leben bleiben. Feuchte Wäschebündel, im schwach belichteten Keller bei niederer Temperatur aufbewahrt, bieten günstigste Conservirungsbedingungen.

Von dem Kranken oder den inficirten Objecten aus wird der Transport der Keime auf die Mund- oder Nasenschleimhaut des Gesunden, abgesehen von etwaiger directer Aufnahme verspritzter Auswurfpartikelchen, stets durch Berührungen erfolgen. Ein Transport durch die Luft auf weitere Entfernungen hin, so dass die Berührungen nicht mehr in Concurrenz treten und die Luft mithin eine specifisch gefährliche Infectionsquelle repräsentirt, scheint nicht stattzufinden, weil die Diphtheriebacillen bei dem Grad von Trockenheit, den Luftstäubchen haben müssen, wenn sie leicht 
transportirbar sein sollen, absterben. ${ }^{1}$ In Folge der oft langen Haltbarkeit des Contagiums im feuchten und nahezu trockenem Zustand und im Hinblick auf die mancherlei Objekte, an denen dasselbe gelegentlich haftet, kann aber trotz des Ausschlusses der Luftinfection die Ansteckung in verschiedenster Weise erfolgen. Das eine Mal erstreckt sie sich nur auf die nächste Umgebung des Kranken und erfolgt hier durch directeste Berührung inficirter Theile des Kranken, durch Küsse, durch beim Husten des Kranken verspritztes Secret; oder durch Vermittelung der Hände, die mit dem Munde, dem Auswurf, den Taschentüchern, der beschmutzten Wäsche des Kranken u.s. w. und darauf mit dem eigenen Munde in Berührung kommen; oder durch Löffel, Tassen und dergl., die vom Kranken oder Reconvalescenten benutzt waren, eventuell auch nachdem sie oberflächlich und mit lauem Wasser gereinigt sind. Ein anderes Mal kann sich die Ansteckung fern vom Kranken ereignen; ein Bündel Wäsche, Spielsachen oder inficirte Nahrungsmittel kommen in andere Familien und rufen hier zuweilen noch nach langer Zeit Infectionen hervor. Oder gesunde dritte Personen, die einerseits mit dem Kranken in Berührung waren und an Kleidern, Händen, Instrumenten u. dgl. Secretpartikelchen fortšchleppen, können fernab wohnende Kịnder durch solche Partikelchen inficiren. Freilich wird es sehr selten sein, dass jene durch Gesunde verschleppte Partikelchen nun gerade in den Mund empfänglicher Kinder gelangen. Aber in gewissen Fällen, z. B. durch Vermittelung der bei der ärztlichen Untersuchung des Mundes benutzten Zungenspatel, ist eine Verschleppung durch Dritte sehr wohl möglich. Ungleich häufiger wird die Uebertragung durch Dritte darauf hinauskommen, dass es sich dabei nur um scheinbar Gesunde handelt, in deren Munde die Erreger - wenn auch in relativ geringer Zahl - vorhanden sind, und dass nun directe Berührungen mit diesen inficirten Personen den Uebertragungsmodus bilden; hierzu sind dann wiederum Küsse, gemeinsames Ess- und Trinkgeschirr, gemeinsame Taschentücher besonders geeignet.

Verschiedenheiten in der epidemischen Ausbreitung der Diphtherie und namentlich örtliche und zeitliche Schwankungen der.Frequenz können bei dieser Art der Ansteckung sehr wohl hervortreten und zwar werden hierzu folgende Ursachen mitwirken:

1. Verschiedene Bedingungen für die Vermehrung und Conservirung der Diphtheriebacillen ausserhalb des Menschen auf irgend welchem Substrat der Umgebung. Da sich indess die Diphtheriebacillen in allen Züchtungsversuchen selbst bei Abwesenheit anderer concurrirender Bakterien, recht wählerisch in Bezug auf Nährsubstrat und Temperatur gezeigt haben, ist an ein Wachsthum derselben in oder auf dem Boden,

\footnotetext{
${ }^{1}$ Besondere Versuche hierüber werde ich demnächst mittheilen.
} 
im Wasser, an Hauswänden, im Fehlboden u. s. w. nicht zu denken, zumal hier stets saprophytische Bakterien zugegen sind. Nur auf Nahrungsmitteln - Fleisch, Fleischbrühe, Milch u. s. w. - ist eine Wucherung denkbar; jedoch auch hier durch concurrirende Saprophyten derartig erschwert, dass dieselbe kaum jemals einen Einfluss auf die Ausbreitung der Krankheit haben wird.

Anders steht es mit der Conservirung des Contagiums an leblosen Objekten. Hier können in der That theils Einflüsse unserer natürlichen Umgebung, theils Sitten und Gebräuche zu merklicher W.irkung gelangen. Niedrige Temperatur, feuchte Luft und Dunkelheit schützen die Bacillen am besten vor dem Absterben. Im excessiven Landklima wird im Sommer das hohe Sättigungsdeficit rasches Austrocknen bewirken; bei feuchter Aufbewahrung der Objekte veranlasst die hohe Temperatur intensive Wucherung von Saprophyten; das lang anhaltende, kräftige Tageslicht unterstützt die Abtödtung. Während des Winters sind im Landklima in den Häusern in Folge der starken Beheizung und der niedrigen absoluten Feuchtigkeit der Aussenluft günstigste Bedingungen für das rasche Austrocknen der Infectionsquellen gegeben. - Dagegen muss im Seeklima mit seiner abgeglichenen Temperatur, seinem geringen Sättigungsdeficit und seinem meist trüben Tageslicht eine Conservirung des Diphtheriecontagiums im Allgemeinen leichter möglich sein. - Im Uebergangsklima kommen möglicher Weise in dem gleichen Sinne Witterungseinflüsse zur Geltung; der Sommer wird der Conservirung der Bacillen etwas ungünstiger sein, wie der Winter.

Einflüsse der künstlichen Umgebung auf die Haltbarkeit des Contagiums können z. B. durch die Wohnungslage zu Stande kommen. In Kellerwohnungen sind die Conservirungsbedingungen unbedingt am günstigsten; ebenso in den unteren Geschossen feuchter Häuser, in dunklen Räumen u. s. w. Ungünstig sind diese Bedingungen dagegen in den trockenen, warmen, hellen, oberen Stockwerken. Besteht die Sitte, die schmutzige Wäsche in geschlossenen Behältern oder in Kellerräumen aufzubewahren, so werden die Bacillen leichter am Leben bleiben, als wenn die Aufberahrung durch Aufhängen und Ausbreiten in trockenen warmen Räumen erfolgt. Reinigen, Trocknen, Sonnen der inficirten Sachen beseitigt das Contagium; ein Belassen im beschmutzten, feuchten Zustand und Einschliessen in Behälter befördert die Haltbarkeit des Contagiums.

Aus diesen Erwägungen über die Bedingungen der Conservirbarkeit folgt nun aber durchaus nicht, dass die hier in Betracht kommenden Einflüsse, wie Klima, Witterung, Behandlung der Krankenwäsche u. s. w. wirklich in ausschlaggebender Weise die Verbreitung der Krankheit bestimmen. Vielmehr ist es in jedem Einzelfall sehr wohl möglich, dass 
die sonstigen auf die Verbreitung einflussreichen Factoren, die gleich zu erwähnen sind, weitaus wirksamer sind und je nach ihrem Verhalten einen Ausschlag eventuell gerade nach der entgegengesetzten Seite hin herbeiführen. Eben darin sind unsere aus den Eigenschaften der Erreger abgeleiteten Schlussfolgerungen ungenügend, dass sie uns zwar auf die bei der Verbreitung mitwirkenden Faktoren hinweisen, dass sie uns aber keine quantitative Schätzung des einen oder anderen Finflusses erlauben. In diesem Punkte müssen eventuell epidemiologische Untersuchungen ergänzend eingreifen.

2. Erleichterung oder Erschwerung des Transports des Con. tagiums zum Gesunden; und da der Transport ausschliesslich oder vorzugsweise mittelst Berührungen erfolgt, durch eine Erleichterung oder Erschwerung der für den Transport des Contagiums geeigneten Berührungen. In dieser Beziehung können locale Differenzen der Diphtherieverbreitung hauptsächlich beruhen auf Sitten und Gebräuchen, die nach Ländern, Städten und Bevölkerungsgruppen oft durchgreifende Verschiedenheiten aufweisen. Eine Erleichterung der Ansteckung muss z. B. zu Stande kommen durch dichtes Zusammenwohnen und namentlich dichte örtliche Häufung der vorzugsweise empfänglichen Kinder. Je mehr von diesen in stetem, innigem Verkehr leben, um so mehr Chancen sind dann, wenn erst die Diphtherie in einem Orte Ausbreitung gewonnen hat, dafür vorhanden, dass das eine oder andere Kind irgendwo Diphtherieerreger aufgenommen hat und nun im Beginn der Krankheit oder nach Ablauf derselben, während es virulente Erreger beherbergt, in gewohnter Weise mit den übrigen Kindern verkehrt und einige derselben inficirt. Die für den Transport der Erreger erforderlichen Berührungen fehlen im Verkehr der Kinder nie. Küsse, gemeinsames Verzehren eines Nahrungsmittels, gemeinsames Spielzeug, Berührungen des eigenen Mundes mit den Fingern, vorher und nachher Berührungen der Hände, der Kleider u. s. w. anderer Kinder, das alles wiederholt sich in stetem Wechsel überall wo grössere Kinderschaaren versammelt sind. Stadtgegenden mit weiträumiger Bebauung und kleinen Häusern, sesshafter Bevölkerung und leichterer räumlicher Trennung der Kinder werden nicht so fortgesetzt Uebertragungen ausgesetzt sein als engbebaute Strassen mit grossen Miethskasernen und fluctuirender Bevölkerung. Hier wird Jahraus Jahrein die Gefahr der Einschleppung und der raschen Weiterverbreitung bestehen. Ist das Contagium einmal in einen kleineren, abgegrenzten Kreis von Kindern (Dörfer) eingeschleppt, dann wird die Krankheit auch hier intensiv um sich greifen können. Aber die Gefahr einer solchen Einschleppung liegt seltener vor. Werden die Kinder fortdauernd beaufsichtigt, ihr Verkehr beschränkt und controlirt, dann muss sich ungleich weniger Infectionsgefahr bieten, als da 
wo die Kinder im Treppenhaus, auf dem Hof, auf der Strasse und auf Spielplätzen das ganze Jahr hindurch mit zahlreichen anderen Kindern aufsichtslos verkehren.

Ein zweites Moment, das die Ausbildung localer Differenzen unterstützen kann, ist die Reinlichkeit der Bevölkerung, die nach Gegenden und Bevölkerungsgruppen Verschiedenheiten aufweist. Zweifellos können durch schleunige und gründliche Reinigung der Krankenwäsche, des Krankenzimmers, der Ess- und Trinkgeschirre u. s. w., ferner durch die Gewohnheit, die Hände häufig zu reinigen und nur mit gereinigten Händen den Mund und Nahrungsmittel zu berühren, die Infectionsgelegenheiten um ein gewisses Maass vermindert werden.

Von grösster Bedeutung ist die gemeinsame.Benutzung von Ess- und Trinkgeschirr und das Küssen der Kinder. Innerhalb der ländlichen Bevölkerung und auch in ziemlich breiten Schichten der städtischen Einwohnerschaft ist es Sitte, aus einer Schüssel zu essen, oder mit dem Löffel eines Anderen zu kosten, oder aus Glas und Tasse eines Anderen $z u$ trinken. Mütter und Kindermädchen pflegen beim Säugling wie beim älteren Kinde die Nahrung erst zu probiren und sie dann mit derselben Flasche oder demselben Löffel dem Kinde zu geben. Ebenso ist es vielfach Sitte, dass Erwachsene Kinder auf den Mund küssen; und zwar nicht nur die eigenen Eltern und die Kindermädchen, sondern auch entfernte Verwandte und Bekannte. Nachdem auf das sicherste nachgewiesen ist, dass Erwachsene gar nicht selten virulente Erreger im Munde beherbergen, ohne dass sie merklich erkrankt sind, ist der gemeinsame Gebrauch von Ess- und Trinkgeschirr und das Küssen der Kinder auf den Mund offenbar als etwas entschieden Gefährliches anzusehen, das directer als alles übrige den Transport der Keime an die Infectionsstelle vermittelt. Auch in Bezug auf diese Sitten haben wir aber erhebliche örtliche Variationen. In Russland küssen sich Erwachsene und Kinder bei zahlreichsten Gelegenheiten; in Frankreich, in Japan u. s. w. ist das Küssen der Kinder auf den Mund selten oder sogar ganz verpönt. Oft ist in wohlhabenden Familien das Küssen der Kinder seitens der Eltern und Dienstmädchen verbreiteter als in den ärmeren Kreisen; dafür sind in letzteren gemeinsames Ess - und Trinkgeschirr und Berührungen der Kinder unter einander um so häufiger.

Betrachtet man die sämmtlichen im Vorstehenden aufgezählten Infectionsgelegenheiten zusammen, so wird man zu dem Schlusse gedrängt, dass durch Dichtigkeit des Zusammenwohnens und Armuth der Bevölkerung die Verbreitung des Diphtheriecontagiums begünstigt werden muss. Namentlich in den von Arbeiterbevölkerung bewohnten Miethskasernen wird die Gelegenheit zur Einschleppung und Weiterverbreitung am gün- 
stigsten sein. Hier werden unter der kinderreichen, fluctuirenden, zu engem Verkehr gezwungenen Bevőlkerung häufig irgendwelche Erkrankungen vorkommen; hat eine Infection stattgefunden, so ist eine Isolirung des Erkrankten nicht möglich; zunächst sind dann die übrigen Kinder derselben Familie gefährdet; aber auch gegenüber den Mitbewohnern ist eine Absperrung nicht durchführbar. Meist stehen einzelne Familien in dem grossen Hause in näherem Connex; sie helfen sich gegenseitig in Krankheitsfallen; im Anfang der Krankheit, ehe dieselbe declarirt ist, ferner in der Reconvalescenz, oder bei leicht verlaufenden Fällen besuchen Nachbarn die Erkrankten, betheiligen sich an der Pflege, lassen ihre Kinder mit dem erkrankten spielen u. s. w. $^{1}$ Unter diesen Verhältnissen hört auch der Schutz, den peinliche Reinlichkeit gewähren kann, vollständig auf; an Wäsche, Essgeräth, Kleidung, Spielsachen u. s. w. bleibt der Infectionsstoff haften, um eventuell noch nach Wochen auf andere Kinder sich zu verbreiten. Häufig werden Erwachsene und unempfängliche Kinder in solchem Hause leichte Affectionen acquiriren; sie beherbergen in ihrem Munde die Erreger und veranlassen weitere Uebertragungen. Wir werden demnach erwarten dürfen, dass gerade in der armen städtischen Bevölkerung sich die Uebertragung des Diphtheriecontagiums am leichtesten vollzieht und dass sie im Allgemeinen mit zunehmender Wohlhabenheit schwieriger wird. Dass manchmal auch in gutsituirten Familien eine intensive Ausbreitung vorkommen kann, das ist selbstverstāndlich, sobald man erwägt, dass in vielen solchen Familien für die Ansteckung durch Küsse und durch Ess- und Trinkgeschirr günstigste Gelegenheit gegeben ist. - In wie weit nun aber aus den besseren Uebertragungschancen innerhalb der ärmeren Bevölkerung eine stärkere Diphtheriefrequenz derselben folgt, das hängt wiederum ab von der Intensität, mit welcher daneben noch andere Einflüsse, namentlich die individuelle Disposition, sich geltend machen.

3. Die individuelle Disposition. Dieselbe kann nach den

\footnotetext{
1 Ueber die Erfahrungen, wie sie der Arzt in den Berliner Vorstädten fast täglich $z u$ machen Gelegenheit hat, äussert sich Kaiser (6) folgendermassen: „Das Bild ist beinabe immer dasselbe; das oder die an Diphtherie erkrankten Kinder liegen wohlverpackt in der warmen Küche, die gesunden oder noch einige Nachbarskinder spielen mit ihnen, dazwischen wird die Matter, die eben ihr krankes Kind gepllegt hat, etwa zum Milchverkauf abgerufen; dem Rathe des Arztes, den Kranken in ein Hospital überzuführen, wird nicht Folge geleistet, und seinen auf Isolirung der Gesunden hinzielenden Anordnungen wird regelmässig entgegengehalten: Wir haben Niemand, zu dem wir sie bringen könnten, und wenn sie die Krankheit bekommen sollen, bekommen sie sie doch. Die fragwürdige Ausführung therapeutischer Anordnungen ist das einzige Resultat, mit dem der Arzt resignirt die Wohnung verlässt, um sich zn derselben Scene weiter zu begeben.“
} 
Laboratoriumsversuchen eine angeborene, vererbte oder eine erworbene sein. Die angeborene Disposition äussert sich, darin, dass verschiedene Thierrassen gegenüber der Einimpfung oder Injection des Virus sehr verschiedene Grade von Empfänglichkeit zeigen; unter den Individuen einer Rasse scheinen gleichfalls Differenzen vorzukommen. Wählt man ferner einen Infectionsmodus, der sich mehr der natürlichen Infection nähert, indem man die Bacillen oberflächlich auf eine Schleimhaut applicirt, so zeigen sich Unterschiede der Empfänglichkeit, die auf eine grössere oder geringere Derbheit und Resistenz des Epithels zurückzuführen sind; namentlich gelingen solche Infectionen bei jungen und versagen bei alten Thieren derselben Rasse; sie gelingen ferner leichter nach vorausgegangenen Läsionen der Schleimhaut. Wir dürfen daraus folgern, dass die angeborene Empfänglichkeit theils von gewissen Schutzvorrichtungen im Innern des Körpers, theils von dem Zustand der exponirten Schleimhaut abhängig ist. - Eine erworbene Immunität beobachten wir bei manchen Thieren nach einmaligem Ueberstehen der durch Einimpfung des Virus entstandenen Krankheit.

Auf Grund dieser experimentellen Ergebnisse müssen wir es als wahrscheinlich ansehen, dass auch bei der Verbreitung der Diphtherie unter den Menschen die Disposition eine erhebliche Rolle spielt. Nicht alle Rassen werden gleich empfänglich sein; und vielleicht giebt es unter den Menschen gleicher Rasse in Bezug auf die inneren Schutzvorrichtungen des Körpers so verschiedene Abstufungen, dass die Uebertragungen desselben Virus bei dem Einen nur leichteste Affection, bei dem Anderen schwerste Erkrankung auslösen kann. Ausserdem ist der Zustand der Rachen- und Nasenschleimhaut in Rechnung zu ziehen. Bei jungen Individuen, ferner bei solchen mit katarrhalischen Affectionen und Epithelläsionen wird ein Haften und Wuchern des Contagiums leichter erfolgen, als bei Menschen mit intacten Schleimhäuten und derberem Epithel. Die Disposition der localen Invasionsstätte sowohl, wie auch die Widerstandsfähigskeit des Organismus gegenüber dem eingedrungenen Virus können sich möglicher Weise vererben und eine sogen. „Familiendisposition“" erzeugen.

Auch die Verschiedenheit der individuellen Disposition kann dann örtliche und zeitliche Differenzen der Verbreitung hervorrufen, z. B. dadurch, dass in dem einen Orte oder in dem einen Stadttheil viele Bewohner einer unempfänglichen Rasse angehören; oder dass die Kinderzabl sehr ungleich vertheilt ist; oder dadurch, dass an manchen Orten und zu gewissen Zeiten katarrhalische Affectionen besonders grassiren; oder auch dadurch, dass an einigen Orten eine sesshafte Bevölkerung durch vieles Heirathen unter einander eine bestimmte "Familiendisposition" 
besonders ausgebildet hat. - Es ist denkbar, dass gerade in der ärmeren Bevölkerung die individuelle Disposition am wenigsten entwickelt ist, weil die Kinder derselben von Jugend auf Temperaturschwankungen und dem Witterungswechsel im Freien mehr ausgesetzt und gegen Erkältungen besser abgehärtet sind als die Kinder der Wohlhabenden. Es ist sogar möglich, dass dieser Einfluss diejenigen oben aufgeführten Momente, welche die Conservirung und den Transport des Contagiums bei den Armen begünstigen, übercompensirt.

Einen weiteren Einfluss auf das Bild der Ausbreitung könnte die Durchseuchung ausüben. Wird eine gewisse Immunität durch einmaliges Ueberstehen der Krankheit hervorgerufen, dann muss der Gang der Seuche, je nachdem er durch eine bereits einmal ergriffene oder durch eine seit lange nicht ergriffene Bevölkerung führt, stark modificirt werden.

Endlich ist noch eine Art von individueller Disposition wohl zu beachten, die sicher oft im Spiele und auch für die örtliche Vertheilung der Krankheitsfälle nicht ohne Belang ist. Es ist dies die Disposition des Individuums und der Familie in Folge von Lebensgewohnheiten. Eine scheinbar auf Eigenthümlichkeiten des Organismus beruhende Disposition innerhalb einer Familie kann auf der Sitte beruhen, dass die Familienmitglieder sich viel küssen, gemeinsames Essgeräth gebrauchen u. s. w. Selbst Kinder sind in dieser Beziehung nicht gleichartig, sondern individuell verschieden geartet; das eine istzurückhaltend, reinlich; das anderezutraulich oder unsauber und mit der Neigung, Finger und Gegenstände immer in den Mund zu bringen. Ersteres hat vergleichsweise wenig, letzteres viel mehr Chancen, sich mit Diphtherie zu inficiren. Es darf diese Eigenart der Sitten und Gewohnheiten nicht ausser Acht gelassen werden; eine rätthselhafte Abweichung in der Körperbeschaffenheit sollte erst dann in Frage kommen, wenn eine Erklärung aus individuellen Verschiedenheiten der für den Transport der Erreger einflussreichen Gewohnheiten schlechterdings nicht möglich erscheint.

B. Die Ergebnisse der bisherigen epidemiologischen Untersuchungen' über die Verbreitungsart der Diphtherie.

Wie harmoniren nun mit diesen auf die jetzt erkannten biologischen Eigenschaften der Diphtherieerreger basirten Vorstellungen über die natürliche Verbreitungsweise der Diphtherie die Ergebnisse der ärztlichen Beobachtungen und namentlich der statistisch-epidemiologischen Untersuchungen? 
Das hervorragendste Resultat der letzteren ist der oft erbrachte Nachweis, dass die epidemische Verbreitung der Diphtherie sich nicht gleichmässig vollzieht, sondern mit örtlichen und zeitlichen Schwankungen. Gerade diese Verschiedenheiten in der räumlichen und zeitlichen Vertheilung suchen die Epidemiologen ziffermässig zu präcisiren, um aus den erhaltenen Zahlen Schlüsse zu ziehen auf .die mitwirkenden Ursachen und letztere in ihrer Bedeutung quantitativ abzuschätzen. Daneben ist man bemüht gewesen, den Einfluss der individuellen Disposition ebenfalls ziffermässig festzustellen.

Die über rāumliche Differenzen der Diphtherieverbreitung angestellten Untersuchungen betreffen zunächst grössere Bezirke, ganze Länder, Provinzen, Regierungsbezirke. Für Preussen liegt aus neuerer Zeit eine Untersuchung vor von Brühl und Jahr (7). Diese Autoren maassen die Diphtheriefrequenz in den versehiedenen Kreisen und Provinzen Preussens dảdurch, dass sie die auf je 10000 Lebende 1875 bis 1882 vorgekommenen Diphtherie to desfälle zählten. Sie fanden die höchste Sterblichkeit in den östlichen Distrikten; das Minimum in den nördlichen, westlichen, südlichen und südöstlichen Bezirken; und zwar nahm die Sterblichkeit von Ost nach West und Süd ab. Das Maximum der durchschnittlichen Diphtheriesterblichkeit im preussischen Staate wurde zwischen den niedrigsten, das Minimum zwischen den höchsten Jahresisothermen beobachtet. - Kalischer (8) leitete aus den Diphtherietodesfällen pro 1875 bis $1889 \mathrm{ab}$, dass Pommern, West- und Ostpreussen am stärksten exponirt sind, während im äussersten Nordwesten die Frequenz am niedrigsten war. Ein entscheidender Einfluss der Höhenlage oder der Bodenbeschaffenheit liess sich dabei nicht auffinden. - Rahts (9) zeigte dagegen, dass auf Grund der gemeldeten Diphtherieerkrankungen in den Jahren 1888 und 1889, ferner auf Grund der Heilanstaltsstatistik und der Heeresstatistik die höchste Diphtheriefrequenz durchaus nicht den östlichen Provinzen zukommt, sondern ausser Berlin namentlich den Regierungsbezirken Hildesheim, Schleswig, Erfurt. Obwohl die Sterblichkeit der Diphtheriekranken grossen örtlichen Schwankungen unterliegt (im Regierungsbezirk Schleswig z. B. 6.9 Procent, im Regierungsbezirk Königsberg 34 Procent), zeigten die Todesfälle an Diphtherie doch im (Ganzen dieselbe Frequenzvertheilung, so dass die östlichen Provinzen weder nach der Morbiditäts- noch nach der Mortalitätsstatistik zu den exponirtesten Distrikten gehören.

Dass solche Vergleichungen grosser Gebiete zu widersprechenden Resultaten führen, ist leicht verständlich. Abgesehen von der ungleichmässigen Beschaffenheit des Urmaterials können sich innerhalb grösserer 
Vergleichsbezirke die erheblichsten Differenzen kleiner Distrikte verbergen. Je nachdem man die Trennungslinie zwischen zwei Bezirken in der einen oder anderen Weise zieht, werden die Mittelzahlen willkürlich verschoben, und alles kommt daher auf die zufällige räumliche Gruppirung an.

Ferner ist es bedenklich, für grössere Bezirke aus einer kürzeren Beobachtungsperiode allgemein gültige Schlüsse abzuleiten, da die folgenden Jahre oft eine ganz andere Vertheilung der Krankheitsfrequenz bringen. So bezeichneten Brühl und Jahr nach ihren über den Zeitraum von 1875 bis 1882 sich erstreckenden Untersuchungen Breslau und Hannover als so gut wie seuchenfrei, dagegen Königsberg als beständig stark ergriffen. Für diese selben Städte ergiebt sich aber für die Jahre 1886 bis 1891 folgende Diphtheriesterblichkeit (pro 10000 Lebende):

\begin{tabular}{c|c|c|c}
\hline & Breslau & Hannover & Königsberg \\
\hline 1886 & $9 \cdot 3$ & $5 \cdot 3$ & $10 \cdot 8$ \\
1887 & $16 \cdot 6$ & $9 \cdot 3$ & $12 \cdot 7$ \\
1888 & $14 \cdot 8$ & $\mathbf{1 4 \cdot 7}$ & $7 \cdot 6$ \\
1889 & $11 \cdot 4$ & $15 \cdot 1$ & $14 \cdot 1$ \\
1890 & $11 \cdot 1$ & $\mathbf{1 4 \cdot 1}$ & $11 \cdot 9$ \\
1891 & $10 \cdot 0$ & $\mathbf{9 \cdot 4}$ & $5 \cdot 3$ \\
im Mittel: & $\mathbf{1 2 \cdot 2}$ & $\mathbf{1 1 \cdot 3}$ & $\mathbf{1 0 \cdot 4}$
\end{tabular}

Noch mehr häufen sich die Fehlerquellen; wenn aus der verschiedenen Krankheitsfrequenz grösserer Bezirke Schlüsse gezogen werden sollen auf diejenigen Einflüsse, welche jene räumliche Vertheilung bewirkt haben.

Brühl und Jahr suchen die von ihnen gefundenen Frequenzunterschiede in Vergleich zu setzen mit örtlichen Differenzen des Klimas. Sie finden das Sterblichkeitsmaximum an Diphtherie da, wo eine weniger gleichmässige Jahrestemperatur und Feuchtigkeit der Luft herrscht, die geringere Sterblichkeit in Gegenden mit mehr gleichmässiger Jahrestemperatur und Feuchtigkeit. In einzelnen Regierungsbezirken mit relativ hoher Diphtheriesterblichkeit soll im Jahresmittel ein grösseres Sättigungsdeficit vorkommen, als in den wenig ergriffenen Bezirken. Darnach sprechen sie den häufigen unvermittelten Uebergang aus einer feuchten Luft in eine austrocknende als dasjenige Moment an, welches vorzugsweise die Diphtherie befördert.

Diese Folgerungen würden auch dann nicht statthaft sein, wenn die Frequenzzahlen selbst von den oben gegen ihre Gültigkeit erhobenen Einwänden frei zu machen wären. Denn erstens sind wiederum die Mittel- 
zahlen für grosse Bezirke selten geeignet, wirksame Factoren richtig zu charakterisiren, weil diese innerhalb der verglichenen grösseren Bezirke starke Differenzen zu zeigen pflegen, die in der Mittelzahl in einer ganz von der zufälligen räumlichen Gruppirung abhängigen Weise abgeglichen werden. Wohl am wenigsten brauchbar sind die üblichen Charakterisirungen des Klimas. Diejenigen Witterungseinflüsse, durch welche im menschlichen Organismus Störungen hervorgerufen werden können, sind doch immer von relativ kurzer Dauer; in der Brühl und Jahr'schen Hypothese handelt es sich um plötzliche Uebergänge aus warmer, feuchter in kalte oder austrockmende Luft. Ueber diese Momentanwirkungen, über die Intensität der Contraste, über deren Häufigkeit, über die Temperaturlage, in welcher sie sich vollziehen $u$. s. w. geben uns die „Jahresmittel" nicht den geringsten Aufschluss. Noch weniger können dann die aus den Jahresmitteln einzelner Orte für grössere Bezirke abgeleiteten Zahlen irgend eine hygienische Bedeutung haben.

$\mathrm{Z}$ weitens würden wir aber den klimatischen Factoren, auch wenn sie zweckmāssiger registrirt wāren, nur dann eine stārkere Beeinflussung der Diphtherie zuschreiben dürfen, wenn wir mit ihrer Hülfe auch die starken räumlichen Differenzen der Ausbreitung erklären können, die innerhalb kleiner Kreise und innerhalb derselben Stadt hervortreten. Solche Gegensätze zwischen einzelnen Stadttheilen sind vielfach beobachtet, aber durch klimatische Einflüsse sicher nicht erklärlich; auch dann nicht, wenn man das künstliche Klima der Wohnungen mit in Betracht zieht. Auffälliger Weise besteht sogar der einzige statistisch sicher erwiesene Wohnungseinfluss, der unten genauer zu besprechen ist, in der besonderen Disposition der Kellerwohnungen für Diphtherie; in diesen haben wir aber gerade die gleichmässigste Temperatur und das geringste Sättigungsdeficit, folglich die Klimabeschaffenheit, die nach Brühl und Jahr mit geringster Diphtheriefrequenz zusammengehen müsste. Zweifellos sind also bei den auf kleinem Raum hervortretenden Gegensätzen und Differenzen in der Diphtherieverbreitung andere Momente ausschlaggebend, als das natürliche oder künstliche Klima. Geben wir aber erst erst einmal zu, dass diese anderen Momente im Kleinen wirksam sind, dann müssen sie auch im Grossen ihren Einfluss äussern und bei den Differenzen grösserer Bezirke ursächlich betheiligt sein. Neue einflussreiche Factoren wird man erst dann zur Erklärung heranziehen dürfen, wenn jene sicher mitwirkenden Momente sich als nicht ausreichend zur Erklärung erweisen. - Die Cholera infantum in ihrer Abhängigkeit von der Temperatur ist ein treffliches Beispiel dafür, wie der wirklich als ausschlaggebend erkannte Factor ebensowohl beim Verfolgen der Fälle in die einzelnen Häuser und Stockwerke, wie bei Zusammen- 
fassungen nach Städten, Ländern und Jahren sich in gleicher Weise als massgebend erweist.

Die Brühl und Jahr'sche Statistik und überhaupt die in grosser Zahl vorliegenden Untersuchungen ausgedehnter Bezirke sind somit wenig geeignet, über die Abhängigkeit der Diphtheriefrequenz von äusseren Einflüssen Aufklärungen zu liefern.

Von grösserem Werth sind die statistischen Untersuchungen, die in einzelnen Städten und kleineren Kreisen vorgenommen sind. Aber auch hier sind die bisherigen Ergebnisse in manchen Punkten widersprechend. Namentlich wird von einigen Beobachtern auf Grund localstatistischer Erhebungen der Localität, dem Boden und dem Hause ein massgebender Einfluss zugeschrieben (Schwarz (10) für Nürnberg, Hauser (11) für Madrid, Heubner (11a) für Leipzig); von Anderen wird dagegen ein solcher Einfluss geleugnet (Reinecke (12) für Göttingen, Geissler (13) für die sächsischen Städte, Almquist (14) für Göteborg, Reck (22) für Braunschweig).

Selbst die neuesten Autoren kommen bezüglich der ,localen Disposition" zu ganz entgegengesetzten Ergebnissen. Heubner constatirt in einer sehr sorgfältigen Bearbeitung der in Leipzig von November 1884 bis Ende December 1885 vorgekommenen Diphtherieerkrankungen, dass einzelne Strassen, so die frei und luftig gelegene Körner- und Südstrasse, eine doppelt so starke Diphtheriefrequenz hatten, wie die gleich dicht bewohnte düstere Sternwartenstrasse. Ferner zeigten sich auffällige Häufungen in der Peripherie der Stadt. Hier waren es besonders neugebaute Häuser, in welchen die stärkste Häufung vorkam. Detaillirte Untersuchungen einzelner heftig ergriffener Häuser ergab ferner, dass zuweilen in demselben Hause die Krankheit länger als ein Jahr mit Monate langen Pausen grassirte und dass wiederholt neu einziehende Familien dort von der Krankheit ergriffen wurden. Heubner zieht aus diesen Beobachtungen den Schluss, ,dass man in allen derartigen Fällen kaum anders kann, als die Oertlichkeit als inficirt ansehen".

Zur entgegengesetzten Ansicht kam Almquist durch seine Untersuchung über 1599 Diphtheriefälle in Göteborg (1870-85). Diese vertheilten sich auf 1026 unter den vorhandenen 3000 städtischen Häusern; in 259 Häusern kamen mehrfache Erkrankungen vor, aber nur in 8 Häusern wiederholten sich letztere. Diese Vertheilung entspricht nach Almquist ganz der Erwartung, wenn eine örtliche Herdbildung völlig fehlt. Er schliesst daher, ,dass die Diphtherie das angegriffene Haus in wenigen Monaten völlig verlässt und keine Neigung zeigt, weder als Epidemie noch als vereinzelter Fall im selben Hause wieder zu erscheinen". 
Bei Aerzten und im grösseren Publikum besteht jedenfalls vielfach die Neigung, eine starke localistische Beeinflussung der Diphtherie anzunehmen. Man bezeichnet gern einzelne Stadttheile, Strassen und Häuser als „Diphtherieherde", und will damit ausdrücken, dass dort das Contagium immer wieder Opfer fordere, einerlei von welcher Qualität die Menschen sind, die daselbst wohnen. Nicht selten herrscht aber auch Unklarheit über das, was unter ,localer Disposition" $\mathrm{zu}$ verstehen ist. Eine locale Disposition kann vorgetäuscht werden dadurch, dass in den betreffenden Häusern ein starker Wechsel der Bewohner oder ein Verkehr zahlreicher Kinder besteht, so dass immer wieder Gelegenheit zur Einschleppung des Contagiums durch Kranke, Reconvalescenten, scheinbar gesunde Erwachsene und Kinder, oder durch inficirte Effecten gegeben ist; ferner dadurch, dass in Folge der Lebensverhältnisse, der Sitten und Gewohnheiten der Bewohner die Beseitigung und Vernichtung des Contagiums erschwert und die Uebertragung erleichtert wird; oder endlich dadurch, dass die individuelle Disposition der Bewohner das Haften und die Wucherung des Contagiums erschwert oder erleichtert. Erst wenn diese von der Zahl und Art der Bewohner abhängigen sehr einflussreichen Momente zur Erklärung einer localen Häufung von Diphtherie nicht ausreichen, sind wir berechtigt, an Einflüsse zu denken, die der Localität anhaften und von dieser ausgehen. Letztere könnten dann entweder darin bestehen, dass der betreffende Ort, das Haus oder die Wohnung besonders geeignet ist zur Conservirung des Diphtheriecontagiums (nur von dieser, nicht aber von einer Wucherung oder von der Bildung einer sonst nicht bekannten Dauerform. kann die Rede sein); oder darin, dass der betreffende Ort die Entstehung der individuellen Empfänglichkeit (Erkältungen u. s. w.) begünstigt. - Diese genauere Begriffsbestimmung der "localen Disposition" ist für die Beurtheilung der Verbreitungsweise der Diphtherie und der parasitären Krankheiten überhaupt von grosser Bedeutung.

Mehrfach betont ist der Unterschied zwischen.Stadt und Land. Auf dem Lande ist nach den Untersuchungen von Brühl und Jahr die Diphtheriemortalität nicht unerheblich höher als in den Stadtgemeinden. Eigenbrodt (15) hat zahlreiche Beiträge gesammelt, wo das erste Auftreten der Diphtherie zunächst in kleineren Ortschaften schwere Epidemieen hervorrief, während die grösseren Stâdte erst später epidemisch ergriffen wurdèn. Almquist stellte für Schweden fest, dass die Städte öfter und beständiger ergriffen werden, dass dagegen auf dem Lande die Epidemieen zwar seltener auftreten, aber intensiver um sich greifen. - Diese Verschiedenheit beziehen Brühl und Jahr auf das dichte Zusammenwohnen der Landbewohner im Winter, auf die mangelhafte Lüftung der Zimmer, 
auf den geringen Bildungsgrad der Frauen und auf die erschwerte ärztliche Behandlung. Eigenbrodt glaubt, dass vorzugsweise die „Familiendisposition" auf dem Lande sehr ausgeprägt sei, weil hier Generationen hindurch Heirathen innerhalb weniger sesshafter Familien vorkommen. Am wahrscheinlichsten ist es wohl, dass nicht ein einziger Factor hierbei in ausschlaggebender Weise wirksam ist; zum Theil mag jene „Familiendisposition" in der That in Frage kommen; daneben werden aber Sitten und Lebensgewohnheiten, der gemeinsame Gebrauch von Ess- und Trinkgeschirr, das enge Zusammenwohnen und die ungenŭgende Isolirung der Erkrankten in Betracht zu ziehen sein.

Merkwürdig umstritten ist der Einfluss der Wohlhabenheit und Wohndichtigkeit auf die örtliche Vertheilung der Diphtherie. Nur wenige Autoren heben ein stärkeres Befallenwerden der ärmeren Bevölkerung hervor, wie wir es auf Grund der hier zweifellos vorhandenen besseren Bedingungen für die Conservirung und den Transport des Contagiums erwarten müssen. So führt $A \operatorname{lm} q$ u ist (14) das rasche Anwachsen der Diphtherie in Göteborg seit 1870 vorzugsweise auf Wohnungsnoth und Uebervölkerung zurück; Johannesen (16) nimmt in Norwegen einen entschieden disponirenden Einfluss ärmlicher und unreinlicher Wohnungen an; Kaiser (6) constatirt für Berlin einen die Ausbreitung fördernden Einfluss von Armuth, Wohnungsdichtigkeit und Uebervölkerung; ferner hat Pistor (17) für Berlin (1886 bis 1888) festgestellt, dass die Bewohner der Keller am meisten erkranken, dass dann die des vierten Stockes und des Erdgeschosses folgen, während die Bewohner des ersten, zweiten und dritten Stockwerkes am wenigsten Diphtheriefälle aufweisen. Aehnliches hat Kaiser ermittelt. - Allerdings ist der letzterwähnte Einfluss der Wohnungslage wohl nicht ausschliesslich aus der Wohlhabenheit zu erklären. Pistor selbst meint, dis stärkere Frequenz in den Kellerwohnungen beruhe darauf, dass ein hoher Feuchtigkeitsgrad die Verbreitung der Krankheit fördert. In der That lässt sich sehr wohl eine bessere Conservirung der Infectionsquellen in den Kellerwohnungen und auch noch in Erdgeschosswohnungen denken und ebenso eine Steigerung der individuellen Disposition durch Begünstigung von Erkältungskrankheiten. Die gegebenen Zahlen sind ausserdem insofern nicht streng beweisend, weil eigentlich die Zahl der Kinder, d. h. der für Diphtherie empfänglichen Individuen, nach der Wohnungslage hätte festgestellt werden müssen. - Endlich haben noch englische, französische und nordamerikanische Aerzte mehrfach darauf hingewiesen - jedoch ohne ziffermässige Feststellungen - , dass Diphtherie bei Ueberfüllung der Wohnungen und bei mangelhafter Reinlichkeit, also namentlich im Proletariat, die meisten Opfer fordert (Hirsch (18)). Diesen mehr oder weniger den Einfluss der Armuth auf die Diph- 
theriefrequenz anerkennenden Berichten stehen zahlreiche Beobachtungen und statistische Untersuchungen gegenüber, welche nachweisen, dass gerade von der Diphtherie Wohlhabende und Arme gleich intensiv, ja erstere oft stärker befallen werden. Derartige Beobachtungen ohne genauere ziffermässige Belege sind z. B. von Trousseau (Loiret), Thoresen (Norwegen), Seitz(München), Geissler (Sachsen), Neucourt (19) (Verdun) veröffentlicht; Hirsch (18) resümirt diese Erfahrungen mit dem Hinweis, „dass die Diphtherie selbst die Höchstgestellten in der Gesellschaft nicht verschont, dass sie wiederholt fürstliche Familien in tiefe Trauer über den Verlust der Ihrigen versetzt hat".

Statistische Daten werden zum Beweis für die Einflusslosigkeit der Wohlhabenheit beigebracht namentlich von Conrad und Körösi. Conrad (19a) gruppirte die in Halle a. S. 1855 bis 1874 vorgekommenen Todesfälle nach 5 Wohlhabenheitsclassen. Er fand, dass in Bezug auf Scharlach, Diphtherie und Keuchhusten „die bevorzugte Gesellschaftsclasse bedeutend grössere Einbusse erleidet als die übrige Bevölkerung“.

Es starben nämlich an Diphtherie

\begin{tabular}{|c|c|c|}
\hline & Absolut: & $\begin{array}{l}\text { In Procenten aller } \\
\text { gestorbenen Kinder } \\
\text { derselben Classe: }\end{array}$ \\
\hline In Classe I (der höheren Bildangsstufe Angehörige) & 27 & $4 \cdot 01$ \\
\hline ",$\quad$ II (Handwerker) . . . . . . . . . & 135 & $2 \cdot 15$ \\
\hline , III (Subalternbeamte) . . . . . . . & 50 & $2 \cdot 55$ \\
\hline "IV (Hand- und Fabrikarbeiter u. s. w.). & 104 & $2 \cdot 72$ \\
\hline " " V (uneheliche Kinder) . . . . . . . & 12 & $0 \cdot 54$ \\
\hline
\end{tabular}

Conrad fügt hinzu: „Es muss dies um so mehr auffallen, als einmal die Gefahr der Ansteckung bei der bevorzugten Gesellschaftsclasse als geringer zu erachten ist, Aufsicht und Pflege in gebildeten und wohlhabenden Familien bei eingetretener Erkrankung im Allgemeinen bedeutend besser ist und gerade hierauf bei diesen Krankheiten ein grosses Gewicht von den Aerzten gelegt wird".

1885 hat dann Körösi (20) in seiner Arbeit über den Einfluss der Wohlhabenheit auf die Sterblichkeit nachzuweisen gesucht, dass nach Maassgabe der 1876 bis 1882 in Budapest vorgekommenen Todesfälle die Armuth das Auftreten der Diphtherie nicht befördert, sondern eine verminderte Disposition schafft. Setzt man die Intensität bei Wohlhabenden $=100$, so beträgt die Intensität der Diphtheriesterblichkeit bei Armen nur 66, und wenn die Kinder bis zu 5 Jahren gesondert gezählt werden, sogar nur 48. 'Körösi beruft sich auf die gleichen Resultate, die Liévin (21) in Danzig und Reck (22) in Braunschweig erhalten hat; ferner auf den $5^{\text {th }}$ Report des Board of health der Stadt Boston. In Zeitschr. f. Hygiene, XVII. 
Danzig betrug nach den von Körösi auf Grund des Liévin'schen Materials angestellten Berechnungen die Quote für Diphtheriesterblichkeit bei Reichen 401, bei Armen 357. Reck gruppirte 1877 die einzelnen Strassen Braunschweigs auf Grund der Steuerlisten nach dem durchschnittlichen Einkommen eines jeden Bewohners und fand, dass ein grösserer Procentsatz von Kindern in den wohlhabenden Strassen als in den armen durch Rachenbräune getödtet wurden. Jährlich erkrankten bezw. starben an Rachenbräune unter 10000 Einwohnern von 0 bis 15 Jahren in Strassen mit einem durchschnittlichen Einkommen von:

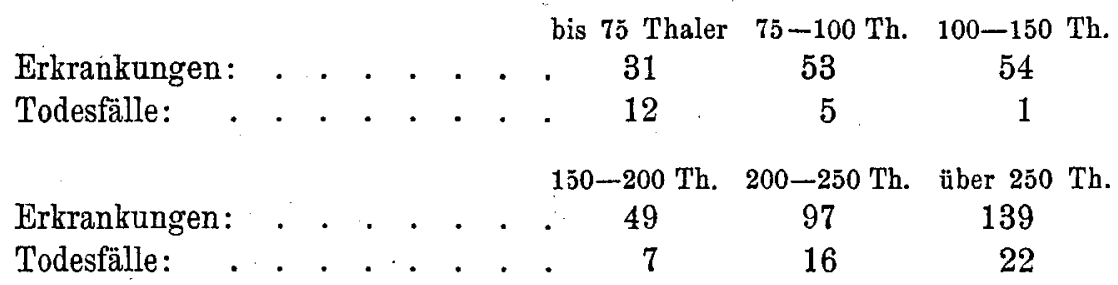

In Boston endlich traten während einer starken Diphtherieepidemie 1875 bis 1877 in den günstig situirten Stadttheilen weitaus die meisten Fälle auf, während die ärmsten Districte (Nordend und Haymarket) fast frei blieben.

Diese auffälligen Resultate der statistischen Untersuchungen über den Einfluss der Wohlhabenheit auf die Diphtheriefrequenz bedürfen vor Allem einer kritischen Revision und Ergänzung. Von vornherein muss man an die Möglichkeit denken, dass in jenen Arbeiten nicht alle Fehlerquellen genügend ausgeschlossen waren. Die Zahlen sind vielfach zu klein, die Diagnosen unsicher, die Beobachtungsperioden zu kurz, der Maassstab der Wohlhabenheit mangelhaft; möglich, dass bei thunlichster Vermeidung dieser Fehler andere Ergebnisse zu Tage treten. Besonders leicht schleichen sich bei den Beobachtungen über die räumliche Gruppirung der Diphtherie einerseits, der Wohlhabenheit und Wohwdichtigkeit andererseits Fehler ein. Hier dürfen die Diphtherieerkrankungen nur bezogen werden auf die Zahl der vorhandenen empfänglichen Kinder, nicht aber auf die Zahl aller Lebenden; die örtlichen Gruppen müssen ausserdem . klein gewählt werden, und auch bei der Abschätzung der Wohlhabenheit sind wo möglich die Kinder besonders zu berücksichtigen.

Durchaus nicht im Widerspruch mit der Annahme eines förderlichen Einflusses der Armuth und Wohndichtigkeit auf die Diphtheriefrequenz stehen jene einzelnen Beobachtungen über intensive' Ausbreitung der Diphtherie in gut situirten Familien. Ein solches Verhalten ist ja in manchen Familien, wo z. B. die Kinder viel geküsst werden und Ess- und 
Trinkgeräth oft gemeinsam benutzt wird, ganz selbstverstäudlich; aber diese mehr vereinzelten Fälle sagen nichts aus über die ziffermässige $\mathrm{Be}-$ theiligung der Wohlhabenden an der Diphtheriefrequenz.

Theilweise unter den Factor der Wohlbabenheit fallen. noch einige andere Momente, die hier und da als besonders bedeutungsvoll für die Ausbreitung der Diphtherie hervorgehoben werden. Dahin gehört z. B. die Anhäufung ron Abfallst offen. Von englischen und nordamerikanischen Aerzten wird noch vielfach angenommen, dass ,Zersetzungsproducte organischer Stoffe der eigentlichen Krankheitsursache einen für ibre Entwickelung oder Reproduction geeigneten Boden bieten und dass daher die Anhäufung thierischer oder pflanzlicher Abfälle in oder auf dem Boden in der Nähe bewohnter Răume oder in denselben die Bildung von Krankheitsherden fördern". Mangelhafte Einrichtungen zur Entfernung der Abfallstoffe, schlechte Canäle, defecte Syphons und ins Haus dringende Canalgase werden in England fortgesetzt in den meisten Fällen von Diphtherie als ätiologisch betheiligt angesehen. Eine Begründung dieser veralteten und mit unseren heutigen Kenntnissen über Natur der Infectionserreger gar nicht zu vereinigenden Anschauungen wird gewöhnlich gar nicht versucht. Wie völlig kritiklos Aerzte und Laien in ihrem blinden Glauben an den bedeutsamen Einfluss der Canalgase bei der ätiologischen Aufklärung von Diphtheriefällen verfahren, daron legt das Buch von Pridgin Teale (23), „Lebensgefahr im eigenen

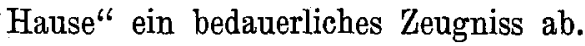

Neuerdings kommen einige französisehe Beobachter, Teissier und Longuet (24) u. A., auf etwas Aehnliches hinaus, indem sie in der Anhäufung von P fer ded ü nger in der Nähe mensehlicher Wohnungen eine Quelle der Diphtherieinfection sehen wollen. Hier ist ebenso wie in den vorgenannten englischen Beobachtungen irgend ein den Sinnen auffäliges Moment vollkommen willkürlich in ätiologische Beziehung zur Diphtherie gebracht. Da wir in den bestangelegten Wohnungen, in Palästen, in gut canalisirten Stadtvierteln, wo Anhäufungen von Pferdedung gar nicht existiren, intensive Diphtherieverbreitung sehen, und da andererseits z. B. in Breslau, wie unten gezeigt werden wird, gerade die ländlichen Wohngebäude der äussersten Peripherie, die zum grössten Theil mit Düngeransammlungen versehen sind, niedrigste Diphtheriefrequenz haben, müssen ganz zweifellos andere Momente als jene Abfallstoffe, Canalgase u. dgl. die Ausbreitung der Krankheit in massgebender Weise beeinflussen können. Existiren aber solche kräftig wirksame Momente, so muss doch deren Mitwirkung erst völlig ausgeschlossen werden, ehe man auf einen neuen ätiologischen Factor verfällt. "Dieses Ausschliessen anderer Momente ist bisher nie versucht; vielmehr hat man die Armuth und die Dichtigkeit der Bewohnung, 
welche so oft mit der Anhäufung von Abfallstoffen und schlechten Reinigungsvorrichtungen zusammen gehen, ebenso die verschiedene individuelle Disposition der verglichenen Menschengruppen, die Gelegenheit zu Erkältungen u. s. w. bei jenen Untersuchungen gar nicht in Erwägung gezogen.

Etwas einheitlichere Resultate haben die Erhebungen über das zeitliche Verhalten der Diphtherie geliefert. Die älteren hierauf bezüglichen Beobachtungen fasst Hirsch dahin zusammen, dass an fast allen Beobachtungsorten in längeren Beobachtungsperioden ein Minimum der Diphtheriefrequenz in den Sommer, ein Maximum in den Winter fällt. Die Excursionen der betreffenden Curven sind indess nicht bedeutend, und in zahlreichen Fällen hat die einmal entwickelte Epidemie unbeeinflusst von der Jahreszeit fortbestanden und häufig ist die Akme von Epidemieen in den Hochsommer gefallen. Auch die neueren Beobachtungen ergaben das gleiche Resultat; so fand Kaiser für Berlin im Mittel der Jahre 1874 bis 1883 ein ziemlich steiles Ansteigen der Frequenz von Ende August bis Mitte November und von da ein langsameres Absinken bis zum April.

Die jahreszeitliche Einwirkung ist bisher fast stets ohne Weiteres auf Witterungseinflüsse bezogen: Entweder hat man in etwas einseitiger Weise ohne Weiteres als charakteristisch für den Sommer und für das Sinken der Diphtheriefrequenz die höhere Wärme, und als charakteristisch für den Winter und die Steigerung der Diphtheriefrequenz die Kälte angesehen. Oder man hat ausser der Wärme noch die übrigen Witterungsfactoren einer genaueren Untersuchung unterzogen. Kaiser findet z. B., dass die Abnahme der Temperatur eine durchschnittliche Vermehrung und die Zunahme eine Verminderung der Zahl der Todesfälle bewirkt; dass aber die Luftfeuchtigkeit, die Niederschlagsmengen und die Ozonmengen keinerlei Beziehung zeigen.

Auch diese statistischen Ergebnisse sind mit Vorsicht aufzunehmen. Da viele Beobachter constatirt haben, dass eine von der Regel stark abweichende jahreszeitliche Vertheilung der Diphtherie durchaus nicht selten ist, so dürfen wir hinter der geringen Häufung der Fälle, welche die Mittelzahlen für den Winter erkennen lassen, keinen irgendwie ausschlaggebenden. Einfluss suchen. Erst dann, wenn auch auf kleinerem Gebiet sich stets dieselbe zeitliche Vertheilung wiederholen würde, dürfte man auf ein bedeutsameres ätiologisches Moment schliessen. Wenn aber nur in der aus sehr verschiedenen Einzelwerthen abgeglichenen Mittelzahl eine einigermassen übereinstimmende und dabei geringfügige 
Differenz hervortritt, so muss es sich um etwas für die Verbreitungsweise relativ Belangloses handeln.

Ausserdem ist es unzulässig, die geringe jahreszeitliche Schwankung ausschliesslich auf directe Witterungseinflüsse zu beziehen. Es können ebensogut z. B. Lebensgewohnheiten und Gebräuche, die an die Jahreszeit gebunden sind und nur ganz indirect mit der Witterung zusammenhängen, auf die Ausbreitung des Contagiums fördernd oder hemmend wirken. So lässt sich die Steigerung der Diphtheriefrequenz im Winter nicht allein daraus erklären, dass die Conservirung des Contagiums im Winter bei Kälte, hoher Feuchtigkeit und Lichtmangel eine bessere ist; sondern auch daraus, dass das Zusammendrängen der Menschen im Hause und die erschwerte Reinigung des Körpers und der Kleidung im Winter die.Ansteckungsgelegenheiten vermehrt; und endlich noch daraus, dass im Winter die katarrhalischen Affectionen und leichten Läsionen der Rachenschleimhaut sich mehren, die dann ein Haften des Contagiums erleichtern. Es ist denkbar, dass alle diese Momente zusammen zu der jahreszeitlichen. Akme der Diphtheriecurve beitragen, oder dass nur einzelne derselben ernstlich in Betracht kommen. Jedenfalls aber sind alle nicht einflussreich genug, um unter allen Umständen eine Steigerung der Fälle im Winter zu bewirken; sondern überaus häufig werden diese Einflüsse durch andere für die Verbreitung massgebendere Momente übercompensirt, so dass gerade im Sommer Steigerung, im Winter Abnahme der Frequenz eintritt.

Schliesslich haben statistische Erhebungen noch einige Resultate zu Tage gefördert, welche die individuelle Disposition betreffen; und zwar stimmen hier die Zahlen der verschiedenen Beobachter im Ganzen gut überein. Namentlich betreffen diese Untersuchungen die Altersdisposition. Schon Oertel und Jacobi bezeichneten die Diphtherie als eine rorzugsweise dem Kindesalter zukommende Krankheit. Nach Brühl und Jahr (7) ist die Sterblichkeit an Diphtherie am grössten bei den Kindern zwischen dem 1. und 2. Lebensjahre, dann folgen die Kinder im 1. Lebensjahr, darauf die Kinder im 2. bis 5. Lebensjahr, dann die im schulpflichtigen Alter stehenden Kinder; vom 15. Jahre ab ist die Betheiligung an der Sterblichkeit eine äusserst geringe. Kaiser (6) fand für Berlin den Höhepunkt der Sterblichkeit im 2. bis 3. Lebensjahr, dann folgt das 4. bis 5. Lebensjahr und darauf erst das erste Lebensjahr; vom 9. Jahr wird die Sterblichkeit schon sehr gering, um mit dem 15. Jahr fast aufzuhören. Diese Beschränkung der Krankheit auf das kindliche Alter - mit wenigen Ausnahmefällen - wird von allen neueren Autoren bestätigt. $\mathrm{Zu}$ wesentlich abweichenden Resultaten gelangen nur einige Arbeiten, in welchen unrichtiger Weise die Erkrankungsfälle der einzelnen 
Lebensalter in Procenten der gesammten beobachteten Fälle berechnet wurden, ohne Rücksicht auf die Zahl der Lebenden der betreffenden Altersclasse. In Folge dieses und anderer Fehler kommt z. B. Reinecke für die in Göttingen 1878 bis 1882 beobachteten Diphtherieerkrankungen zu der Annahme eines Gleichbleibens der Erkrankungsfähigkeit bis zum 25. Lebensjahr.

Gewöhnlich wird noch ein anderes statistisches Ergebniss auf die individuelle Disposition bezogen; nämlich das mehrfäch beobachtete stärkere Befallenwerden der Knaben bezw. der Mädchen. Vielfach, aber nicht überall, scheint eine höhere Frequenz bei Knaben festgestellt zu sein. Nach Brühl und Jahr überwiegt die Sterblichkeit der Knaben in den östlichen Bezirken des preussischen Staates, während in den südlichsten Districten die der Mädchen durchgehends höher ist und in den nördlichen und westlichen Bezirken regellose Abweichungen vorkommen. Heubner fand, dass in Leipzig 1883 bis 188423.4 pro mille Knaben und $25 \cdot 2$ pro mille Nädchen an Diphtherie erkrankten. Kaiser ermittelte für Berlin, dass die Disposition für Diphtherie bis zum 5 . Lebensjahre bei Knaben höher ist als bei Mädchen, vom 5. bis zum 10. Lebensjahre dagegen umgekehrt bei Mädchen höher. - Dieser Unterschied im Verhalten der beiden Geschlechter könnte auf einer entsprechenden differenten Beschaffenheit der exponirten Schleimhäute oder der im Körper functionirenden Abwehrvorrichtungen beruhen; vielleicht aber giebt sich auch hier eine ungezwungenere Erklärung aus den Lebensgewohnheiten. Kaiser meint, dass in Berlin Knaben in den ersten Lebensjahren im Allgemeinen sorgfältiger gehegt, wärmer und mehr im Zimmerklima gehalten werden und deshalb (entsprechend den Krieger'schen Beobachtungen) in diesen Jahren stärker disponirt sind. Vielleicht wirkt auch die grössere Zärtlichkeit der Eltern, Geschwister und Nachbarn gegen Knaben in diesem Alter in demselben Sinne. Später tummeln sich die Knaben mehr im Freien, die Mädchen sind mehr auf das Zimmer beschränkt und in Folge dessen kehrt sich die Disposition um. - Uebrigens sind die Erkrankungsdifferenzen zwischen beiden Geschlechtern äusserst gering und schon deshalb einer sicheren Deutung kaum zugänglich.

Die Ausbeute der bisherigen statistisch-epidemiologischen Untersuchungen über die Diphtherieverbreitung ist somit eine relativ geringe. In Bezug auf die räumliche Vertheilung liegen Zusammenfassungen nach grösseren Bezirken vor, die aus verschiedenen Gründen nicht für die ätiologische Aufklärung verwerthbar erscheinen. Die Statistik kleinerer Gebiete (einzelner Städte) führte einige Beobachter zur Annahme localer Herde, während 
andere eine Localisation der Diphtherie durch Einflüsse der Oertlichkeit in Abrede stellen. Ferner wird die Wohlhabenheit der Bewohner von einigen Statistikern als ausschlaggebender, von anderen als irrelevanter oder in entgegengesetztem Sinne wirkender Factor angesehen. Ueber das zeitliche Verhalten der Diphtherie liegen gleichmässigere Resultate vor; indess ist die Erklärung der zeitlichen Schwankung und die Abschätzung ihrer Bedeutung schwierig und unsicher. Nur bezüglich der Altersdisposition hat die Statistik einigermassen übereinstimmende und für die Verbreitungsart der Krankheit wichtige Ergebnisse geliefert.

Ueber einige der interessantesten Fragen in Bezug auf den Ausbreitungsmodus der Diphtherie, nämlich die Herdbildung durch locale Einflüsse und die Bedeutung von Armuth und Wohlhabenheit können wir, wie oben ausgeführt wurde, auch durch die neueren Untersuchungen über die biologischen Eigenschaften der Diphtheriebacillen keine Auskunft bekommen. Um so mehr erscheint es wünschenswerth, erneute möglichst fehlerfreie statistische Untersuchungen nach dieser Richtung anzustellen und mit Hülfe derselben rielleicht einen klareren Einblick in die natürliche Verbreitungsweise der epidemischen Diphtherie zu gewinnen.

Für solche Untersuchungen sind jetzt die grösseren deutschen Städte besonders geeignet, da hier seit einer Reihe von Jahren die Erkrankungen an Diphtherie ärztlicherseits resp. von den Angehörigen gemeldet und registrirt werden. Hierdurch wird voraussichtlich ein besseres Urmaterial gewonnen, da die bisher ausschliesslich benutzte Mortalität bei der Diphtherie zeitlich, örtlich und je nach dem Alter des Kindes ausserordentlich stark schwankt (vergl. Rahts, S. 411; ferner Heubner a. a. 0.) und deshalb ein sehr ungenaues Bild der Diphtherieverbreitung giebt. In den grösseren deutschen Städten pflegen andererseits genaue Aufzeichnungen über die Zusammensetzung der Bevölkerung, über die örtliche Vertheilung der Wohlhabenheit, über die Dichtigkeit der Bewohnung, über das Verhalten des Bodens, des Grundwassers und der meteorologischen Faktoren vorzuliegen. Auch für Breslau treffen alle diese Voraussetzungen zu, und ich benutzte deshalb die hier gebotene Gelegenheit, um eine neue statistische Ontersuchung über die Diphtherieverbreitung unter möglichst sorgfältiger Kritik der Leistungsfähigkeit der angewendeten Methoden auszuführen.

\section{Die Verbreitung der Diphtherie in Breslau 1886 bis 1890.}

In Breslau besteht die obligatorische Meldepflicht für Diphtherieerkrankungen seit 1886. Cnvollständige und auffällige Angaben auf den Meldekarten werden Dank den energischen Bumühungen des städtischen 
statistischen Büreaus nach Möglichkeit geklärt. Zunächst wurden 5 Jahre, $1886,1887,1888,1889$ und 1890 in Untersuchung gezogen, die ein beträchtliches Material darboten, da in mehreren dieser Jahre starke Epidemieen von Diphtherie in der Stadt herrschten. Im Ganzen waren 6394 Erkrankungen an Diphtherie in den 5 Jahren gemeldet; und diese bildeten die Basis für die vorliegende Untersuchung. ${ }^{1}$

Gewisse Bedenken müssen allerdings gegen die Zuverlässigkeit und Verwerthbarkeit dieses Materials erhoben werden.

Zunächst kann man einwenden, dass unter den gemeldeten Diphtherieerkrankungen sich häufig Fälle von Angina follicularis s. lacunaris und von Scharlachdiphtherie befinden, die ätiologisch nichts mit der Diphtherie gemein haben. Kaiser zieht sogar die Benutzung nur der Todesfälle an Diphtherie der statistischen Verarbeitung der Krankheitsfälle vor, weil bei letzteren zu oft und wechselnd je nach den individuellen Ansichten des behandelnden Arztes eine folliculäre Angina als Diphtherie ausgegeben würde. Aber, wie wir oben gesehen haben, schwankt die Mortalität der an Diphtherie Erkrankten örtlich und zeitlich ganz ausserordentlich; jeder Versuch, die Verbreitungsart der Diphtherie aus den Todesfällen abzuleiten, ist daher ganz zweifellos ron vornherein mit einem bedeutenden Fehler behaftet.

Gerade für unsere Breslauer Statistik ist der Einwand einer Verwechselung mit leichten Fällen kaum erheblich. Eine solche wird weitaus am häufigsten in wohlhabenden Familien vorkommen, weil hier der Arzt schon bei geringfügigen Erkrankungen zugezogen wird und weil er hier auch in einem zweifelhaften Fall lieber sofort alle bei echter Diphtherie indicirten Maassregeln trifft, als dass er zunächst den Verlauf abwartet. Bei der armen Bevölkerung bekommt der Arzt die meisten Fälle von Angina follicularis gar nicht $z u$ sehen, weil die Leute erst 1 bis 2 Tage mit der Consultation zögern und in dieser Frist bereits Besserung einzutreten pflegt. Wird aber der Arzt zugezogen, dann geht er nicht so freigebig mit der Diagnose "Diphtherie" um, weil die Absperrung, das Meiden der Schule, die Desinfection etc., die sich unweigerlich daran knüpfen, für arme Leute höchst unangenehme und gefürchtete Lasten

I Die Zählungen, Berechnungen und kartographischen.Auftragungen wurden von Herrn Dr. med. J. Olbrich, jetzt praktischem Arzt in Rengersdorf, mit grossem Fleiss und ausserordentlicher Sorgfalt ausgeführt. Einen Theil der erhaltenen Resultate hat Herr Dr. Olbrich in seiner 1892 erschienenen Inaugural-Dissertation: „Die Verbreitung der Diphtherie in Breslau in den Jahren 1886-1890" mitgetheilt. - Das ganze Material und die mannigfaltigste Unterstützung erhielten wir durch das statistische Bureau der Stadt Breslau, dessen Director, Hrn. Dr. Neefe, wir uns zu lebhaftestem Dank verpflichtet fühlen. 
darstellen, die man ihnen nur im wirklichen Nothfall aufbürdet. Thatsächlich betragen nun die Diphtheriefälle, die in Breslau bei Wohlhabenden vorgekommen sind, nur $1 / 10$ aller registrirten Fälle, wie unten gezeigt werden wird. Die fälschlich als Diphtherie gemeldeten Anginen können daher nur einen sehr kleinen Bruchtheil des ganzen Materials ausmachen und dessen Verlässlichkeit wenig alteriren.

Auch eine Verwechselung mit Scharlachdiphtherie wird selten in Frage kommen. Bei Scarlatina gehen meist so viele andere nicht leicht zu übersehende Symptome der Diphtherie voraus, dass die Krankheit gewöhnlich schon früher als Scarlatina gemeldet wird, ehe die diphtherieähnlichen Erscheinungen zum Ausbruch kommen. Einzelne Ausnahmen von dieser Regel sind gegenüber dem grossen Umfang des Materials belanglos.

Viel schwerer fällt ein anderer Einwand ins Gewicht, nämlich der, dass die Meldungen aus den Schichten der ärmsten Bevölkerung unvollständig sind, weil häufig der Arzt überhaupt nicht zugezogen wird, während im Gegensatz hierzu die Meldungen aus den wohlhabenden Kreisen sehr vollständig eingehen. Dadurch kann in der That eine künstliche Verschiebung in die Vertheilung der Diphtheriefälle hineingebracht werden, die an verschiedenen Stellen der folgenden Betrachtung und namentlich dann wohl zu berücksichtigen ist, wenn die Antheilnahme der Wohlhabenden und des Proletariats an der Diphtheriefrequenz bestimmt werden soll.

Die auf Grund dieses jedenfalls nach Möglichkeit brauchbaren Materials vorgenommene Untersuchung sollte sich nun im Hinblick auf die im vorigen Abschnitt entwickelten Gesichtspunkte nach folgenden Richtungen erstrecken:

Erstens war die räumliche Vertheilung der vorgekommenen Diphtheriefälle übersichtlich darzulegen; und zwar war hierbei sowohl die absolute Zahl der in jedem räumlichen Bezirk vorgekommenen Erkrankungen wie auch die Frequenz zu berücksichtigen, wobei unter letzterer zu verstehen ist die Zahl der vorgekommenen Erkrankungen ausgedrückt in Procenten der in dem betreffenden Bezirk wohnhaften erkrankungsfähigen Personen.

Zweitens war die räumliche Vertheilung der Diphtheriefrequenz in Beziehung zu setzen zu denjenigen Einflüssen der natürlichen und künstlichen Umgebung, welche eine locale Häufung der Diphtheriefälle bewirken könnten.

Drittens sollte das Verhältniss der Diphtheriefrequenz zur Wohlhabenheit der Bevölkerung ermittelt werden. 
Viertens war die zeitliche Vertheilung der Diphtherie während der Beobachtungsjahre zu analysiren.

Fünftens sollte mit Rücksicht auf die besondere Leistungsfähigkeit detaillirter Beobachtungen versucht werden, durch genauere Verfolgung der Einzelfälle, die in stark ergriffenen Häusern vorgekommen sind, einen näheren Einblick in die Verbreitungsart der Seuche und speciell in die Ursachen der sogen. Herdbildung zu gewinnen.

I.

Um zunächst die örtliche Verbreitung übersichtlich darzustellen, wurden auf einem genügend geräumigen Plan des Stadtgebiets von Breslau (1:5000) die sämmtlichen 6394 Fälle eingetragen, und zwar so, dass die auf jedes Grundstück kommenden Fälle deutlich erkennbar waren; ferner waren die auf verschiedene Jahre fallenden Erkrankungen durch besondere Zeichen markirt $(1886=\perp, 1887=\bullet, 1888=<, 1889=+$, $1890=Y$ ).

Auf diese Weise war einerseits ein Ueberblick über die örtliche Vertheilung und Gruppirung der Einzelfälle, sowie über deren zeitliche $\mathrm{Zu}$ sammengehörigkeit, andererseits ein directes Ablesen der Summe der Einzelfälle in einem Hause oder einer Strasse ermöglicht.

Auf Tafel IV ist dieser Plan in photographischer Aufnahme stark verkleinert wiedergegeben; unter Zuhülfenahme der Lupe lassen sich auch in der Reproduction die jedem Hause zukommenden Einzelfälle gut unterscheiden.

Gegen diese ganze Art der örtlichen Registrirung der Erkrankungsund Todesfälle, die früher für die verschiedensten Infectionskrankheiten gebräuchlich waren, lässt sich ein sehr berechtigter Einwand erheben: es wird dabei ohne Weiteres die Wohnung des Erkrankten als der Ort angesehen, wo die Krankheit acquirirt wurde. Diese Voraussetzung trifft 2weifellos bei vielen Krankheiten nicht zu. Bezüglich der Cholera habe ich bereits darauf hingewiesen, ${ }^{1}$ dass häufig eine Aufnahme des Contagiums ausser dem Hause, im Restaurant, im Geschäftslocal, an der Arbeitsstelle u. s. w. vorkommen muss. Das Gleiche gilt rom Abdominaltyphus; selbst Malaria kann auf Gängen und Besuchen ausser dem Hause acquirirt werden. Besteht nicht dieselbe Möglichkeit für die Diphtherie und ist es nicht deshalb von vornherein unrichtig, von der Eintragung der Fälle auf die Wohnungen eine Aufklärung über die Verbreitungswege des Contagiums zu erwarten?

\footnotetext{
${ }^{1}$ Diese Zeitschrift. B̀d. XV.
} 
Bei der Diphtherie liegt die Sache doch erheblich anders. Volle zwei Drittheile aller Fälle kommen auf kleine noch nicht schulpflichtige Kinder, bei welchen fast ausschliesslich das Wohnhaus als Infectionsstätte in Rechnung zu ziehen ist. Das übrig bleibende Drittel setzt sich sicher auch noch ganz überwiegend aus Erkrankungen zusammen, die durch den Verkehr mit Geschwistern und anderen Kindern desselben Hauses im Hause erworben wurden; nur ein im Vergleich zur Gesammtzahl jedenfalls sehr kleiner Theil der Erkrankungen mag bei den älteren Kindern in der Schule, durch Besuche in entlegeneren Häusern u. s. w. vermittelt sein. Leider war es nicht möglich, die Ansteckung durch die Schule gesondert zu registriren. In Breslau wie in allen grossen Städten werden die Volksschulen (die hier fast ausschliesslich in Betracht kommen) von den Kindern eines bestimmten Stadttheils besucht, die dann natürlich auch ausserhalb der Schule vielfache Gelegenheit zu gegenseitiger Ansteckung haben; diese anderen Gelegenheiten auszuschliessen und mit Bestimmtheit die Schule als Infectionsstätte zu bezeichnen, das kann nuihöchst selten gelingen. So viel lässt sich aber mit Bestimmtheit sagen, dass die in der Schule erfolgenden Uebertragungen nur einen sehr kleinen Bruchtheil aller Fälle ausmachen. Das geht einmal aus der hier und in anderen Städten gemachten Erfahrung hervor; dass ein Schliessen der Schule in der Regel wenig Einfluss auf die Ausbreitung der Epidemie hat. Ferner aber muss man diese Ueberzeugung gewinnen aus der unten (S. 430) gegebenen Alterscurve. In Breslau und mehr noch in Berlin sinkt die Frequenz vom 6 . Jahre an steil abwärts, mit relativ geringfügigen Unterbrechungen, während letztere doch erheblich stärker sein müssten; wenn wirklich die Schulzeit eine irgend wesentliche Vermehrung der Uebertragungen bewirkte: In höherem Grade wird die Ansteckung durch die Schule wohl nur bedeutungsvoll bei Kindern wohlbabender Familien, die vor der Schulzeit von dem Verkehr mit anderen Kindern ferngehalten oder in ihrem Verkehr wenigstens stets controlirt werden. Solche Kinder bleiben oft bis zur Schule frei von ansteckenden Krankheiten, acquiriren dieselben aber, sobald die Schule sie mit anderen Kindern aus den verschiedensten Stadtgegenden in Verkehr gebracht hat. Auch die ron Heubner (11a) festgestellten, das Vorkommen von Diphtherieübertragungen in der Schule zweifellos beweisenden Fälle betreffen gauz überwiegend höhere Schulen. Auf die statistischen Zusammenstellungen können aber diese seltenen Vorkommnisse keinen Einfluss haben.

Endlich sei noch verwiesen auf die im letzten Abschnitt dieser Arbeit erörterte Untersuchung über den genaueren Gang der Diphtherie innerbalb einiger besonders ergriffener Häuser, die ebenfalls dafür spricht, dass überall da, wo locale Häufung von Erkrankungen auftritt, die Ueber- 
tragung sich ganz rorwiegend im Hause vollzieht. Gerade bei der Diphtherie wird somit die Identificirung der Wohnhäuser der Erkrankten mit den Infectionsstätten ohne allzu grossen Fehler zulässig sein.

Betrachten wir nunmehr Tafel IV, so zeigt sich sofort, dass eine auffallend verschiedene Vertheilung der Erkrankungen besteht; theils finden sich dicht gedrängte Herde, theils kleinere oder grössere relativ freigebliebene Bezirke. - Auch eine gewisse Regelmässigkeit scheint die Vertheilung der Fälle zu beherrschen. Namentlich zeigt fast die ganze innere Stadt und namentlich dje Gegend in der Umgebung des Stadtgrabens sehr spärliche Fälle, während in der Peripherie an verschiedenen Punkten die stärksten Häufungen hervortreten.

Diese Gruppirung ist aber nicht als Ausdruck der Frequenz der Krankheit oder der Erkrankungsintensität anzusehen. Dichte Häufung von Diphtheriefällen an einzelnen Stellen des Plans kann auch dadurch zu Stande kommen, dass dort sehr viel Menschen und Kinder zusammengedrängt wohnen, leere Stellen können solche sein, wo weiträumige Bebauung mit kleineren Häusern vorliegt. Oder es kann z. B. ein Bezirk relativ frei bleiben, obwohl er ziemlich dicht bewohnt ist, weil hier die katholische Geistlichkeit, oder Studirende oder junge Arbeiter in überwiegender Zahl wohnen, so dass wenig von den ausschliesslich empfänglichen Kindern vorhanden sind. Die örtliche Vertheilung der Einzelfälle giebt uns somit nicht ohne Weiteres einen Maassstab der Frequenz, wie dies irrthümlicherweise in manchen älteren und neueren epidemiologischen Arbeiten angenommen ist.

Da für die Diphtherie seit lange eine ausgesprochene Altersdisposition festgestellt ist, war es erforderlich, zınächst für Breslauer Verhältnisse den Lmfang und die Grenze dieser Empfänglichkeit bezw. Unempfänglichkeit genauer zu ermitteln, um dann die in jedem Bezirk vorhandenen empfänglichen Individuen festzustellen und auf diese die ebendort vorgekommenen Diphtheriefälle zu vertheilen.

Die Altersdisposition für Diphtherie ergab sich dadurch, dass die 6394 Diphtherieerkrankungen nach dem Alter der Erkrankten zusammengelegt und dann mit der Zahl der Lebenden der betreffenden Altersclasse verglichen wurden. Die Zahl der Lebenden jeder Altersclasse war in Breslau für das Jahr 1885 festgestellt worden, und diese Zahlen durften ohne erheblichen Fehler hier zu Grunde gelegt werden. So ergab sich das Resultat, welches die nebenstehende Tabelle zeigt.

In Fig. 1 (S. 430) ist die Altersdisposition graphisch dargestellt. Zum Vergleich ist die von Kaiser für Berlin aus den Diphtherietodesfällen abgeleitete Curve beigefügt. 
Die Verbreitungsweise der Diphtherie.

\begin{tabular}{|c|c|c|c|c|}
\hline $\begin{array}{c}\text { Im Alter von: } \\
\text { Jahre }\end{array}$ & $\begin{array}{c}\text { Diphtherie- } \\
\text { erkrankungen } \\
\text { 1886-1890 }\end{array}$ & $\begin{array}{c}\text { Durchschnittlich } \\
\text { pro Jahr }\end{array}$ & $\begin{array}{c}\text { Lebende } \\
\text { der betreffenden } \\
\text { Altersclasse }\end{array}$ & $\begin{array}{c}\text { Auf } \\
1000 \text { Lebende } \\
\text { jährlich erkrankt }\end{array}$ \\
\hline $0-1$ & 160 & 32 & 7393 & $4 \cdot 32$ \\
\hline $1-2$ & 574 & 115 & 6682 & $17 \cdot 18$ \\
\hline $2-3$ & 813 & 163 & 6143 & $26 \cdot 47$ \\
\hline $3-4$ & 787 & 157 & 6184 & $25 \cdot 45$ \\
\hline $4-5$ & 655 & 131 & 5783 & $22 \cdot 65$ \\
\hline $5-6$ & 660 & 132 & 5640 & $23 \cdot 40$ \\
\hline $6-7$ & 565 & 113 & 6031 & $18 \cdot 73$ \\
\hline $7-8$ & 550 & 110 & 5952 & $18 \cdot 51$ \\
\hline $8-9$ & 325 & 65 & 6201 & $10 \cdot 48$ \\
\hline $9-10$ & 258 & 52 & 6311 & $8 \cdot 17$ \\
\hline $10-11$ & 126 & 25 & 5765 & $4 \cdot 37$ \\
\hline $11-12$ & 150 & 30 & 5738 & $5 \cdot 23$ \\
\hline $12-13$ & 125 & 25 & 5639 & $4 \cdot 43$ \\
\hline $13-14$ & 65 & 13 & 5645 & $2 \cdot 30$ \\
\hline $14-15$ & 41 & 8 & 4511 & $1 \cdot 82$ \\
\hline $15-16$ & 35 & 7 & 5521 & $\quad 1.23$ \\
\hline $16-17$ & 32 & 6 & 5979 & 1.07 \\
\hline $17-18$ & 35 & 7 & 5983 & $1 \cdot 17$ \\
\hline $18-19$ & 23. & 5 & 5942 & 0.75 \\
\hline $19-20$ & 22 & 4 & 6097 & 0.72 \\
\hline
\end{tabular}

Demnach war bei den Erwachsenen die Empfänglichkeit eine so verschwindende gegenüber derjenigen der Kinder, dass die Erwachsenen bei der vorliegenden Untersuchung vollständig bei Seite gelassen werden dürfen. Allerdings ist es schwer, eine scharfe Grenze zwischen noch einigermaassen empfänglichen und so gut wie gar nicht mehr empfänglichen Altersclassen zu ziehen. Wir haben es für das richtigste gehalten, im Folgenden die Kinder bis zum Alter von 15 Jahren als empfänglich zu bezeichnen, dagegen die über $15 \mathrm{Jahr}$ alten Menschen als unempfänglich ausser Betracht $2 u$. lassen. Für diese Grenze war uns die Erwägung massgebend, dass die Kinder bis zum 15. Jahre in der Familie zu verbleiben, an den Infectionsgefahren, von welchen dieselbe bedroht wird, zu participiren, und ebenso ihrerseits Infectionsgefahr in die Familie hineinzutragen pflegen; während sie jenseits dieser Altersgrenze meist als Lehrlinge, Arbeiter, Dienstmägde u. s. w. auswärts unter wesentlich anderen Bedingungen leben. $O b$ übrigens die Grenze ein Jahr früher oder später gelegt 
wird, das ist schliesslich von geringem Belang; für uns wurden weitere Zweifel schon einfach dadurch beseitigt, dass gerade die Kinder unter 15 Jahren in der "Breslauer Statistik" genau nach ihrer ôrtlichen Vertheilung registrirt waren.

Genau genommen hätte nun für jedes der Beobachtungsjahre die Zahl der Kinder bis zu 15 Jahren festgestellt und zu den in dem gleichen Jahre vorgekommenen Diphtheriefällen in Beziehung gesetzt werden müssen. Eine solche jährliche Auszählung existirt aber für keine Stadt. Dieselbe ist nur möglich bei Gelegenheit der alle $\mathbf{5}$ Jahr stattfindenden Volks-

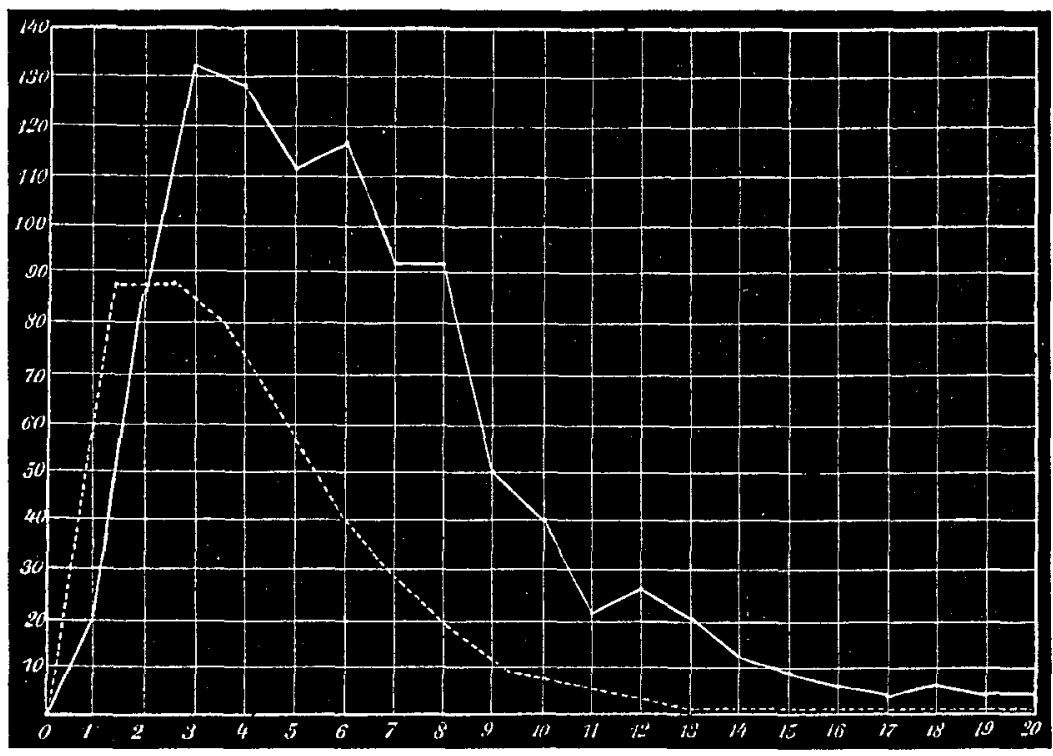

Abscisse: Alter in Jahren. Ordinaten: Die ausgezogene Linie = Zahl der Erkrankungen in Breslan 1886-90 in \% der Lebenden der betreffenden Altersclasse. Die gestrichelte Linie $=$ Zahl der Todesfälle in Berlin 1874-83 in \%o der betreffenden Altersclasse (nach $\mathrm{Ka}$ is e r).

zählungen. Uns lagen daher nur die betreffenden Auszählungen einmal für das Jahr 1885 und zweitens für das Jahr 1890 for, und wir waren darauf angewiesen, aus diesen beiden Zahlen das Mittel - also ungefähr den Berölkerungsstand pro 1888 - zu nehmen und zu dieser Ziffer die Summe oder den Durchschnitt der Diphtheriefälle aus den Jahren 1886 bis $\mathbf{1 8 9 0}$ in Relation zu bringen; eine Rechnungsweise, die offenbar nur einen geringen Fehler bedingt.

Die auf 1000 Kinder unter 15 Jahren entfallenden Diphtherieerkran- 
kungen, welche in sämmtlichen 5 Beobachtungsjahren ${ }^{1}$ : in einem Bezirk beobachtet wurden, sind nun im Folgenden kurz als ,Frequenz der Diphtherie" bezeichnet; und diese Frequenz wurde zunächst für grössere, dann auch für kleinere Bezirke der Stadt berechnet.

Die „Breslauer Statistik" zerlegt die Stadt in 8 grosse „Stad theile"; durch weitere Zerlegung dieser resultiren 24 „Stadtriertel"; dann $48 \mathrm{Be}$ zirksgruppen; schliesslich werden 157,0 rtsbezirke" unterschieden, deren jeder im Durchschnitt nur ca. 80 Gebäude und 2000 Einwohner umfasst. Vorläufig sind an einigen noch schwach bebauten Stellen der Peripherie je 2 Bezirke zusammengefasst, so dass thatsächlich 1885141 Bezirke unterschieden wurden. Auf dem Plan (Tafel IV) sind die Grenzen der Ortsbezirke durch feinere ausgezogene Linien markirt; die Nummer jedes Ortsbezirks ist durch eine kleine arabische Ziffer bezeichnet. Die grossen arabischen Ziffern bezeichnen die 24 Stadtviertel.

Die 8 Stadttheile zeigten folgende mittlere Diphtheriefrequenz:

1. Innere Stadt, westl. Theil . . . . 68 p. m.

2. " " , östl. Theil . . . . . . . 60 "

3. Oderrorstadt . . . . . . . . . . 73 "

4. Sandvorstadt . . . . . . . . . 61 "

5. Ohlauervorstadt . . . . . . . . . 62 "

6. Schweidnitzervorstadt, südlicher Theil - . 65 "

$7 . \quad$, nördl. Theil . . . 74 "

8. Nicolaivorstadt . . . . . . . . 74 "

Auf Tafel Va sind die Differenzen der Diphtherie-Frequenz in den einzelnen Stadttheilen durch Farbentöne kenntlich gemacht.

Manche der in dieser Zusammenstellung hervortretenden Resultate sind sehr auffällig. So gilt die nördliche Schweidnitzerrorstadt als einer der vornehmsten Stadttheile mit eleganten Häusern und wohlhabender Bevölkerung; und doch haben wir hier eine hohe Frequenzzahl. Dagegen ist weniger Diphtherie in der durehschnittlich von armer Bevölkerung bewohnten Sandrorstadt.

Solche Resultate klären sich indessen bald auf, wenn man die grossen Complexe der Stadttheile in die kleineren Stadtriertel auflöst. Die Diphtheriefrequẹnz der letzteren ist auf Tafel $\mathrm{Vb}$ farbig aufgetragen. Man ersieht nun sofort, dass der Stadttheil: nördliche Schweidnitzervorstadt sich aus zwei sehr verschieden ergriffenen Vierteln zusammensetzt, dem Viertel 19 mit geringer und dem Viertel 20 mit sehr hoher Diphtherie-

1 Um einen Vergleich mit den absoluten Zahlen zu erleichtern, wurden bei allen folgenden Uebersichten nicht die mittleren jährlichen Erkrankungen berechnet, sondern die Summen aus allen 5 Beobachtungsjahren. 
frequenz. Ebenso setzt sich die Sandvorstadt aus ganz verschieden ergriffenen Bezirken zusammen. - Auf beiden Karten tritt deutlich hervor, wie die innere Stadt und die östlichen Vorstädte eine relativ geringe Frequenz zeigen, während in der westlichen Peripherie eine ungemein starke Häufung der Erkrankungen stattfindet. Auch hier lässt aber die Karte der 24 Stadtviertel mehrfach Unterschiede erkennen, welche die Zusammenfassung nach Stadttheilen verwischt.

Gehen wir gleich noch über zu der Vertheilung der Diphtheriefrequenz auf 157 Ortsbezirke, so ergiebt sich das in der Tabelle am Schluss dieser Arbeit in Zahlen gegebene Resultat. Das Verhalten Verhalten der 157 Ortsbezirke ist ausserdem topographisch dargestellt auf Tafel IV, dadurch, dass unter den kleinen arabischen Ziffern, welche die Nummer des Ortsbezirks angeben, mit römischen Ziffern die Diphtheriefrequenz hinzugefügt ist; und zwar bezeichnet I eine Frequenz bis zu 39 p. m. der Kinder unter 15 Jahren; II bezeichnet 40 bis 49 , $\mathrm{III}=50$ bis $59, \mathrm{IV}=60$ bis $69, \mathrm{~V}=70$ bis $79, \mathrm{VI}=80$ bis $89, \mathrm{VII}=$ 90 bis 99 , VIII $=$ über 99 p. $\mathrm{m}$.

Eine farbige Auftragung des gleichen Ergebnisses giebt Tafel VI, wo die steigenden Frequenzstufen durch entsprechend dunklere Schraffirung gekennzeichnet sind.

Diese letzte Karte liefert ein buntes Bild ron contrastirenden Bezirken; in schroffem Wechsel reihen sich stark und schwach ergriffene Bezirle an einander. Nur schwierig lässt sich eine gesetzmässige Gruppirung der gleichen bezw. nahestehenden Frequenzstufen erkennen.

Nur so viel lässt sich sagen, dass zunächst im Centrum der Stadt im Allgemeinen eine geringe Frequenz vorherrscht. Aber in den Bezirken 2, 4, 5, 8, 12, 24, 28 u. A. erhebt sich die Frequenz über das Mittel und erreicht im Bezirk 9 sogar die höchste Stufe.

An das Centrum schliesst sich im Halbkreis der Stadtgraben mit den anstossenden Strassen, ausgezeichnet durch eine durchweg unter dem Mittel sich haltende Frequenz, die sich nur in den Bezirken 93, 122 und 124 etwas höher erhebt.

Um diesen centralen Kern schliesst sich ein innerer peripherer Ring mit meist sehr hohen Frequenzzahlen; in jeder der fünf Vorstädte begegnen wir in grosser Ausdehnung der 5. und 6. Stufe, hier und da allerdings von besseren Bezirken unterbrochen; im Südwesten, Westen und Nordwesten sind sogar die 7. und 8. Stufe vorherrschend.

An den meisten Stellen des Umkreises erreicht aber die hohe Diphtheriefrequenz nicht die äusserste Peripherie der Stadt. Hier kommen vielmehr noch Bezirke, die zu den vorigen einen starken Gegensatz dadurch bilden, dass sie die niedrigste Stufe der Diphtheriefrequenz aufweisen. 
Es wiederholt sich dies fast in allen Vorstädten; am ausgesprochensten in der Nicolai-Vorstadt (Bezirke 139, 140, 149/152), in der Odervorstadt $(39 / 40,41,42 / 43)$, in der Sandrorstadt $(52 / 53,54 / 55,56 / 67,60)$, in der Schweidnitzer-Vorstadt (103, 105, 114/115, 117/118, 133, 137/138).

Von grossem Interesse ist eine Vergleichung der nach Ortsbezirken geordneten Uebersicht mit derjenigen der 8 Stadttheile und 24 Stadtviertel. Offenbar zeigt sich auch hier wieder, dass viele Mittelwerthe der Stadttheile und Stadtviertel sich aus den Zahlen für ganz verschiedenartig ergriffene Bezirke zusammensetzen. So enthält das Stadtviertel 8 mit einer durchschnittlich sehr niedrigen Diphtheriefrequenz den sehr stark ergriffenen Bezirk 58 und daneben die ganz peripheren, hervorragend günstig situirten Bezirke 52 bis 57. In dem Stadtriertel 1 mit mittlerer Frequenz finden wir die einzelnen Bezirke mit den Stufen 2 bis 8 vertreten; ebenso in den Vierteln 6, 7, 20, 21, 23.

Die Zusammenfassung nach grösseren Bezirken verwischt alle diese Differenzen und führt daher zu unrichtigen Vorstellungen über die Diphtherievertheilung und deren Ursachen.

Ebenso wie in dem vorliegenden speciellen Fall, sind auch bei vielen anderen epidemiologischen Untersuchungen die Zusammenfassungen nach grösseren örtlichen Bezirken für ätiologische Schlussfolgerungen ungeeignet, obwohl die Statistik für andere Zwecke sich mit besonderem Vortheil der grossen Zahlen bedient. Nur dann werden wir auch für die ätiologische Erforschung von Epidemieen brauchbare Werthe durch grosse räumliche Zusammenfassungen erhalten, wenn die grösseren Bezirke aus einigermassen homogenen kleineren Gruppen, nicht aus contrastirenden, gebildet sind. Diese Voraussetzung trifft aber meist nicht zu; und daher werden wir, mit wenigen Ausnahmen, beim Studium der Aetiologie der Krankheiten um so zuverlässigere Resultate bekommen, je mehr wir ins Detail gehen, und nicht je mehr wir die verglichenen Zahlen und Bezirke vergrössern.

Selbst innerhalb der relativ kleinen 157 Breslauer Ortsbezirke können noch beachtenswerthe Differenzen zu Tage treten, wenn man auf Häusergruppen und einzelne Häuser zurückgreift. Wo daher im Verhalten eines Ortsbezirks Abweichungen von sonst beobachteten Gesetzmässigkeiten hervortreten, ist die Möglichkeit wohl zu berücksichtigen, dass in Folge der zufälligen Abgrenzung der Bezirke innerhalb derselben Contraste vorkommen, welche selbst diese relativ kleinen Mittelzahlen unbrauchbar machen.

Von Interesse ist ferner noch, dass, wie ein Blick auf Tafel IV zeigt, die örtliche Häufung der Diphtheriefalle mit der durch arabische Ziffern angegebenen Diphtheriefrequenz des Bezirks vielfach nicht zusammengeht. So sind z. B. im Bezirk 62 sehr wenig Diphtheriefälle eingetragen, 
und doch ist die Frequenzstufe VI; nahe daneben in den Bezirken 67 bis 69 sind dichtgehäufte Diphtheriefälle eingezeichnet, und doch ist die Diphtheriefrequenz hier sehr gering, nämlich Stufe II bezw. III. Die Zahl der vorhandenen Kinder variirt eben in den einzelnen Bezirken ganz enorm und dementsprechend kann uns nur die Berechmung der Diphtheriefrequenz, wie sie hier durchgeführt wurde; ein richtiges Bild von der Verbreitungsintensität der Diphtherie geben.

\section{II.}

Zu den localen Einflüssen, von welchen die vorstehend geschilderte räumliche Verbreitung der Diphtherie abhängen kann, rechnet man gewöhnlich Bodenstructur, Bodenverunreinigung, das Grundwasser, die Luftbeschaffenheit, die Beschaffenheit der Häuser, die Einrichtungen zur Entfernung der Abfallstoffe und zur Wasserversorgung. Alle diese $\mathrm{M}_{0}$ mente sind theils bei anderen Infectionskrankheiten, theils bei Diphtherie als Vermittler der Einflüsse einer Localität angesprochen. Es fragt sich, ob irgend eines derselben geeignet ist, eine Erklärung für die in Breslau beobachtete Vertheilung der Diphtherie zu liefern.

Ueber die Bodenverhältnisse der Stadt sind wir genau orientirt durch die vor Beginn der Canalisation ausgeführten zahlreichen Bohrungen, deren Ergebnisse Jacobi (25) beschrieben hat. Dem betreffenden Bericht Jacobi's ist folgendes zu entnehmen:

Der Theil der Stadt rechts von der Oder, die Oderinseln, und die nördlichen Abschnitte der Schweidnitzervorstadt stehen auf Oder-oder Ohle-Alluvium, das fast überall von einer mächtigen, stellenweise bis zu $4 \mathrm{~m}$ Höhe aufgeschichteten, im Laufe der Zeit vielfach umgestalteten Humusschicht bedeckt ist. Die darunter liegenden Schichten werden vorwiegend gebildet von Sand verschiedener Korngrösse und zeigen hier und da, in der Sandvorstadt fast durchweg, unmittelbar unter der Humusschicht dünne Lagen thonigen Oderlehms.

Im Süden der Schweidnitzervorstadt trifft man dagegen auf sedimentäre Schichten diluvialen Ursprungs. Hier ist der Untergrund gebildet von mächtigen Lehm- und Lettelagern, die in der Lehmgrubenstrasse, Neudorf-, Nachod- und Sadowastrasse bis zur Oberfläche reichen, im übrigen der Oberfläche ungefähr parallel gehen und weiter nördlich sich unter Sandschichten senken, bis sie in der Gegend der Tauentzienstrasse, des Schweidnitzer Stadtgrabens, des Niederschlesisch-Märkischen Bahnhofes, des Striegauer Platzes und Chaussee soweit hinabgehen, dass die städtischen Bohrungen sie nicht mehr erreichen. Nur an wenigen Stellen hat diese Lehmschicht eine geringere Dicke oder ist ron Kiesschichten unterbrochen. 
Trotzdem also hier eine durchgreifende Verschiedenheit des Untergrundes vorliegt, wie sie selten innerhalb einer Stadt beobachtet wird, sehen wir doch keinerlei Einfluss auf die örtliche Vertheilung der Diphtherie von derselben ausgehen.

Diesseits wie jenseits der Grenze zwischen diluvialem und alluvialem Terrain liegen zahlreiche stark von Diphtherie ergriffene Bezirke und dazwischen schwach ergriffene; das ganze Bild der Vertheilung wird durch das plötzliche Hervortreten des diluvialen Lehms gar nicht alterirt. Auch wenn man genauer in's Detail geht und die Resultate der einzelnen Bohrlöcher zum Vergleich heranzieht, giebt sich diese Unabhängigkeit der Diphtheriefrequenz von der Bodenbeschaffenheit zu erkennen; so haben wir ein Winimum der Frequenz bei einer nur $1 / 2{ }^{m}$ unter der Oberfläche lagernden Lehmschicht (Bohrloch 22, Schlosshof), bei einer 1 m unter Terrain liegenden Schlammschicht (Bohrloch 20, Universitätsplatz), über einer in $4^{\mathrm{m}}$ Tiefe beginnenden Sandschicht (Bohrloch 21, Ring), bei rein sandigem Untergrund (Bohrloch 28, Zwingerplatz, Bohrloch 26, Neumarkt, Bohrloch 25, Heilige Geiststrasse). Höchsten Frequenzstufen begegnen wir z. B. bei sandigem Untergrund in Bohrloch 7, Kurzegasse, Bohrloch 29, Tauentzienplatz; bei lehmigem Untergrund in Bohrloch 13, Matthiasplatz u. s. w.

Noch eine andere Bodeneigenschaft liess sich hier in Breslau gut zu einer Prüfung ihres Einflusses heranziehen, die von einigen Autoren in ätiologische Beziehung zur Diphtheriefrequenz gebracht wird, nämlich die Bodenverunreinigung. In dem alten Schutt- und Humusboden der centralen Stadt, namentlich in der Gegend der früher berüchtigten, jetzt zugeschütteten Ohlen ist die Verunreinigung des Bodens eine ungewöhnlich hohe; während dagegen der Boden in der inneren peripheren Zone vielfach als rein gelten kann, weil die Bebauung erst nach oder gleichzeitig mit der Anlage der Canäle erfolgte, so dass stärkere Verunreinigung des Bodens mit städtischen Abfallstoffen ausgeschlossen war. Die Diphtheriefrequenz zeigt nahezu ein entgegengesetztes Verhalten; in der inneren peripheren Zone fast durchweg die stärkste Häufung, dagegen im Centrum der Stadt eine durchschnittlich geringe Frequenz (z. B. Bezirke 13, 14, $15,23,26,27,29)$, die nur selten durch hohe Zahlen unterbrochen wird (Bez. 8, 9).

Ebensowenig zeigen die örtlichen Differenzen des Grundwasserabstands irgend eine Beziehung zur Diphtheriefrequenz. Durch Jacobi's Untersuchungen sind die mittleren, die minimalen und maximalen Grundwasserstände von zahlreichen Stellen der Stadt bekannt. Dieselben lassen indess trotz zahlreicher Combinirungsversuche keinerlei Zusammenhang mit der Diphtheriefrequenz erkennen. Auch die Grösse der jähr- 
lichen Grundwasserschwankung (Differenz zwischen minimalem und maximalem Grundwasserstand) ist ohne Einfluss; denn in den Bezirken in der nächsten Nähe der Oder, wo das Grundwasser von der Höhe des Oderwassers abhängig ist und die weitaus bedeutendsten Schwankungen durchmacht, finden wir die verschiedensten Diphtheriefrequenzen (Bezirke 34, 64, 81 mit Frequenzstufe 1 bis 2, Bezirke 30, 39 und 40, 70, 74, 79 und 80 mit Stufe 3, dagegen die Bezirke 28, 35, 157 mit Stufe 6, Bezirke 156 und 159 mit Stufe 7, Bezirke 32, 33 und 63 mit Stufe 8).

Das Fehlen aller Beziehungen zwischen Grundwasserabstand und Diphtheriefrequenz wird übrigens auch von dèn meisten früheren Autoren hervorgehoben; es ist hier nur noch besonders darauf hingewiesen, weil auffallender Weise unter den Aerzten und Laien Breslaus die Meinung ziemlich weit verbreitet ist, dass das Grundwasser alle möglichen Infectionskrankheiten, und darunter auch die Diphtherie, beeinflusse. Die an die Oder grenzenden Stadttheile werden wegen der grossen Grundwasserschwankungen und der damit vermeintlich verbundenen Diphtheriegefahr vielfach gefürchtet. Es sind aber nirgends Thatsachen aufzufinden, durch welche diese Furcht begründet wird; dieselbe verdankt ịren Ursprung wohl nur einer ungenauen und missverständlichen Bekanntschaft mit der Pettenkofer'schen Typhus- und Cholerahypothese.

Auch über den Einfluss der atmosphärischen Luft auf die Diphtherieerkrankungen wird in ärztlichen und Laienkreisen viel gefabelt. Die „reinere" Luft der Vorstädte soll weniger Diphtherieübertragungen veranlassen, als die "unreine" Luft der inneren Stadt. Es ist durch viele Beobachtungen und Experimente erwiesen, dass die atmosphärische Luft für die Erregung der meisten Infectionskrankheiten überhaupt gar nicht in Betracht kommt. Speciell für Diphtherie ist aber sogar constatirt, dass ihre Ausbreitung auf dem Lande intensiver vor sich geht als in der Stadt (Brühl und Jahr, Eigenbrodt); und auch die vorliegende Untersuchung über die Diphtherie in Bresliu lässt auf das Bestimmteste erkennen, dass die Frequenz dieser Krankheit von der sogen. Reinheit und Güte der Luft ganz unabhängig ist. Gerade in den peripheren Bezirken, zum Theil sogar in der äussersten Peripherie, und zwar am stärksten nach der Himmelsrichtung der vorherrschenden Winde, finden wir die höchste Diphtheriefrequenz, während im Innern der Stadt, im dichtest bebauten Centrum (Bezirk 13, 14, 26) und im östlichen Viertel die niedrigsten Frequenzstufen sich finden.

Weiter könnten als locale die Diphtheriefrequenz beeinflussende Momente noch einige künstliche, durch Menschenhand entstandene Einrichtungen in Betracht gezogen werden. Die Bauart der Häuser zeigt, wenn man ron denjenigen Differenzen absieht, welche die Grösse des Hauses 
und die Zahl der in demselben concentrirten Personen betreffen und die im folgenden Abschnitt genauer zu besprechen sind, keine nennenswerthen Unterschiede in den einzelnen Stadtbezirken. Hier könnte höchstens noch das Alter des Hauses in Betracht kommen, das zuerst von Heubner in ätiologische Beziehung zur Diphtherie gebracht ist. Heubner glaubte aus seinen Beobachtungen in Leipzig entnehmen zu können, dass neugebaute, d. h. erst 6 bis 8 Jahre bewohnte Häuser eine Häufung der Diphtheriefälle bewirken. Heubner führt allerdings selbst an, dass beispielsweise die Friedrichstrasse, Webergasse und Glockenstrasse, deren Häuser alle weit über 20 Jahre stehen, unter den Stadtgegenden mit höchster Diphtheriemorbidität rangiren; ebenso weist er selbst darauf hin, dass die neugebauten Häuser der Vorstädte zuerst gerade von der dichtwohnenden, unbemittelten Bevölkerungsclasse besetzt werden, und dass schon dadurch die Chancen für die Diphtherieausbreitung steigen. - In der That ist dann, wenn Armuth und Wohndichtigkeit einen fördernden Einfluss auf die Diphtheriefrequenz ausüben, die ătiologische Rolle der Neubauten kaum zu erweisen, da diese ganz vorwiegend von ärmeren Leuten occupirt zu werden pflegen.

Für Breslau lässt sich der Einfluss der Neubauten abschätzen, wenn man einmal diejenigen Bezirke auf ihre Diphtheriefrequenz prüft, in welchen die Zahl der Kinder bis zu 15 Jahren (oder auch, was ungefähr zu dem gleichen Resultat führt, die Zahl sämmtlicher Einwohner) von 1885 bis 1890 sich sehr stark, um 100 Procent und darüber, vermehrt hat. In diesen Bezirken kann die ganz abnorme Vermehrung nicht durch Geburtenüberschuss oder Wohnungswechsel bedingt sein, sondern muss vorzugsweise auf Bauthätigkeit bezogen werden. Aus der Tabelle am Schluss der Arbeit ergeben sich folgende Zahlen:

\begin{tabular}{l|r|r|r}
\hline \hline Bezirk & Kinder 1885 & Kinder 1890 & $\begin{array}{c}\text { Diphtheriefrequenz } \\
\text { (Stufe) }\end{array}$ \\
\hline 34 & 658 & 1012 & 1 \\
48 & 1099 & 2029 & 6 \\
$56 / 57$ & 788 & 1627 & 1 \\
60 & 516 & 1054 & 3 \\
71 & 564 & 1053 & 4 \\
104 & 465 & 902 & 1 \\
105 & 589 & 1075 & 2 \\
$114 / 115$ & 427 & 803 & 3 \\
133 & 1055 & 3067 & 3 \\
152 & 468 & 1114 & 1 \\
$153 / 154$ & 620 & 1658 & 4
\end{tabular}


Wir begegnen also in diesen überwiegend ron Neubauten besetzten Bezirken 8 Mal niedrigen, 2 Mal mittleren Frequenzstufen; nur einmal wird das Mittel überschritten.

Wählt man andererseits die sämmtlichen Ortsbezirke aus, welche am stärksten ron Diphtherie ergriffen sind, und prüft, ob daselbst eine lebhaftere Zunahme der Bewohner von 1885 bis 1890 stattgefunden hat, die auf Bauthätigkeit schliessen lāsst, so ergiebt sich folgendes Resultat:

\begin{tabular}{c|c|c|c}
\hline \hline Bezirk & $\begin{array}{c}\text { Diphtheriefrequenz } \\
\text { (Stufe) }\end{array}$ & Kinder 1885 & Kinder 1890 \\
\hline 9 & 8 & 554 & 516 \\
$32 / 33$ & 8 & 880 & 860 \\
37 & 8 & 431 & 499 \\
46 & 8 & 782 & 744 \\
50 & 7 & 542 & 510 \\
58 & 8 & 616 & 687 \\
63 & 8 & 577 & 600 \\
129 & 8 & 972 & 873 \\
$130 ; 131$ & 8 & 666 & 893 \\
132 & 7 & 895 & 1013 \\
134 & 7 & 934 & 829 \\
142 & 8 & 664 & 758 \\
144 & 8 & 617 & 508 \\
148 & 7 & 751 & 722 \\
155 & 7 & 548 & 608 \\
156 & 7 & 276 & 252 \\
\hline
\end{tabular}

In diesen stärkst ergriffenen Bezirken begegnen wir nur einmal einer etwas erheblichen Zunahme der Bevölkerung; die übrigen Bezirke sind auffällig stabil, 9 Bezirke zeigen sogar eine Abnahme der Bevölkerung.

Demnach tritt in Breslau der Einfluss der Neubauten auf die Diphtheriefrequenz gegenüber anderen Momenten röllig in den Hintergrund.

Die Beseitigung der Abfallstoffe erfolgt in Breslau mit Ausnahme einzelner in der äussersten Peripherie gelegenen Häuser durch Schwemmcanalisation. Die Canalanlagen sind allerdings ungleichwerthig. Ein älteres, in mancher Hinsicht ungenügendes Canalnetz durchzieht namentlich die Ohlen und die aussen an den Stadtgraben grenzenden Stadttheile, ferner einen Theil der Odervorstadt. Die Nicolaivorstadt und der an diese angrenzende Theil der Odervorstadt, ferner die im Süden gelegenen Bezirke 129 bis 133 haben dagegen tadellose neue Canäle; 
gerade die letzteren Bezirke sind aber solche, in denen höchste Diphtheriefrequenz herrscht, während mehrere der mit alten Canälen versehenen Stadtgegenden niedrige Frequenz aufweisen.

Die Wasserversorgung erfolgt in der ganzen Stadt durch filtrirtes Oderwasser. Nicht an die Leitung angeschlossen sind nur wenige Häuser in der äussersten, von Diphtherie wenig ergriffenen Peripherie. Es existiren zwar im ganzen Bereich der Stadt noch etwa. 600 Brunnen; aber die meisten derselben sind schon seit langer Zeit geschlossen, nur etwa 200 werden noch mehr oder weniger benutzt. Die Zahl dieser Brunnen, deren Beschaffenheit übrigens eine demnächst mitzutheilende Arbeit Dr. Harazim's auf das Genaueste kennen gelehrt hat, ist im Vergleich zu der Zahl der von Diphtherie ergriffenen Häuser völlig belanglos; in vielen von Diphtherie stark ergriffenen Bezirken fehlen die Brunnen sogar vollständig.

Kein einziger der in Betracht kommenden localen Einflüsse zeigt mithin ein solches Verhalten, dass durch dasselbe entweder die Abstufung der Diphtheriefrequenz in Bezug auf das Centrum, die innere und die äussere Peripherie der Stadt, oder die starken Gegensätze in unmittelbar neben einander gelegenen Bezirken einer Erklärung näher geführt werden könnten.

III.

Das Verhältniss der Diphtherieverbreitung zur Wohlhabenheit der Bevölkerung sollte durch zwei Untersuchungsreihen ermittelt werden:

Erstens sollte durch eine Analyse der Wohlhabenheit der Erkrankten festgestellt werden, in welcher Proportion Arme und Wohlhabende sich an den vorgekummenen Diphtheriefällen betheiligen; und andererseits sollte aus den statistischen Berichten der Stadt entnommen werden, in welcher Proportion Arme und Wohlhabende in der Berölkerung Breslaus vorhanden sind.

Zweitens war darzulegen, wie die räumliche Gruppirung der Armen und der Wohlhabenden in Breslau mit der räumlichen Gruppirung der Diphtheriefrequenz harmonirt; und zwar schien uns als Maassstab der Wohlhabenheit die Wohndichtigkeit am besten brauchbar zu sein.

1. Für die erste Enquête liess sich der Grad der Wohlhabenheit der Erkrankten am sichersten aus der Steuerstufe ermitteln. Zunächst wurden die Diphtheriefälle (unter Ausscheidung der Doppelfälle) nach Haushaltungsrorständen, i. e. Familien, ausgezählt; für diese sollte das 
Verhältniss der steuerfreien zu den steuerzahlenden (ein Einkommen von mehr als 900 Mark beziehenden) Familien berechnet werden. Eine weitere Unterscheidung war leider nicht durchführbar.

Von den 5434 ergriffenen Familien waren 3497 nach den Angaben der Meldekarte ohne Weiteres zu den steterfreien zu rechnen; es waren dies Arbeiter, Handwerkergesellen u. s. w., deren Wohnung im vierten Stockwerk oder Keller, noch dazu in ärmlicher Gegend lag. - Ausserdem waren 556 Haushaltungsvorstände vorhanden, deren Beruf und Wohnung Garantie leistete, dass sie zu den Wohlhabenden zu rechnen waren. Bezüglich der übrigen 1180 Familien, deren Steuerstufe in dieser Weise nicht genügend sicher geschätzt werden konnte, wurden Seitens der hiesigen Steuerveranlagungs-Commission in entgegenkommendster Weise, jedoch unter Beobachtung vollster Discretion, Mittheilungen über die bezügliche Steuerstufe gemacht. Daraus ging hervor, dass von den 1180 fraglichen Familien 7.75 zu den steuerzahlenden und 405 zu den steuerfreien gehörten.

Im Ganzen waren also unter den ron Diphtherie befallenen Familien 4103 steuerfreie und 1331 steuerzahlende, d. h. auf 3.08 steuerfreie kommt 1 steuerzahlende.

Zum Tergleich dieser Ziffern mit dem Verhältniss, in welchem überhaupt in Breslau steuerzahlende und steuerfreie Familien vorhanden sind, dürfen nun allerdings nicht alle Steuereinheiten herangezogen werden. Unter diesen und namentlich unter den steuerfreien Arbeitern, findet sich ein sehr hoher Procentsatz Unverheiratheter, die als Steuereinheiten zählen, die aber als unempfänglich gegen Diphtherie hier gar nicht in Betracht kommen. Vielmehr sind zum Vergleich höchstens diejenigen Steuerzahler geeignet, welche als Haushaltungsvorstände bezeichnet werden und Familie haben; noch besser eignet sich eine Zählung nur der Angehörigen der Haushaltungsvorstände; die richtigste Vergleichsziffer würde eine Auszählung der Kinder unter 15 Jahren einmal in den steuerzahlenden und zweitens in den steuerfreien Familien liefern.

Nach dem „Verwaltungsbericht der Stadt Breslau“ pro 1886 bis 1889 fanden sich in Breslau in jenen Jahren 38990 steuerfreie und 20823 steuerzahlende Haushaltungsvorstände; also auf 1.87 steuerfreie Familien kommt 1 steuerzahlende.

Ferner betrug damals die Zahl der Angehörigen von steuerpflichtigen Familien 61400; die der Angehörigen von steuerfreien Familien 112200. Auf $\mathbf{1 . 8 3}$ steuerfreie Angehörige kommt also 1 steuerzahlender. Die beiden letzten Berechnungen ergeben mithin ein fast identisches Resultat. - Eine gesonderte Auszählung der Kinder war leider nicht vorbanden. 
Folglich sind die steuerfreien Familien in einem erheblich stärkeren, nabezu doppelt so hohen Procentsatz an der Diphtheriefrequenz betheiligt, als die steuerzahlenden. Gerade bei diesem Vergleich fällt aber der oben schon besprochene Umstand zum weiteren Nachtheil der steuerfreien Bevölkerung ins Gewicht, dass die bei letzteren vorgekommenen Diphtheriefälle nicht annähernd so vollständig gemeldet werden, wie bei den Wohlhabenden. In Wahrheit muss also die Betheiligung der ärmeren Volksclasse eine noch viel überwiegendere sein.

2. Bezüglich eines Vergleichs der räumlichen Diphtherieverbreitung mit der räumlichen Vertheilung der Wohlhabenheit waren wir auf das Material angewiesen, das in der „Breslauer Statistik“ vorlag. Die Wohndichtigkeit der Bevölkerung war hier besonders eingehend berücksichtigt und auch nach kleineren Bezirken registrirt.

Unter Wohndichtigkeit ist nicht die engere oder weiträumigere Bebauung zu verstehen (die sich übrigens annähernd aus der räumlichen Ausdehnung der 157 ungefähr von der gleichen Einwohnerzahl bewohnten Ortsbezirke auf Tafel VI ersehen lässt, und der offenbar ein erheblicher Einfluss nicht zukommt), sondern die Zahl der Bewohner, die auf ein heizbares Zimmer entfällt. Damit ist der richtigste Ausdruck für diejenige Folge- und Begleiterscheinung der Armuth gegeben, welche vorzugsweise auf die Verbreitung der Contagien ron Einfluss ist. Nur erschien es geboten, speciell für die Untersuchung über Diphtherie noch eine Einschränkung vorzunehmen: $\mathrm{Da}$ für diese Krankheit nicht jede Altersclasse, sondern nur das kindliche Alter bis zu 15 Jahren empfänglich ist, so dass dicht von Erwachsenen besetzte Wohnungen eine ungleich geringere Disposition für die Ausbreitung der Krankheit liefern müssen als Wohnungen, in denen vorzugsweise Kinder sich häufen, so musste versucht werden, speciell die Dichtigkeit der Bewohnung in Bezug auf Kinder unter 15 Jahren zu ermitteln. Auf diese Weise wurden diejenigen Momente, welche bei der Weiterverbreitung der Diphtherie speciell in Frage kommen, schärfer und directer gefasst, als bei dex Anwendung irgend eines anderen Maassstabes der Wohlhabenheit.

Die räumliche Vertheilung sollte auch hier so viel als möglich wieder nach kleinen Ortsbezirken durchgeführt werden, ebenso wie die Diphtheriefrequenz. Eine Auftragung nach 24 Stadtvierteln wurde zwar ebenfalls ausgeführt und zeigte wohl im Allgemeinen eine Uebereinstimmung zwischen Diphtheriefrequenz und Wohndichtigkeit, aber daneben doch auch sehr auffällige Contraste. Schon bei der genaueren Analyse der Diphtheriefrequenz hatten wir kennen gelernt, wie leicht wichtige örtliche Differenzen durch die Zusammenfassung nach grösseren 
Bezirken verwischt werden; derselbe Fehler musste bei der nach grossen Bezirken unterschiedenen Wohndichtigkeit hervortreten und die Vergleichbarkeit beider Zahlenreihen erst recht in Frage stellen.

So wurde denn fürr die 157 (eigentlich 141) Ortsbezirke berechnet, wie viel Kinder im Alter von 0 bis 15 Jahren auf ein heizbares Zimmer entfallen. Leider existirte nur eine Auszählung der heizbaren Zimmer jedes Bezirks für das Jahr 1885. Es konnte daher nicht wie bei der Ermittelung der Diphtheriefrequenz eine Mittelzahl aus den Ergebnissen pro 1885 und 1890 abgeleitet werden, sondern wir mussten uns mit der Feststellung der Wohndichtigkeit für das Jahr 1885 begnügen. Hierdurch wird die Vergleichung mit einem nicht unerheblichen, aber örtlich verschieden grossen Fehler belastet. Derselbe wird nämlich nur da gering sein, wo es sich um einigermassen unveränderliche Bezirke handelt. Wo aber in einem Bezirk die Zahl der Bevölkerung stark ab- oder zunimmt; wo lebhafte Bauthätigkeit entfaltet wird; oder wo auch nur in den angrenzenden nach aussen gelegenen Bezirken stark gebaut wird, so dass die ärmste Bevölkerung der anstossenden alten Bezirke dorthin übersiedeln und eine an Zahl vielleicht gleiche, aber weséntlich anders componirte Bevölkerung in den alten Bezirken zurücklassen kann, da wird die Vergleichung zwischen Wohndichtigkeit und Diphtheriefrequenz durchaus ungenau werden. Die Bezirke, deren Kinderzahl sich von 1885 bis 1890 besonders stark rerändert, vielleicht gar verdoppelt hat, werden daher bei dieser Vergleichung ganz ausser Rechnung zu lassen sein.

Die so erhaltenen Zahlen für die Wohndichtigkeit finden sich in der Schlusstabelle; wie bei der Diphtheriefrequenz wurden anch hier 8 Stufen der Wohndichtigkeit (1. Stufe bis 0.38 Kinder auf 1 Zimmer, 2. Stufe 0.39 bis 0.50 u. s. w. bis 8 . Stufe über 1.10 ) unterschieden.

Unter den 141 Bezirken sind zunächst die Bezirke .Nr. 34, 38, 45, $48,51,56 / 57,60,62,71,84,86 / 87,104,105,107,110,114 / 115,124$, $128,133,152,153 / 154$ auszuscheiden, weil in denselben die Zunahme oder Abnahme der Kinder vom Jahre 1885 bis 1890 mehr als 30 Procent betrug. Es bleiben daun 120 relativ stabile Bezirke übrig, bei welchen eine Vergleichung der Diphtheriefrequenz und der Wohndichtigkeit zulässig erscheint: Diese Vergleichung ergiebt, dass in 52 Bezirken Diphtheriefrequenz und Wohndichtigkeit gar nicht oder nur um 1 Stufe differiren; 24 mal beträgt die Differenz 2 Stufen; 13 mal 3 Stufen. Die Differenz hält sich also unter dem Mittel in 89 Bezirken, d. b. in 74 Procent der verglichenen. $31 \mathrm{mal}$ geht die Abweichung über 3 Stufen hinaus (14 mal 4 Stufen, 12 mal 5 Stufen, 3 mal 6 Stufen, 2 mal 7 Stufen). Somit tritt eine Harmonie zwischen hoher Wohndichtigkeit und hoher Diphtheriefrequenz entschieden hervor. Fine grössere Gleichmässigkeit 
dürfte, selbst wenn die Wohndichtigkeit einen durchaus massgebenden Einfluss ausübt, kaum erwartet werden, da geringere und vielfach sogar nicht unbeträchtliche Aenderungen in Bezug auf Quantität und Qualität der Bewohner fast in jedem Bezirk vorkommen.

Besonders gross ist dementsprechend die Uebereinstimmung in den den stabilen Kern der Stadt bildenden Bezirken im Centrum und am Stadtgrabenring. Um die örtliche Lage der disharmonirenden Bezirke zu kennzeichnen, sind letztere auf den Karten Tafel VII und VIII so aufgetragen, dass die dunkelsten Farbentöne den stärksten Abweichuingen entsprechen. Tafel VII zeigt die Bezirke, in welchen im Verhältniss zur Dichtigkeit der Bewohnung zu viel Diphtherie gefunden wurde; Tafel VIII die zahlreicheren Bezirke, in denen weniger Diphtherie bestand, als man nach der Wohndichtigkeit hätte erwarten sollen.

An dieser letzten Tafel fällt es auf, dass es ganz vorwiegend Bezirke der äussersten Peripherie sind, welche starke Abweichungen zeigen; es sind dies namentlich Nr. 42/43, 52/53, 54/55, 86/87, 103, 117/118, 139, 140, 149/150. Dabei sind dies alles Bezirke, die keine stärkere Zuoder Abnahme der Berölkerung erfahreu haben und in denen regere Bauthätigkeit entweder noch nicht begonnen hat oder schon vorüber ist. Es liegt nahe, für das abweichende Verhalten dieser peripheren Bezirke nach einer gemeinsamen Erklärung zu suchen.

Unzweifelhaft ist es nicht zulässig, hier Eigenthümlichkeiten der Bodenbeschaffenheit, des Grundwasserstandes oder der Luft, die dann gerade für die äusserste Begrenzung der Stadt ein charakteristisches Verhalten zeigen müssten, zur Erklärung heranzuzieben. Denn die gleiche Abweichung findet sich ja durchaus nicht gleichmässig an der ganzen Peripherie der Stadt, sondern zwischendurch treten periphere Bezirke auf, wo keinerlei Abweichung von dem allgemeinen Parallelismus besteht. Boden, Grundwasser und Luft zeigen innerhalb der äussersten Peripherie sicher keine local begrenzte Differenzen, welche dieser Mannigfiltigkeit im Verhalten der peripheren Bezirke entsprechen. - Ausserdem stehen jene periphersten Bezirke in Bezug auf die Bodenverunreinigung, die Entfernung der Abfallstoffe, die Wasserversorgung u. s. w. meistens am ungünstigsten. Canalisation und Wasserleitung haben diese Häuser vielfach noch nicht erreicht; Fäkalien und Dünger von Pferden und Kühen werden hier in sorglos behandelten Depots aufgespeichert. Es muss um so auffälliger erscheinen, dass trotz dieser primitiven Zustände und trotz der grossen Wohndichtigkeit die Diphtheriefrequenz sich auf so niedriger Stufe hält.

Ein Moment, welches das abweichende Verhalten der Peripherie vielleicht erklären könnte, und das bei einer unbefangenen Besichtigung der 
betreffenden Bezirke sofort ins Auge fällt, ist die ganz verschiedene Art der Bebauung dieser Bezirke gegenüber der eigentlichen Stadt. Schon aus der Tafel VIII ist ersichtlich; dass es sich hier überall um räumlich sehr grosse Bezirke handelt, auf denen doch nur, wie in den anderen Bezirken, je 2000 Menschen leben; ja in den meisten dieser ausgedehnten peripheren Bezirke bleibt einstweilen die Bevölkerungszahl hinter der Durchschnittszahl von 2000 erheblich zurück. Dementsprechend ist dort geradezu ländliche Bebauung; wir finden dort vorzugsweise zerstreut liegende kleine Einzelhäuser, in denen Garten- und Ackerwirthschaft betrieben wird; zuweilen kleine Complexe solcher Häuser; hier und da auch ein mehrstöckiges Haus von städtischem Charakter, und auch diese wohl zu kleinen Gruppen vereinigt, dann aber doch fast immer durch weite Zwischenräume -von den umliegenden getrennt.

Diese Art der Bebauung muss, auch wenn die Bewohner arm sind und in engen Räumen sich zusammendrängen, der Ausbreitung der Diphtherie in gewissem Grade entgegenarbeiten.

In den mit grossen Miethshäusern dicht bebauten Bezirken der inneren peripheren Zone sind die Kinder fortdauernd der Ansteckungsgefahr ausgesetzt; kaum ein paar Wochen rergehen, dass nicht in einem der benachbarten Häuser, mit deren Kindern die anderen in Verkehr stehen, ein Diphtheriefall vorkommt. Fortwährend findet unter den 50 bis 100 Familien eines solchen Hauses ein Wechsel der Wohnungen statt, und immer sind die Chancen für neue Einschleppung des Virus vorhanden. Jede der zahlreichen Familien in einem solchen Complex von Miethshäusern unterhält wiederum Verkehr mit Verwandten und Freunden und erwirbt dadurch eventuell eine Erkrankung, die den Nachbarn gefährlich werden kann.

In jenen weitläufig bebauten Bezirken der äussersten Peripherie sind die Einschleppungsgefahren, die Chancen für eine Ausbreitung durch den Verkehr der Kinder u. s. w. bei weitem nicht so häufig vorhanden, und es werdeu lange Pausen eintreten, in denen kein Fall in der Nachbarschaft vorliegt und wo also Ansteckungsgefahr überhaupt nicht besteht.

Ist erst einmal ein Fall eingetreten, dann pflegt auch in dem peripher gelegenen Haus unter Mitwirkung der Armuth und Wohndichtigkeit die Krankheit sich energisch weiter zu verbreiten. Betrachtet man auf dem Hauptplan (Tafel IV) die peripheren Bezirke genauer, so sieht man, dass Häufungen von Diphtheriefällen in einem Hause oder in zwei Nachbarhäusern gar nicht selten sind, dass dafür aber zahlreiche Grundstücke, die ausreichende räumliche Trennung zeigen, um den intimen Verkehr der Bewohner zu erschweren, vollkommen 
frei bleiben. - Es entspricht dies Verhalten also im Wesentlichen der mehrfach beobachteten Verbreitungsweise der Diphtherie auf dem Lande im Gegensatz zu der Verbreitung in der Stadt, die bereits oben besprochen wurde.

Bei dieser Auffassung erklärt sich auch die Uebereinstimmung anderer peripherer Bezirke in Bezug auf Wohndichtigkeit und Diphtheriefrequenz in ungezwungener Weise. In allen solchen Bezirken sind nämlich städtische Miethscasernen in fortlaufender Reihe bis an die äusserste Peripherie vorgeschoben und dieselben stellen mithin eine unmittelbare Fortsetzung der besonders stark ergriffenen inneren peripheren Zone dar. Hier liegen dann die Verbreitungsverhältnisse genau so wie in typischen Stadtquartieren mit armer, dichtgedrängter Bevölkerung.

Wenn somit die Abweichungen der äussersten peripheren Bezirke von der sonst geltenden Norm sich einer Erklärung wohl zugänglich erweisen, so ist das nicht in demselben Maasse der Fall mit den sonstigen Differenzen, die in einzelnen Bezirken in der inneren peripheren Zone und im Centrum der Stadt hervortreten. Zu den auffälligsten Abweichungen gehört z. B. das relative Ueberwiegen der Diphtheriefrequenz in den Bezirken $50,58,63,121,122,127,129$; andererseits die merkwürdig geringe Frequenz in den Bezirken 13, 67, 68, 109.

Versuche, auch diese einzelnen Abweichungen zu erklären, dürften verfrüht erscheinen. Das Material, das uns vorliegt, ist noch zu sehr mit Fehlern behaftet und der Zeitraum, dem es entstammt, ist zu kurz, als dass eine durchgehende ausnahmslose Uebereinstimmung mit irgend einem Vergleichsfactor erwartet werden dürfte.

In manchen Bezirken ist insbesondere die absolute Zahl der vorgekommenen Diphtheriefälle so gering, dass jeder Zufall eine starke Verschiebung des Resultats bewirken muss. Oder es sind gewisse Häufungen auf den gemeinsamen Einfluss einer Schule zurückzuführen. In wieder anderen Bezirken ist sehr an die bereits oben betonte Möglichkeit zu denken, dass die Meldungen zu einem besonders hohen Procentsatz unrollkommen eingegangen sind; die krassesten Proletariatsbezirke sind in dieser Beziehung am verdächtigsten. Ferner tritt innerhalb der fünf Jahre ein zeitlich entschieden ungleichmässiges Befallenwerden der einzelnen Stadttheile zu Tage; um so mehr bedarf es langer Zeiträume, um die örtliche Vertheilung mit Sicherheit zu erkennen. - Endlich ist die künstliche Eintheilung selbst in solch' relativ kleine Bezirke noch im Stande, Mittelwerthe zu liefern, die sich aus heterogenen Elementen zusammensetzen und dadurch zu Täuschungen Anlass geben können. Befinden sich z. B. in einem Bezirk eine Reihe sehr wohlhabender Nenschen mit grossen Wohnungen und daneben in Hinterhäusern oder in einem anderen Theil 
der Strasse eine Anzahl sehr armer, dicht gedrängt wohnender Leute, so kann die durchschnittliche Wohlhabenheit des Bezirks noch ziemlich gross und die Wohndichtigkeit ziemlich gering sein, während die Diphtheriefrequenz sich im Vergleich hierzu abnorm hoch hält. Wären die Wohlhabenden des Bezirks einige Stufen weniger reich, so würde bezüglich der Diphtheriefrequenz sich kaum etwas ändern; denn bei einer gewissen Stufe der Wohlhabenheit wird die Diphtheriefrequenz bereits ihr Mini mum erreicht haben und weitere Steigerung der Wohlhabenheit wird die Diphtheriefrequenz nicht noch weiter herabsetzen. Dagegen würde dann die durchschnittliche Wohlhabenheit des Bezirks absinken und damit das Verbältniss zwischen Wohlhabenheit und Diphtheriefrequenz sich wieder der Norm nähern. Je homogener die einzelnen Constituenten der Bezirlie sind, um so weniger Täuschungen sind wir in den Durchschnittswerthen ausgesetzt; es wird daher in dieser Beziehung auf eine geeignete Construction der Bezirksgrenzen sehr viel ankommen.

Auf einen Bezirk sei noch besonders aufmerksam gemacht, der im Innern der Stadt eine stärkere Abweichung von der Regel zeigt; es ist dies der Bezirk 13, wo die Diphtheriefrequenz um 4 Stufen niedriger ausfällt als die Wohndichtigkeit. In diesem auch durch seine knappe räumliche Ausdehuung auffallenden Bezirk mit 2478 Seelen wohnen bekanntermassen zahlreiche Juden; und man könnte versucht sein, aus der abnorm geringen Frequenz dieses Bezirks zu folgern, dass den Juden vielleicht eine angeborene Rassenimmunität gegen Diphtherie zukomme. In der That ist von Felix (26) in Bukarest, von Hochstein (27) in Windheim u. A. ein auffälliges Verschontbleiben der jüdischen Rasse bei Diphtherieepidemieen beobachtet. Aber es fehlt auch nicht an Beobachtungen, die im entgegengesetzten Sinne von einer besonderen Empfänglichkeit der jüdischen Rasse berichten (Stockvis (28) in Amsterdam, Glatter in Wien). Wo ein Verschontbleiben der jüdischen Bevölkerung hervortritt, da ist ausserdem nicht nothwendig an eine vererbbare Rassenimmunität zu denken; vielmehr können auch hier Sitten und Lebensgewohnheiten den Ausschlag geben. Die Zurückhaltung der Juden, der beschränktere Verkehr der Kinder, die zum Theil in rituellen Gebräuchen begründete grössere Reinlichkeit in Bezug auf Ess- und Trinkgeschirr, ferner die Sorgsamkeit der Juden in der Pflege der Kinder und in der Behandlung beginnender Krankheiten können sehr wohl bewirken, dass die Diphtherie in diesen Kreisen erheblich weniger Opfer fordert als in ebenso dicht oder weniger dicht bewohnten Arbeiterbezirken, wo die Kinder grossentheils in einer gewissen Verwahrlosung aufwachsen.

Uebrigens zeigt eine genauere statistische Untersuchung sofort, dass die Rassenimmunität an der Ausnahmestellung des Bezirks 13 nicht 
betheiligt ist. Nach der „Breslauer Statistik“ kommen in diesem Bezirk auf 1000 Bewohner 383 Juden. Im Bezirk 16 ist der Procentsatz aber noch erheblich höher, 480 Juden auf 1000 Bewohner, und im Bezirk 12 und 15 ist derselbe annähernd so hoch (377 bezw. 333); und doch haben die Bezirke 12, 15, 16 eine der Wohndichtigkeit entsprechende und keineswegs abnorm niedrige Diphtheriefrequenz.

Somit führen beide mit dem Breslauer Material ausgeführten Untersuchungen zu dem Ergebniss, dass die Diphtheriefrequenz durch Wohlhabenheit herabgesetzt, durch Armuth erhöht wird; und zwar tritt dies Resultat in der gröberen Scheidung sämmtlicher Erkrankter in eine steuerzahlende und eine steuerfreie Gruppe schärfer hervor, als in der topographischen auf 8 verschiedene Wohndichtigkeitsstufen gegründeten Analyse. Letztere Berechnung schliesst, wie an verschiedenen Stellen betont wurde, mancherlei Fehlerquellen ein, und nur mit grosser Reserre dürfen Folgerungen aus derselben abgeleitet werden. Immerhin ist auch hier ein ähnliches Resultat herausgekommen, wie durch die erste Methode, und um so sicherer dürfen wir mithin den disponirenden Einfluss der Armuth auf die Diphtherieverbreitung für das Breslauer Material . als erwiesen ansehen. Die Annahme eines solchen Einflusses entspricht auch weitaus am besten den Vorstellungen über die Verbreitungsweise der Diphtherie, die wir aus den biologischen Eigenschaften der Dipbtheriebacillen uns ableiten müssen.

Wie ist dann aber das völlig entgegengesetzte Ergebniss zu erklären, zu dem Conrad, Körösi, Liévin, Reck und der Bostoner Bericht gekommen sind? Ist das Verhalten der Diphtherie in Breslau etwa ein ausnahmsweises, und wird in anderen Städten und zu anderen Zeiten die Diphtheriefrequenz wirklich durch Wohlhabenheit gesteigert? Oder sind etwa alle diese eitirten Untersuchungen mit erheblicheren Fehlern belastet, so dass sie nicht beweiskräftig sind?

In der That ist letzteres wahrscheinlich, wie eine genauere Kritik der betreffenden Arbeiten zeigt. Ich glaubte eine solche Kritik nicht unterlassen zu sollen, weil es entschieden wünschenswerth ist, Klarheit in die widersprechenden und auffälligen Ansichten über die Beziehungen zwischen Diphtherie und Wohlhabenheit zu bringen.

In der Conrad'schen Arbeit ist zunächst die Gruppirung nicht eigentlich nach Wohlhabenheitsclassen vorgenommen, sondern nach dem Beruf und der Bildungsstufe. Classe I umfasst z. B. sämmtliche der höheren Bildungsstufe Angehörige; in diese Classe wird dann selbst die ärmste Predigerswittwe aufgenommen. Aber abgesehen pon diesem, viel- 
leicht unbeträchtlichen, vielleicht beträchtlichen Fehler, liegt eine viel bedenklichere Fehlerquelle darin, dass die an Diphtherie Gestorbenen in Procenten aller gestorbenen Kinder derselben Wohlhabenheitsclasse ausgedrückt und dass die so erhaltenen Procente als Ausdruck der Frequenz der Krankheit in der betreffenden Wohlhabenheitsclasse angesehen werden. Das ist offenbar ganz unzulässig, weil der Procentsatz der gestorbenen Kinder in den verschiedenen Gesellschaftsclassen ein ausserordentlich verschiedener ist; im Proletariat sterben enorm viel Kinder in den ersten Lebensjahren, namentlich an Darmkrankheiten, und die Diphtheriefälle machen daher nur einen geringen Bruchtheil aller dieser zahlreichen Todesfälle aus; bei den Wohlhabenden sterben überhaupt sehr viel weniger Kinder und die gleiche Zahl von Diphtheriefällen bedingt daher hier einen relativ hohen Procentsatz aller Todesfälle. - Auch für das Conrad'sche Material ist die sehr verschiedene Gesammtsterblichkeit der Kinder leicht zu berechnen, wie dies in folgender Tabelle geschehen ist:

\begin{tabular}{c|c|c|c}
\hline \hline Classe: & $\begin{array}{c}\text { Summe } \\
\text { aller Todesfälle }\end{array}$ & $\begin{array}{c}\text { Summe der Todesfälle } \\
\text { in Alter von 0-15 J. }\end{array}$ & $\begin{array}{c}\text { Todesfälle der Kinder } \\
\text { in Procent }\end{array}$ \\
\hline I & 2327 & 670 & $28 \cdot 8$ \\
II & 10936 & 6282 & $57 \cdot 4$ \\
III & 3943 & 1914 & $49 \cdot 3$ \\
IV & 7128 & 3825 & $53 \cdot 7$ \\
V & 2234 & 2234 & $100 \cdot 0$
\end{tabular}

Durch diese Verschiedenheit der Gesammtsterblichkeit werden die Zahlen für die Betheiligung der Diphtherie an der Sterblichkeit dermassen beeinflusst, dass aus denselben gar kein Schluss auf die Häufigkeit der Diphtherie innerhalb jeder Classe zulässig ist. Die einzig rich tige Vergleichung würde darin bestehen, dass die in jeder Classe vorgekommenen. Diphtheriefälle in Proportion gesetzt werden zu den in derselben Classe vorhandenen lebenden Kindern im Alter von 0 bis 15 Jahren. Auch Conrad betont in seiner Arbeit wiederholt, dass eigentlich nur die Vergleichung mit den Lebenden zu brauchbaren Resultaten führen könne; er ist sich aber anscheinend nicht bewusst geworden, welch' bedeutende Fehler sich gerade für die Krankheiten im Kindesalter aus der Vergleichung mit der Gesammtmortalität ergeben.

Gegen Körösi's Schlussfolgerungen sind Bedenken gerechtfertigt zunächst deshalb, weil er eine Periode für seine Untersuchung benutzt hat, in der Budapest wenig von Diphtherie heimgesucht war; in den $7 \mathrm{Be}$ obachtungsjahren waren unter 85600 Todesfällen nur 1745 Diphtheriefälle, also 2.0 Procent. (In Breslau 1881 bis $1890=3.6$ Procent.) Mit Rücksicht hierauf ist die Periode kaum lang genug, um weitgehende 
Schlüsse daraus abzuleiten. Ausserdem ist bei 20 Procent aller Todesfälle der Wohlhabenheitsgrad nicht angegeben und diese grosse Zahl ist unberūcksichtigt geblieben. Ferner erscheint der Ort Budapest in den Jahren 1876 bis 1882 wenig geeignet, um als Paradigma für die Aufdeckung ätiologischer Beziehungen zu dienen. Erst 2 Jahre früher war die Vereinigung der beiden Schwesterstädte erfolgt; dabei waren eine Menge geradezu ländlicher, mit primitivsten Einrichtungen versehener Bezirke mit modern städtischen Bezirken zusammengethan. Eine aus solchen contrastirenden Elementen bestehende Stadt muss eine Menge von Besonderheiten darbieten, die für die Ableitung von Gesetzmässigkeiten aus statistischem Material nicht günstig sind. - Viel wesentlicher als diese Fehlerquellen ist aber der Umstand, dass auch Körösi für seine Vergleichungen nicht die in Procenten der Lebenden ausgedrückten Todesfālle benutzt, sondern das Verhältniss der letzteren zu den Gesammt-Todesfällen. Allerdings legt Körösi besonderen Werth auf die Berechnung der „relativen Intensität", d. h. er bestimmt, wie viel Todesfälle an jeder Krankheit auf je 100 Todesfälle an nichtinfectiösen Krankheiten kommen, und zwar einmal bei Bemittelten und andererseits bei Unbemittelten. Nun aber betreffen gerade die Todesfälle nicht infectiöser Krankheiten im kindlichen Alter ganz überwiegend die ärmeren Classen. $\mathrm{Zu}$ den nichtinfectiösen Krankheiten zählt Körösi z. B. Lungentuberculose und Darmkatarrh. Speciell an diesen Krankheiten und weiter an sämmtlichen nichtinfectiösen Krankheiten überhaupt starben im Alter von 0 bis 5 Jahren:

\begin{tabular}{|c|c|c|c|c|c|c|}
\hline & \multicolumn{3}{|c|}{ Absolute Zahlen } & \multicolumn{3}{|c|}{ In Procenten } \\
\hline & Reiche & $\begin{array}{l}\text { Mittel- } \\
\text { classe }\end{array}$ & Arme & Reiche & $\begin{array}{c}\text { Mittel- } \\
\text { classe }\end{array}$ & Arme \\
\hline Lungentuberculose & 7 & 208 & 4160 & $0 \cdot 16$ & $4 \cdot 75$ & $95 \cdot 09$ \\
\hline Darmkatarrh . . . . . . . . . & 11 & 594 & 7053 & $0 \cdot 14$ & $7 \cdot 76$ & $92 \cdot 10$ \\
\hline Sämmtliche nicht infectiöse Krankheit. & 102 & 3621 & 35437 & $0 \cdot 29$ & $10 \cdot 22$ & $89 \cdot 49$ \\
\hline
\end{tabular}

Wenn somit auf 100 Todesfälle an nichtinfectiösen Krankheiten bei den Aermeren 1 Diphtheriefall kommt, bei den Reichen dagegen auf 100 Todesfälle 2 Diphtheriefälle, so ist darum doch dıe Häufigkeit der Diphtherie unter den lebenden Reichen geringer, weil unter der gleichen Anzahl lebender Armer jene 100 Todesfälle an nichtinfectiösen Krankheiten doppelt, dreifach und mehr vorkommen, als bei den Reichen.

Auch gegenüber den Körösi'schen Vergleichungen müssen wir daher daran festhalten, dass nur durch Beziehung der Erkrankungen oder 
Todesfälle auf die Zahl der Lebenden jeder Wohlhabenheitsclasse beweisende Ziffern erhalten werden können. - Uebrigens kommt Körösi selbst im 2. Theil seiner Arbeit bei der Untersuchung des Materials nach der Villermé'schen topographischen Methode zu dem entgegengesetzten Resultat wie im ersten Theil. Körösi theilt hier die 10 Bezirke der Stadt in 4 Wohlhabenheitsgruppen, und zwar ist als Maassstab der Wohlhabenheit die Anzahl des Gesindes angesehen. Aus dieser Zusammenstellung, die allerdings an manchen von Körösi selbst hervorgehobenen Mängeln leidet, ergiebt sich, dass Diphtherie und Croup durch die Armuth begünstigt werden, und zwar starben von je 10000 Lebenden jährlich in Classe I (Wohlhabendste) $=4$, in Classe II $=5 \cdot 5$, in Classe III $=7$, in Classe IV (Aermste) $=8$.

Auf die Liévin'sche Statistik beruft sich Körösi ganz mit Unrecht. Einmal legt Körösi seinen Berechnungen für Diphtherie irrthümlicher Weise die Liévin'schen Zahlen für Scharlach zu Grunde. 'Ferner waren in Danzig 1863 bis 1869 unter 17794 Todesfällen nur 160 Diphtheriefälle registrirt; bei der räumlichen Gruppirung der Todesfälle sagt Liévin selbst: „Von einer weiteren Betrachtung der Diphtherie ist schon der geringen Zahl wegen Abstand zu nehmen; dazu kommt, dass unter diesem Rubrum nicht bloss idiopathische, sondern der grossen Mehrzahl nach symptomatische Fälle enthalten sind": - Auch die Berufung auf Boston ist kaum berechtigt. Die betreffende Beobachtungsperiode beträgt kaum 3 Jahre, ist also viel zu kurz; vielleicht hat sich schon in den folgenden Jahren eine ganz andere Vertheilung der Diphtherie ergeben; ich habe leider hierüber nichts ermitteln können.

Am interessantesten und scheinbar am beweisendsten sind die von Reck für die Stadt Braunschweig gewonnenen Zahlen. Hier ist ein relatir einwandfreier Maassstab für die Wohlhabenheit benutzt und die Diphtheriefälle, sowohl Erkrankungen wie Todesfälle, sind auf die Zahl der empfänglichen Lebenden in jeder Wohlhabenheitsclasse berechnet. Was indess bei den Reck'schen Zahlen auffallen muss, das ist die enorme Differenz in dem Verbältniss zwisehen Erkrankungen und Todesfällen (s. S. 418). Dies lässt darauf schliessen, dass die Krankheitsmeldungen und die diagnostische Bezeichnung der Halsaffectionen sehr ungleich waren. Ausserdem bezogen sich Reck's Untersuchungen nur auf die innere Stadt und daher ist ein grosser Theil desjenigen Proletariats ausser Rechnung gelassen, der sonst am deutlichsten den Einfluss der Armuth auf die Sterblichkeit hervortreten lässt. Es ergiebt sich dies ohne Weiteres aus einer Uebersicht der Zahl der Einwohner in jeder Classe; es lebten mit einem pro Kopf berechneten jährlichen Einkommen: 


\begin{tabular}{c|c|c}
$\begin{array}{c}\text { bis } 75 \text { Thaler } \\
9550 \text { Einw. }\end{array}$ & von 75 bis 100 Thaler & von 100 bis 150 Tha \\
10481 Einw. & 12428 Einw. \\
von 150 bis 200 Thaler & von 200 bis 250 Thaler & uiber 250 Thaler \\
6761 Einw. & 2186 Einw. & 2427 Einw.
\end{tabular}

Besonders hervorzuheben ist aber, dass die Reck'sche Statistik sich über eine verhältnissmässig diphtheriefreie Zeit erstreckt und im Anfang einer stärkeren Epide mie abbricht. Im Ganzen sind in den 10 Jahren 1864 bis 1873771 Diphtherie-Erkrankungen und 251 Diphtherie-Todesfälle registrirt; von ersteren entfallen 531, von den Todesfällen 160, also 70 bezw. 64 Procent, auf die 2 letzten Jahre 1872 und 1873. Es ist selbstverständlich und geht noch besonders aus der unten folgenden Analyse des zeitlichen Verlaufs der Breslauer Epidemie hervor, dass die Diphtherie nicht sofort die ganze Stadt gleichmässig zu befallen braucht, sondern schrittweise den einen Stadttheil nach dem anderen besonders stark ergreift. In einer Periode, wo nach längerer Pause die Diphtherie wieder beginnt sich auszubreiten, giebt daher die topographische Vertheilung der Diphtheriefalle kein richtiges Bild der gesammten Verbreitung.

Der von mehreren Autoren unternommene Beweis für die Begünstigung der Diphtherie durch Wohlhabenheit kann somit nicht als erbracht angesehen werden. Vielmehr müssen wir wahrscheinlich das für Breslau erhaltene und im Allgemeinen von Kaiser für Berlin und Heubner für I eipzig bestätigte Resultat, dass mit dem Sinken der Wohlhabenheit die Diphtheriefrequenz steigt, auch auf die Mehrzahl der übrigen Städte ausdehnen.

IV.

Das zeitliche Verhalten der Diphtherie in Breslau sollte in der vorliegenden Untersuchung eine Vergleichung mit den einzelnen meteorologischen Factoren nicht erfahren, weil die Beobachtungsperiode von 5 Jahren hierfür zu kurz ist und weil die oben betonte unbrauchbare Registrirung der meteorologischen Daten diese Vergleichung von vornherein aussichtslos macht.

Zulässig und im Hinblick auf die Vortheile, welche uns bereits mehrfach eine genauere Detaillirung ergeben hatte, entschieden von Interesse erschien dagegen eine. Analyse des vorliegenden Materials in dem Sinne, dass das zeitliche Verhalten der Diphtherie zerlegt und nach den einzelnen Stad theilen Breslaus gesondert untersucht wurde. Hierzu wurden nur die Jahre 1887 bis 1890 verwendet, 1886 dagegen fortgelassen, weil 
in diesem ersten Beobachtungsjahre relativ wenig Diphtherie in der Stadt war und erst im nächsten Jahr die Ausbreitung zur Epidemie erfolgte. In den Curven auf Tafel IX ist nun für jeden Stadttheil der Verlauf der Diphtherie-Epidemie mit einer besonderen farbigen Linie dargestellt. Aus denselben geht hervor, dass das Anschwellen zur Epidemie keineswegs in der ganzen Stadt gleichmässig von Statten gegangen ist; sondern den Anfang macht im März und April 1887 ein einzelner Stadttheil, die westliche Hälfte der inneren Stadt. Sehr bald schliessen sich dann periphere Bezirke an, die ja überhaupt die stärkste Frequenz aufweisen; nicht aber alle in gleicher Weise, sondern zunächst nur die Odervorstadt und dann die Nicolaivorstadt, d. h. die beiden peripheren Bezirke, welche mit der westlichen inneren Stadt die ausgedehnteste unmittelbare Berührung haben und in regstem Verkehr mit derselben stehen. Allmählich, erst von der Mitte des folgenden Jahres ab, betheiligen sich dann auch dio Sandrorstadt und die Ohlauervorstadt mit mässiger breiter Erhebung der Curve an der Zunahme der Diphtherie. Ende 1888 erfährt die Krankheit endlich auch in der Schweidnitzervorstadt eine geringe Zunahme, während ein starkes Ansteigen der Curve hier erst im Herbst 1889 zu Stande kommt. Die beiden Theile der Schweidnitzervorstadt gehen dabei fast stets zusammen.

Diejenigen Stadttheile, die schon früh die Höhe der Epidemie erreicht haben, bleiben dafür später verschont. So erhebt sich die westliche innere Stadt zuerst zu einem starken Gipfel, bleibt dann aber die ganzen folgenden Jahre auf niedrigem Niveau; ebenso die Odervorstadt, die auch mit einer sehr starken Steigerung einsetzt und nachher relativ verschont bleibt. Die Nicolaivorstadt erfährt dagegen Anfangs eine mässigere Frequenzzunahme, dafür kommt hier im folgenden Jahre noch ein deutlicher zweiter Gipfel zu Stande. Die Gipfel der übrigen Curren fallen in ein zu spätes Stadium unserer Beobachtungsreihe, als dass ihre Folgen noch innerhalb derselben zu Tage treten könnten.

Völlig verschieden sind die Jahreszeiten und Witterungsverhältnisse, unter welchen sich in den einzelnen Stadttheilen das Anschwellen der Epidemie und die Ausbildung der Akme vollzieht. Bei der westlichen inneren Stadt fällt die Höhe der Epidemie in den Mai, bei der Odervorstadt in den October; die Nicolaivorstadt hat den ersten Gipfel im Norember, den zweiten im September; die Sandvorstadt im October und im Juni; die Schweidnitzervorstadt im November und März.

Diese Zusammenstellung zeigt recht deutlich, wie indifferent die Witterung für die Ausbreitung der Diphtherie ist. Die Witterungs- und klimatischen Verhältnisse der verschiedenen Stadttheile Breslaus sind sicher nicht als principiell verschieden anzusehen; und doch breitet sich die 
Diphtherie zu so ungleichen Jahreszeiten in den einzelnen Stadttheilen aus. Eine gewisse Begünstigung der Ausbreitung durch die Wintermonate besteht zweifellos; zahlreiche Beobachtungen weisen darauf hin und auch in unserer Beobachtungsperiode lässt sich ein Ueberwiegen der im Winter aufgetretenen Erkrankungen herausrechnen. Aber der Ausschlag ist ein mässiger und offenbar kann dieser Einfluss der Witterung sehr leicht durch andere massgebendere Factoren überholt werden. Aus den Curven der einzelnen Stadttheile geht z. B. deutlich hervor, dass da, wo eine seit langer Zeit nicht durchseuchte, vollempfängliche Bevölkerung vorhanden ist und wo ein starker Verkehr mit inficirten Bezirken für ausgiebige Einschleppung des Contagiums sorgt, intensive Ausbreitung der Diphtherie die Folge ist, ganz unbekümmert darum, welche Jahreszeit und welche Witterung herrscht. Der jahreszeitliche Einfluss zeigt sich mithin bei genauerer Analyse als ein nebensächliches Moment. dessen Bedeutung für die Diphtherieausbreitung vielfach stark überschätzt ist.

V.

Die Erkenntniss, dass eine Einsicht in das örtliche und zeitliche Verhalten der Diphtherie und in ihre Beziehungen zu einflussreichen Factoren um so eher gelingt, je mehr wir von grossen Bezirken und grossen Zeiträumen absehen und ins Detail eingehen, musste es räthlich erscheinen Iassen, mit der Analyse noch weiter zu gehen und im einzelnen Hause die örtliche und zeitliche Ausbreitung der Diphtherie, namentlich mit Rücksicht auf die sogen. "Herdbildung", zu verfolgen.

Es wurden zu diesem Zweck an der Hand der karlographischen Uebersicht die 50 am stärksten befallenen $\mathrm{Häuser}$ in den verschiedensten Theilen der Stadt herausgesucht. Zuerst bestand die Absicht, in diesen Häusern eine detaillirte Enquête mit Hülfe von Fragebogen anzustellen und durch die Polizei-Commissariate gleichzeitig alle Verziehungen und damit die etwaigen Verschleppungen des Virus kennen zu lernen.

Leider mussten diese Versuche als völlig aussichtslos aufgegeben werden, weil es sich bei den stark ergriffenen Häusern stets um solche handelte, die von der ärmsten Bevölkerung bewohnt waren. Von diesen Bewohnern waren, wie wir uns durch ausgedehnte und zeitraubende Recherchen überzeugten, brauchbare und wahrheitsgemässe Antworten auf die Fragen nicht zu erlangen.

Ich habe mich daher darauf beschränkt, im Folgenden die im gleichen Hause vorgekommenen Diphtheriefälle so aufzutragen, dass die Etagen, 
welche die befallenen Familien bewohnen, sowie das Datum jeder einzelnen Erkrankung hervortreten; eine horizontale Klammer um mehrere Daten bezeichnet dabei, dass diese Fälle in der gleichen Familie vorkommen. Wo die Erkrankungen in verschiedene Jahre fallen, sind die Jahreszahlen beigefügt.

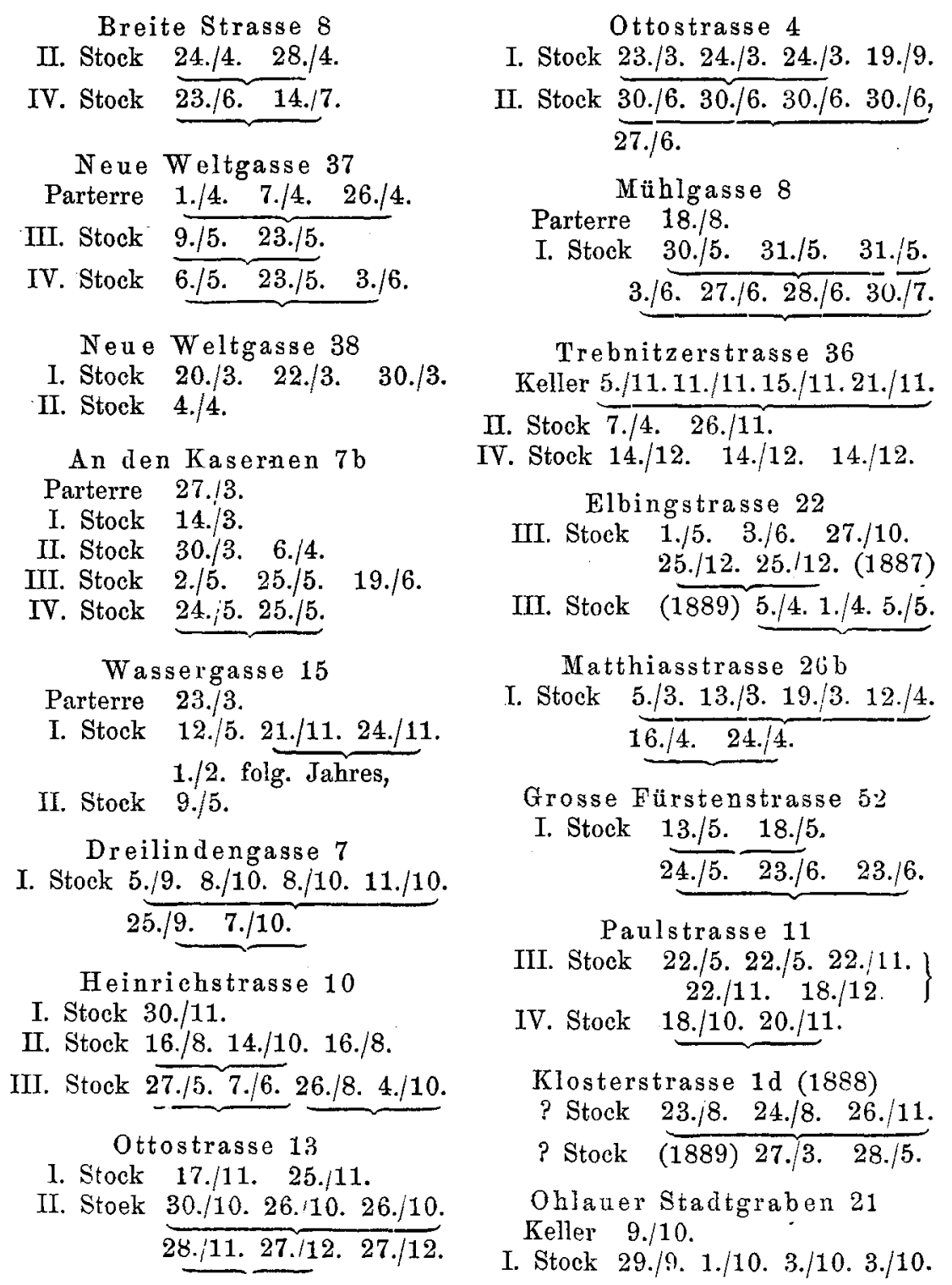


Paradiesstrasse 24

Keller 26./8. 26./8.

Hinterh. Parterre 22./10.

II. Stock 1./10. 14./9. 21./10. 21./10.

Paradiesstrasse 29

Keller 27./7.

Parterre 15./11.

I. Stock 24./10.

III. Stock 16./8.

TV. Stock 4./3. 27./10.

Klosterstrasse $31 / 32$

Parterre 25./2.

II. Stock 21./2. 15./3. 15./3.

III. Stock $5 . / 3$.

IV. Stock 21./2. 4./11.

Löschstrasse 18

II. Stock 22./1. 22./1.

III. Stock 24./10.

TV. Stock 5./10.

Vorwerkstrasse 92

Parterre 10./8.

II. Stock 1/8. $1 / 8$.

III. Stock $\overrightarrow{12 . / 8.26 . / 10 .}$

Neue Tauentzienstrasse $35 \mathrm{~h}$

II. Stock 11./1. 17./2. 25./5.

IV. Stock 21./3. 21./4.

Vorwerkstrasse 63 a

Parterre 14. 10.

II. Stock 1./10.

III. Stock 24./8. 28./8.

IV. Stock $29 . / 9$.

Löschstrasse 39

Parterre 1./9. 13./11.

II. Stock 10./11.

IV. Stock 10./1. d. folg. Jahres.

Neue Tauentzienstrasse 85

Keller 21./5. 23./5. 23./5. 1./7.

II. Stock 30./4. 15./5. 21/5.

Hubenstrasse $30 / 32$

Keller 1. 5 .
I. Stock 12./9. 13./9. 13./9.

II. Stock $3 . / 5 . \quad 13 . / 5$.

III. Stock 28./11. 24./4.

Hubenstrasse $58 / 60$

II. Stock 10./11. 13./11.

III. Stock $\frac{\overbrace{22 / 11}^{10 / 16 / 11} \text { 16./11. }}{12 . / 11.13}$

Sadowastrasse 19

Parterre 26./6.

I. Stock 15./11. 3./12. (1889)

III. Stock $7 . / 5$. 21./1.26./1.28./1. (1890),

Friedrichstrasse 49

II. Stock 7./9. 25./9.

III. Stock 5./6. 26./6. 14./8. 15./8.

Friedrichstrasse 51

Parterre 30,/9. 30./9.

II. Stock 7./4.

IV. Stock 30./10.

IV. Stock 30./11. 1./12. 2./1. 4./1. 1887

Friedrichstrasse 64

Keller 15./5. 16./5. 20./11. $\left.\right|_{\infty} ^{\infty}$

Parterre 20./11. 20./11. 30./11. $\int_{-1}^{\infty}$

II. Stock 1./9.

III. Stock $\left.\frac{20 / 824 / 824 / 83 / 93 / 9}{2.112}\right\} \stackrel{8}{\stackrel{\infty}{\infty}}$

Friedrichstrasse 69

IV. Stock 25./2.29./2.8./3.8./5.11./3.

Friedrichstrasse 89

Parterre 4.6.

II. Stock 25./7. 21./6. 7./7.

III. Stock 24./7. 28./8.

IV. Stock 17./10.

Neudorfstrasse 37

Part. 8./8. 13./9. 21./9. 21./9. 23./9. 


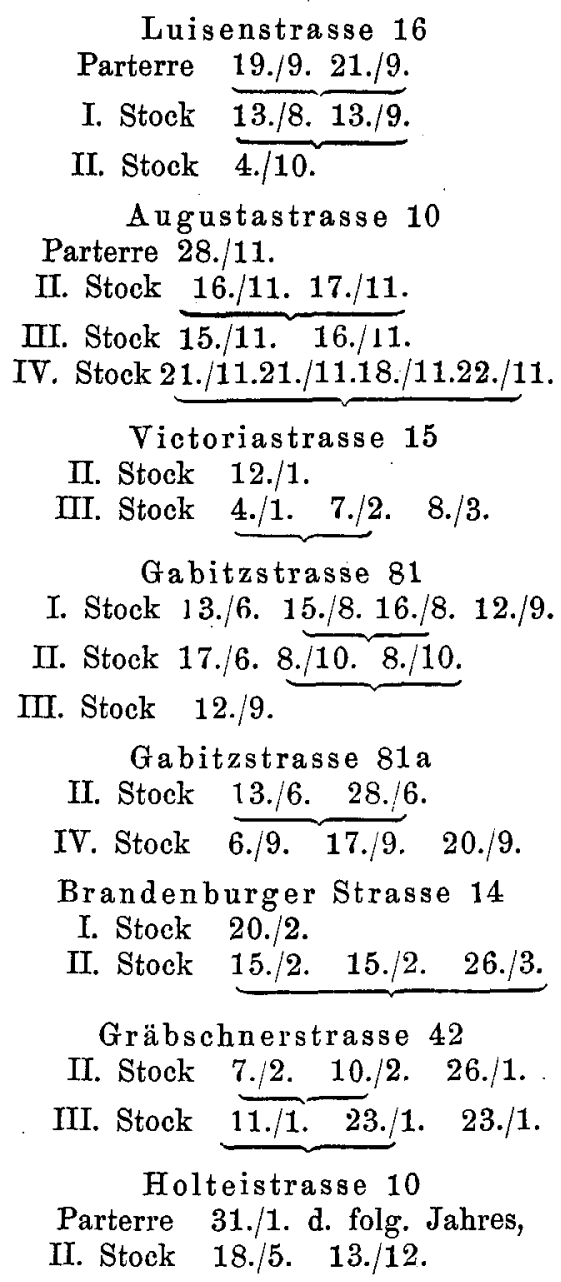

III. Stock 17./11.

IV. Stock 24./4.

Trinitatisstrasse 13

Parterre 16./10.

IV. Stock 14./10. 25./10. 28./10.

Karuthstrasse 11

Parterre 24./9.

I. Stock 18./9. 28./10. 28./10.

IV. Stock 17./9.22./9.18./9.20./9 $24 . / 10$.

Mariannenstrasse 5

I. Stock 6./8. 11./8. 28./8.

III. Stock 17./7. 19./7. 21./7.

Friedrich-Wilhelmstrasse 35

Parterre 14./10. 25./10. 24./11. 26./12. ? $30 . / 10$.

Kurze Gasse 54

Parterre 17./7. 20./7. 26./7. 28./7.

I. Stock 16./11.

II. Stock $28 . / 8$.

Lange Gasse 64

II. Stock 20/1. $27 / 1$.

III. Stock $5 . / 8$.

IV. Stock 21./2. 7./3.

Posenerstrasse 11

I. Stock 21./1.

II. Stock 22./1. 3./2.

III. Stock 28./5. 25./8.

Aus dieser Zusammenstellung ergiebt sich, dass in den meisten Häusern die Diphtherieepidemieen sich mit kürzeren oder längeren Pausen über 2 bis 3 Monate hinziehen. Zuerst wird gewöhnlich nur ein Kind ergriffen; daran reihen sich einige Tage bis Wochen später ein oder mehrere weitere Fälle in derselben Familie; nach der gleichen Frist setzt die Krankheit oft bei einer anderen Familie desselben Hauses ein, verschleppt durch leblose oder lebende Infectionsquellen (Reconvalescenten, Erwachsene, unempfängliche Kinder); nach einigen weiteren Wochen wird vielleicht noch eine Familie mit ein oder zwei Erkrankungen betheiligt und damit ist die Hausepidemie erloschen. Zuweilen kommen vereinzelte Er- 
krankungen noch nach einer Pause von 6 bis 7 Mlonaten ror. Es ist dann natürlich zweifelhaft, ob hier noch eine Verbindung mit den früheren Fällen besteht, oder ob neue Einschleppung stattgefunden hat; letztere Möglichkeit liegt angesichts des Umstandes, dass es sich stets um grosse Miethskasernen und eine äusserst fluctuirende Bevölkerung handelt, entschieden immer vor.

Aber auch wenn diese Möglichkeit ausgeschlossen ist, so haben Pausen von derartiger Dauer nichts Befremdliches, da wir ja durch bakteriologische Untersuchungen wissen, dass bei geeigneter Art der Aufbewahrung die Diphtheriebacillen an Wäsche, Spielzeug u. s. w. sich 7 Monate und länger lebend erhalten können und also eine Verbindung mit den früheren Fällen sehr wohl bestehen kann.

Fast nie kommt es zu einem explosionsartigen Ausbruch der Art, dass ron Anfang an gleichzeitig Kinder mehrerer Familien desselben Hauses erkranken. Solche Fälle sind nur drei Mal registrirt: Augustastrasse 10, Karuthstrasse 11 und Friedrichstrasse 64. Auch hier nöthigt indess nichts, einen von der Localität ausgehenden Einfluss anzunehmen. Vielmehr ist es selbstverständlich, dass zuweilen mehrere in dem gleichen Hause wohnende Kinder bei ihrem intimen Verkehr unter einander einer gleichzeitigen Ansteckung entweder durch ein anderes inficirtes Kind, oder durch irgend eine leblose Infectionsquelle ausgesetzt waren.

Von besonderem interesse ist ferner, dass unter den 50 am stärksten ergriffenen Häusern nur drei sich finden, welche mehrfach in grōsseren Zwischenrāumen von einer stärkeren Diphtherieausbreitung heimgesucht sind. Wo im Uebrigen die Diphtheriefälle verschiedenen Jahren angehören, da handelt es sich entweder um continuirliche Ketten, die aus dem einen Jahr in's andere herüberreichen; oder einer epidemischen kettenförmigen Ausbreitung der Krankheit im einen Jahr folgen in den nächsten Jahren nur einzelne isolirt bleibende Fälle. In diesen wenigen Häusern, wo es wiederholt zur Epidemie gekommen ist, müssen wir als wahrscheinlichste Ursache wiederum erneute Einschleppungen ansehen, die ja bei dieser Art der Miethwohnungen einige Male ganz selbstverständlich sich ereignen werden. Erst wenn solche wiederholte Explosionen an derselben Stätte viel häufiger vorkommen würden, dann würden wir eventuell an besondere local disponirende Momente denken dürfen und nach diesen suchen müssen.

Nirgends liegen somit bis jetzt Anzeichen vor für eine sogenannte Herdbildung und für einen aussehlaggebenden Einfluss der Localität, des Bodens, der Luft oder des Hauses auf die Diphtherieausbreitung; sondern in erster Linie sind die Menschen, ihre Lebensverhältnisse, ihr Verkehr und ihre Sitten, sowie ihre individuelle Empfänglichkeit bestimmend für 


\begin{tabular}{|c|c|}
\hline 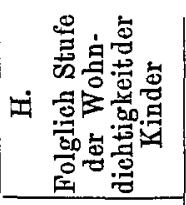 & 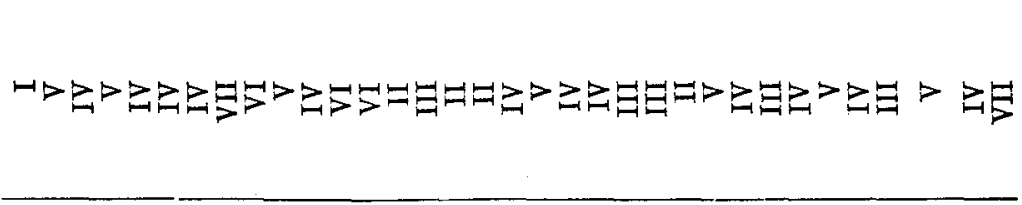 \\
\hline 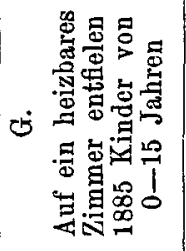 & 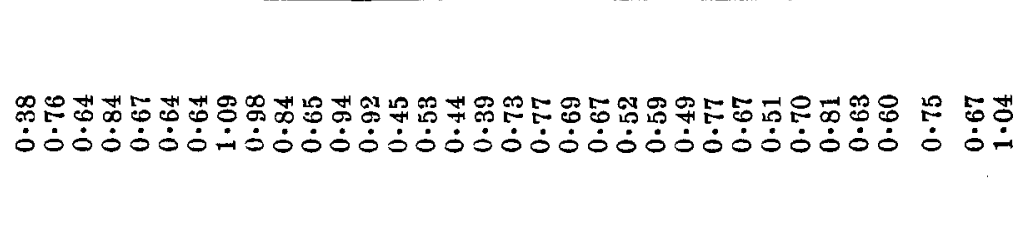 \\
\hline 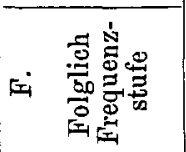 & 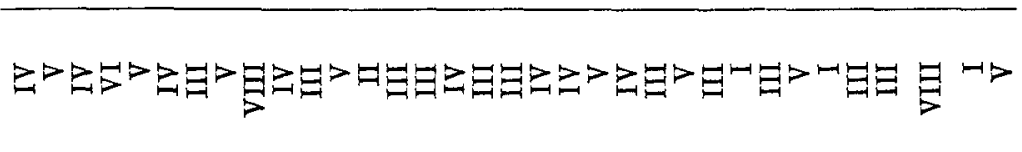 \\
\hline 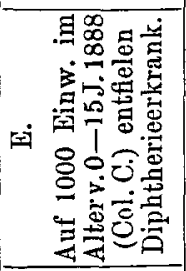 & 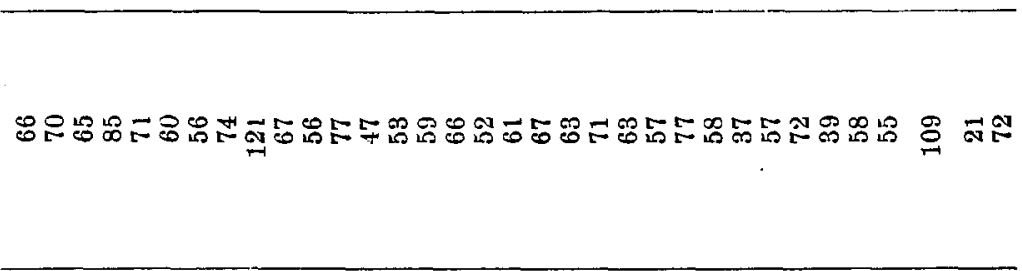 \\
\hline 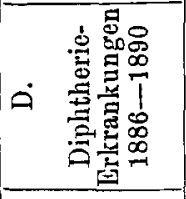 & 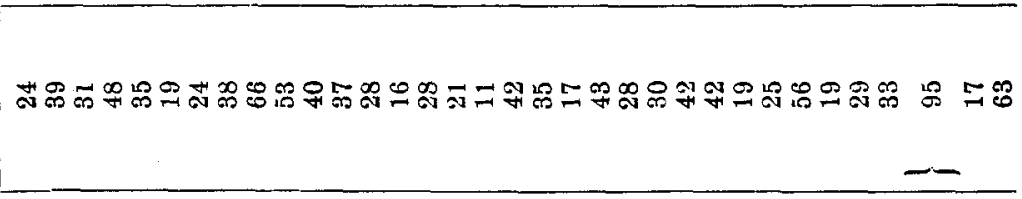 \\
\hline ن & 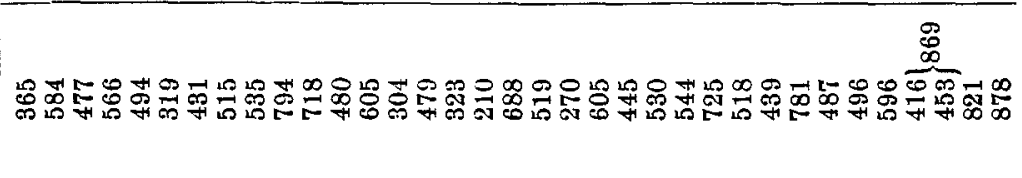 \\
\hline 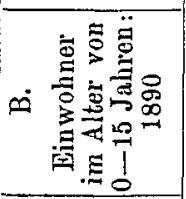 & 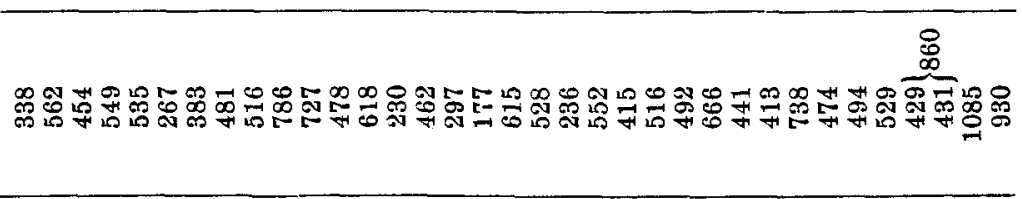 \\
\hline 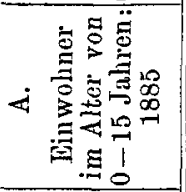 & 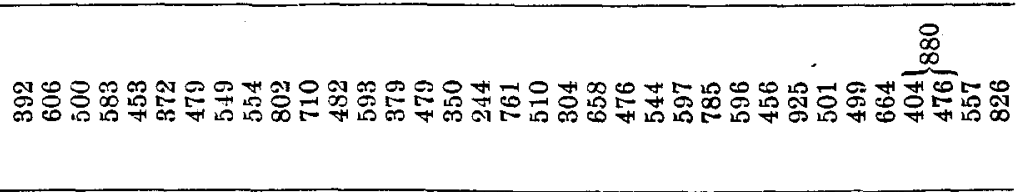 \\
\hline 啇 & 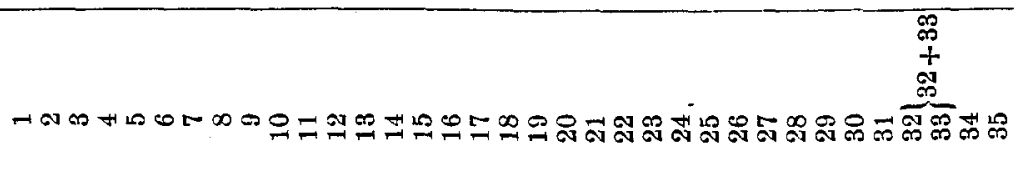 \\
\hline
\end{tabular}




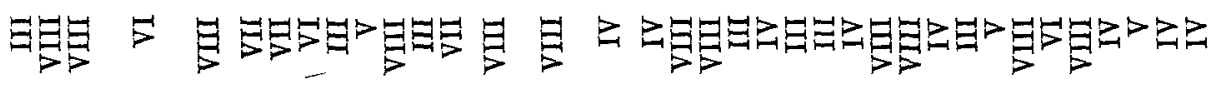

㗊茟

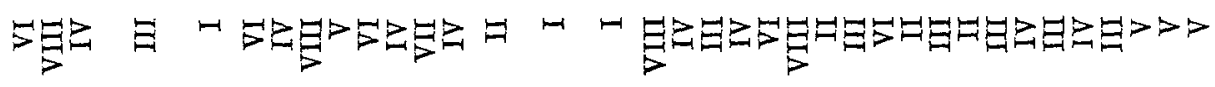

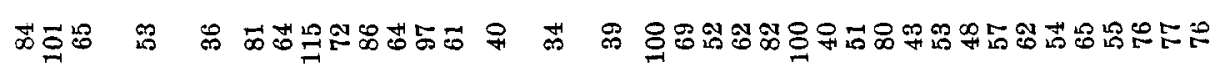

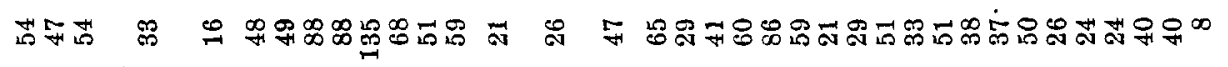

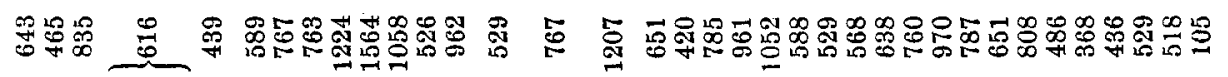

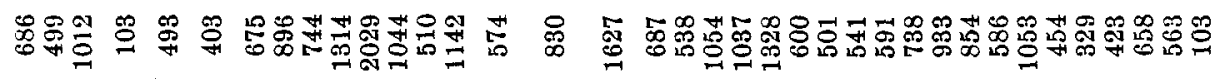

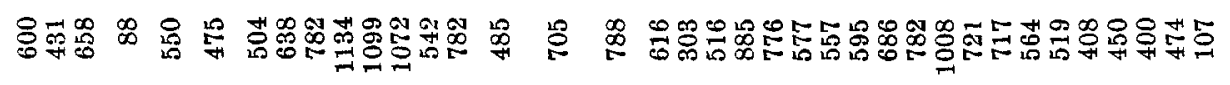

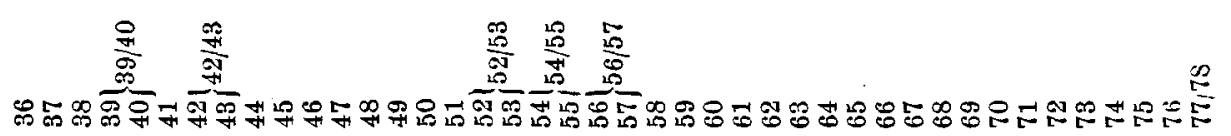




\begin{tabular}{|c|c|}
\hline 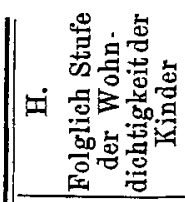 & 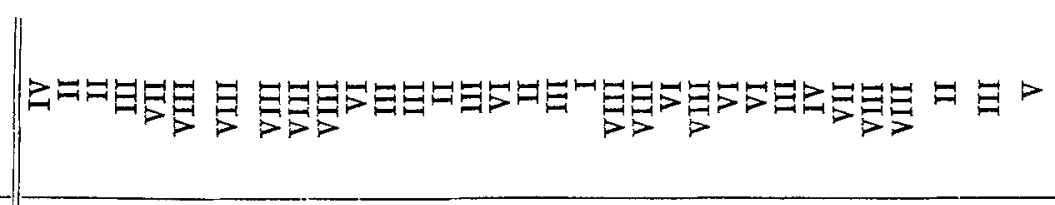 \\
\hline 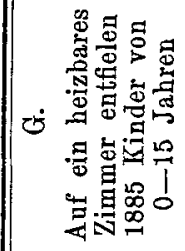 & 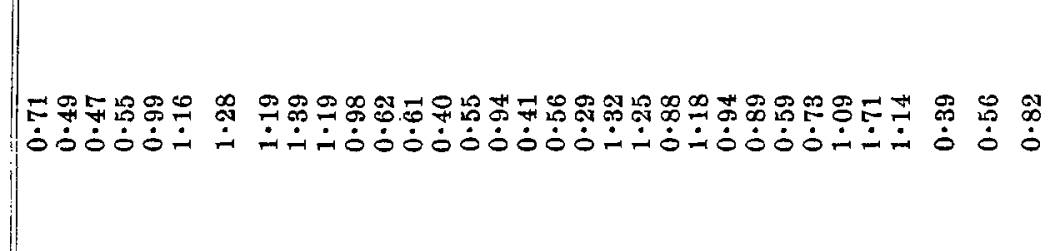 \\
\hline 应 & 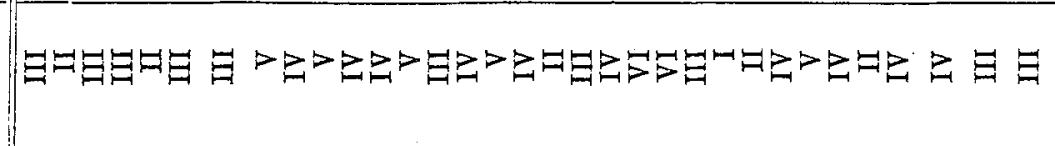 \\
\hline 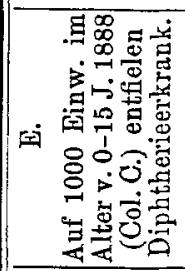 & 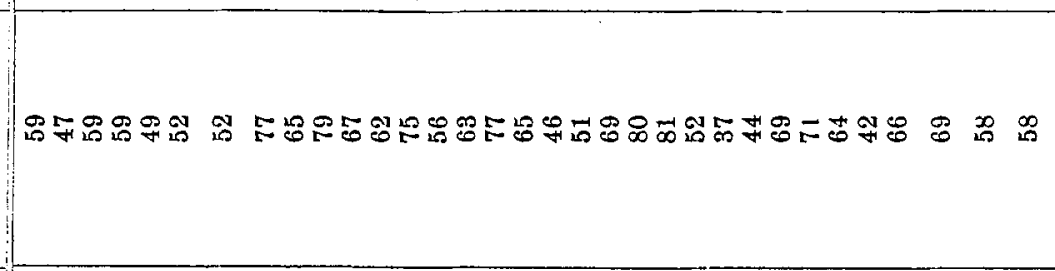 \\
\hline 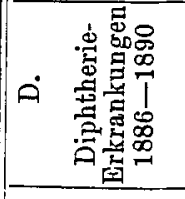 & 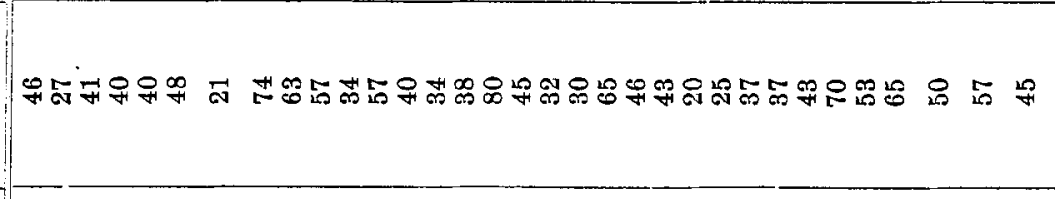 \\
\hline 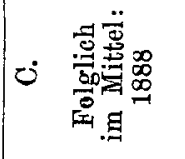 & 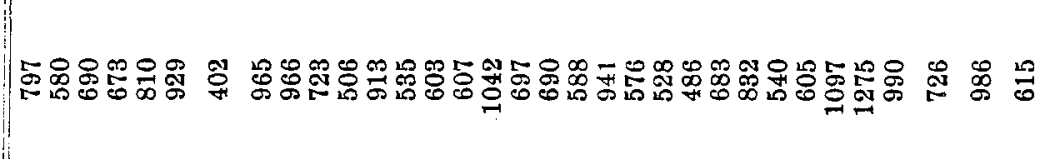 \\
\hline 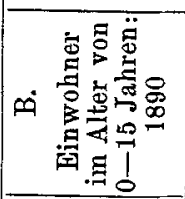 & 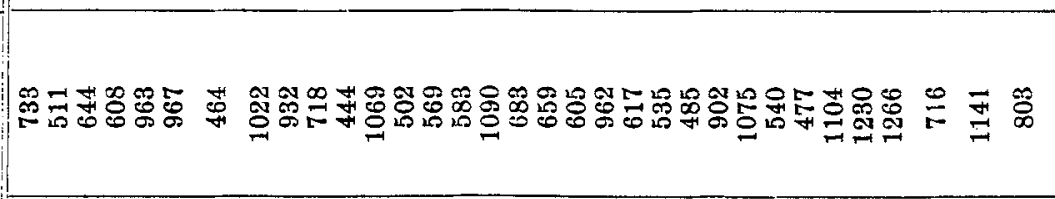 \\
\hline 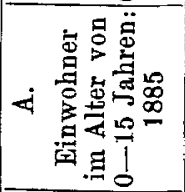 & 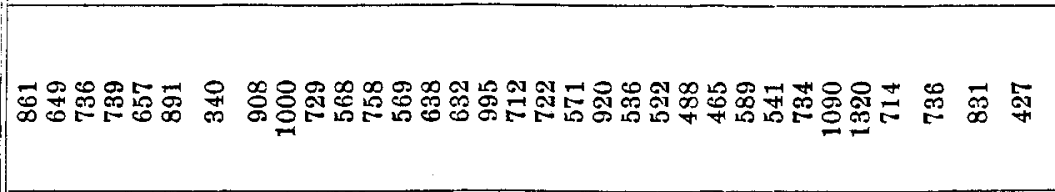 \\
\hline 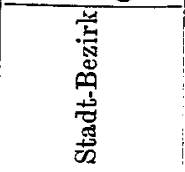 & 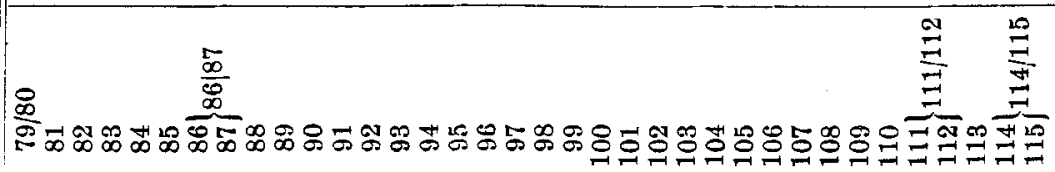 \\
\hline
\end{tabular}




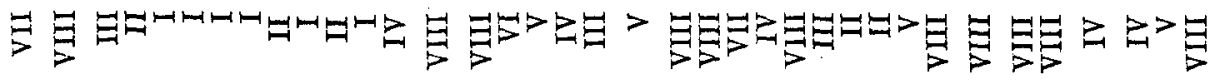

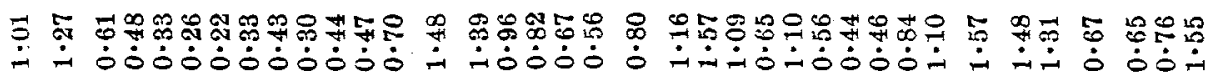

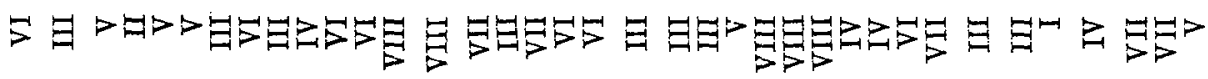

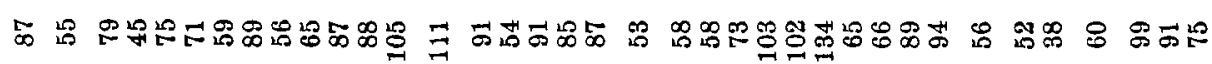

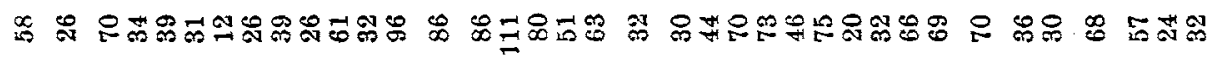

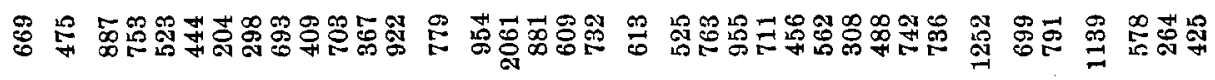

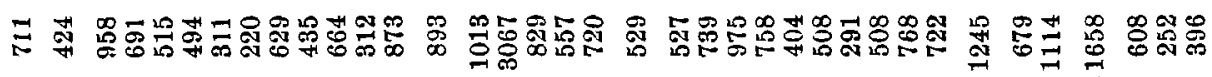

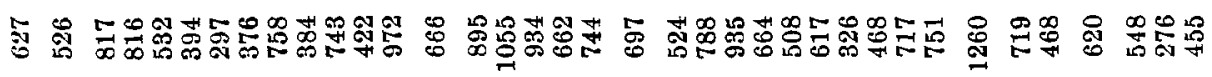

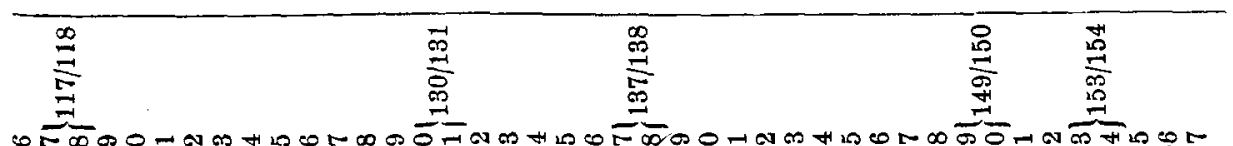

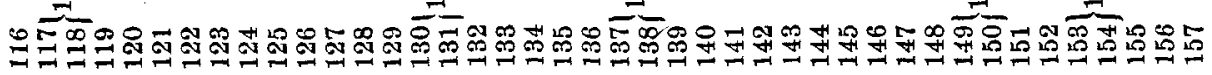


die stärkere oder geringere Ausbreitung der Diphtherie; und wenn sie Boden und Wohnung verlassen, um dem tückischen Feinde zu entfliehen, so „sitzt der Kobold hinten im Fass", wie es im Trinius'schen Gedichte heisst, d. h. die Lebensgewohnheiten und die Eigenart der Menschen bringen ihnen meistens am neuen Wohnort die gleichen Gefahren.

Die vorstehenden epidemiologischen Beobachtungen führen uns somit ungefähr auf den gleichen Verbreitungsmodus der Krankheit wie die experimentellen Forschungen über das Diphtheriecontagium.

Wenn frühere epidemiologische Untersuchungen andere Resultate ergeben haben, so dürfen wir um so eher Fehler in der statistischen Zusammenstellung vermuthen, als ja gerade die hier mitgetheilte Untersuchung uns gelehrt hat, wie ungemein zahlreiche Fehlerquellen sowohl im Ausgangsmaterial, wie in der Art der Gruppirung und Vergleichung enthalten sein können. Auch die vorstehende Untersuchung war nicht völlig von solchen Fehlern zu befreien, und gesichertere Resultate werden wir daher erst erwarten dürfen;, wenn etwa für eine spätere Periode dieselbe Untersuchung über die Diphtherieverbreitung in Breslau durchgeführt und zu dem gleichen Ergebniss wie die jetzige gelangt sein wird. 


\section{Litteratur-Verzeichniss.}

1. Löffler. Mittheilungen aus dem Kaiserl. Gesundheitsamt. 1884. Bd. II. Deutsche medicinische Wochenschrift. 1890, Nr. 5 u. 6.

2. Roux et Yersin. Annales de l'Institut Pasteur. 1888.

3. Babes. Diese Zeitschrift. Bd. V.

4. v. Hofmann. Wiener medicinische Wochenschrift. 1888.

5. Kolisko und Paltauf. Wiener klinische Wochenschrift. 1889.

6. Kaiser. Eulenberg's Vierteljahrschrift. 1885. N. F. Bd. XIII. Hft. 2.

7. Brühl und Jahr. Diphtherie u. Croup im Königr. Preussen. Berlin 1889.

8. Kalischer. Deutsche medicinische Zeitung. 1890. Nr, $80 \mathrm{ff}$.

9. Rahts. Arbeiten aus dem Kaiserl. Gesundheitsamt. 1890. Bd. VI.

10. Schwarz, Die Sterblichkeit an Diphtherie und Croup in Nürnberg. Dissertation. Würzburg 1886.

11. Hauser, citirt nach Hirsch, s. unten 18.

11 a. Heubner. Jahrbuch für Kinderheilkunde. 1887. N. F. Bd. XXVI.

12. Reinecke, Die Diphtheritis in Göttingen 1878-82. Dissert. Göttingen 1884.

13. Geissler, Die Ausbreitung der Diphtherie im Königr. Sachsen. X. Jahresbericht des Med.-Coll. Leipzig 1880.

14. Almquist; Ueber die Ausbreitungsweise von Diphtherie und Croup, Göteborg 1885. - Diese Zeitschrift. Bd. V.

15. Eigenbrodt.' Deutsche Vierteljahrschr. f. öffentl. Ges. 1893. Bd. XXV. Hft. 3.

16. Johannesen, Difteriens Forekomst i Norge, Christiana 1888. - Deutsche medicinische Wochenschrift. 1891. Nr. 12.

17. Pistor. Das öffentl. Gesundheitswesen in der Stadt Berlin 1886-1888. Berlin 1890. S. 62.

18. Hirsch. Handbuch der histor.-geogr. Pathologie. Bd. IV. S. 71.

19. Neucourt, nach Hirsch, a. a. O. S. 73.

19a. Conrad. Beitrag zur Untersuchung des Einflusses von Lebensstellung und Beruf auf die Mortalitätsverhältnisse. Jena 1877.

20. Körösi. Ueber den Einfluss der Wohlhabenheit ... auf Sterblichkeit u. s. $v$. Stuttgart 1885 . 
464 C. Flügge: Die Verbatitungsweise der Dipgtherie.

21. Liévin. Deutsche Vierteljahrschrift für öffentl. Ges. Bd. III. S. 364 u. 375.

22. Reck. Die Gesundheitsverhältnisse der Stadt Braunschweig in den Jahren 1864-73. Brannschweig, Druck der Waisenhaus-Buchdruckerei.

23. Pridgin Teale. Lebensgefahr im eigenen Hause. Kiel 1886.

24. Teissier u. Longuet. Verhandlungen des internat. Hygiene-Congresses zu Wien 1888.

25. Jacobi. Breslauer Statistik. Bd. I.

26. Felix. Wiener medicinische Wochenschrift. 1870.

27. Hochstein. Generalbericht über die Sanitätsverwaltung im Königr. Bayern 1.868. Bd. I.

28. Stockvis, Glatter, citirt nach Eigenbrodt, a. a. O. 


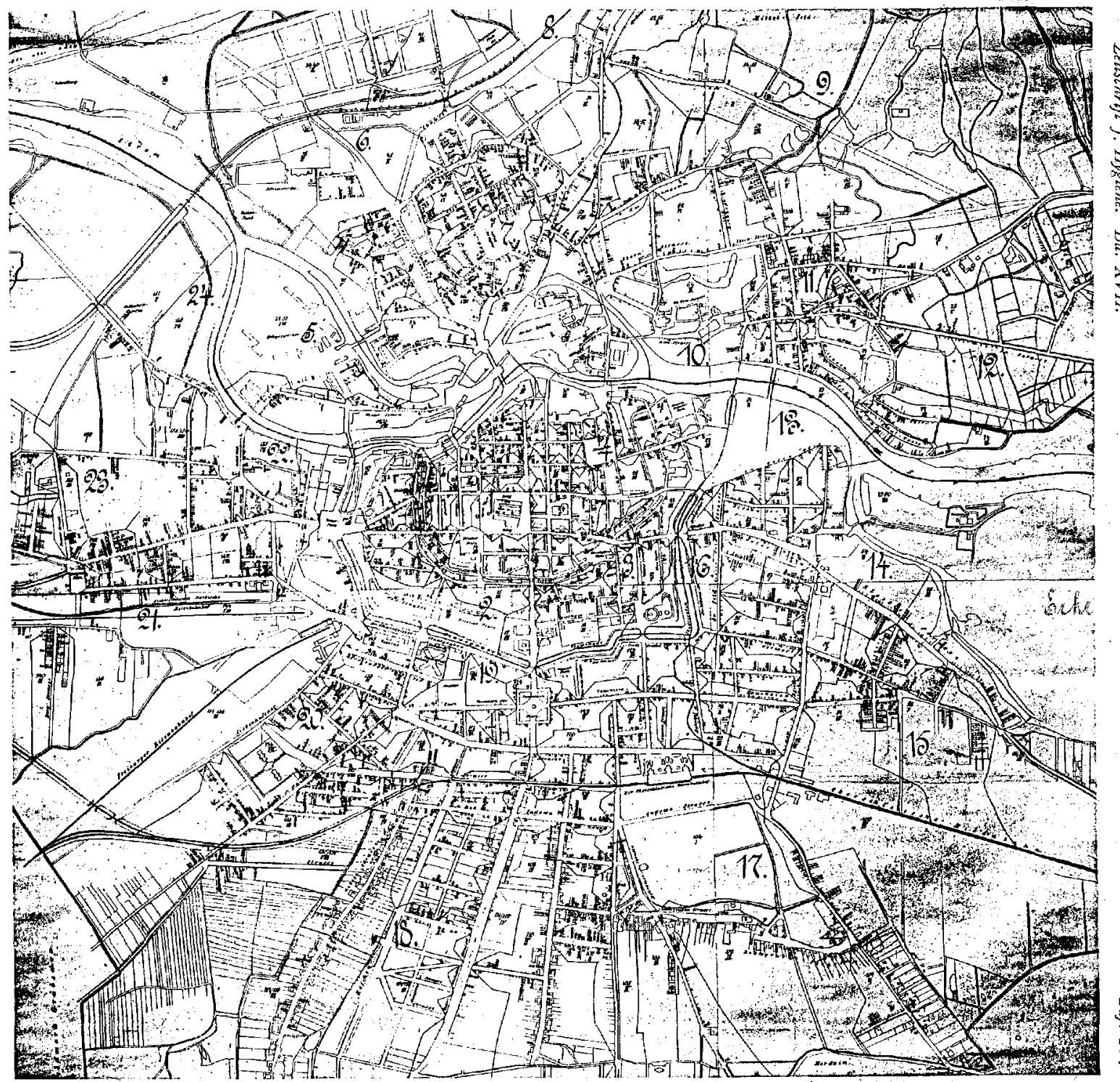

Plan von Breslau. 
Zeitschrift für Hygiene BdXVII.

Tat.V.

Diphtheriefrequenz nach 8 Stadtheilen.

Yon. 1000 kindern von 0.15 Jahren. sind 1886 _1890 erkrankt.

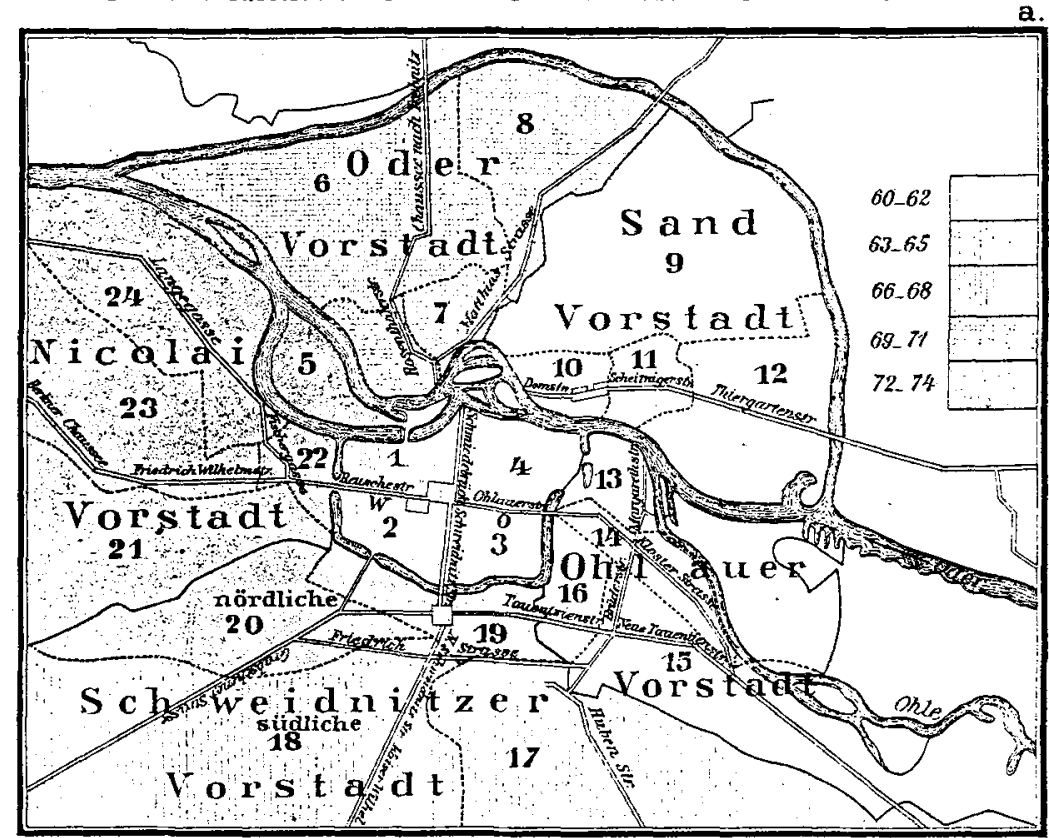

Diphtheriefrequen $x$ nach 24 Stadtvierteln.

Ton 1000 Kindern von $0 \_15$ Jahren sind 1886_1890 erkrankt.

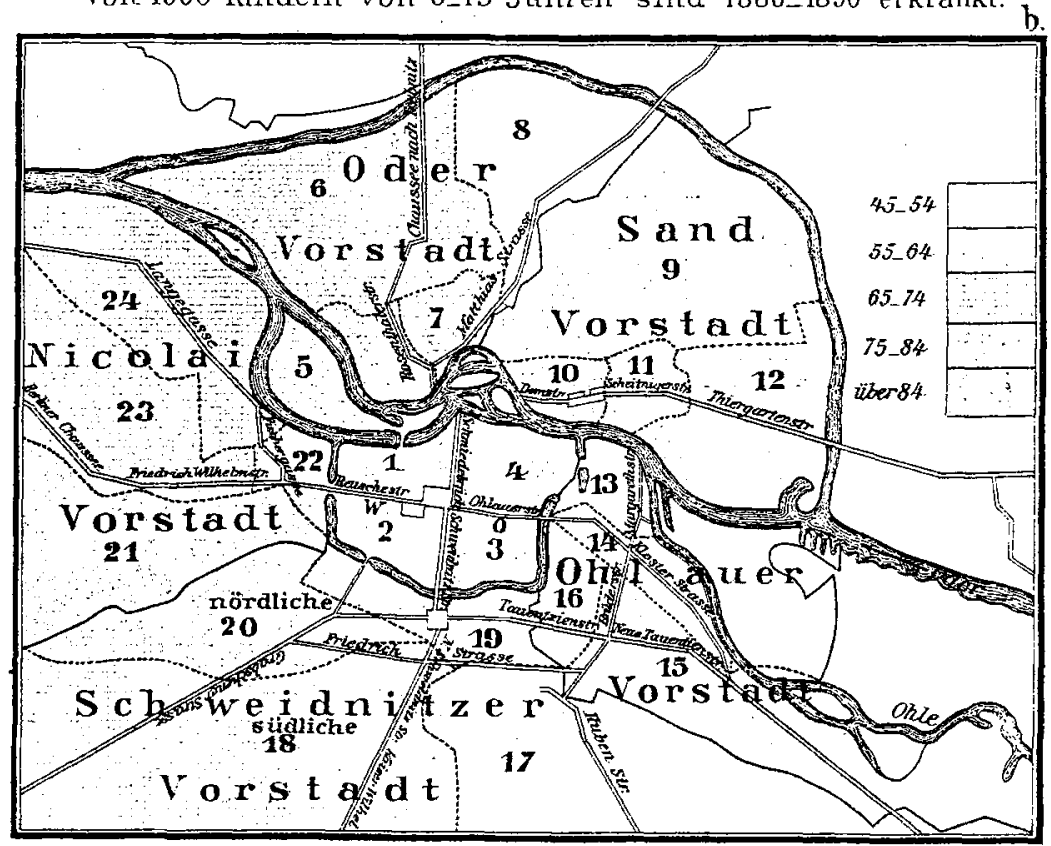




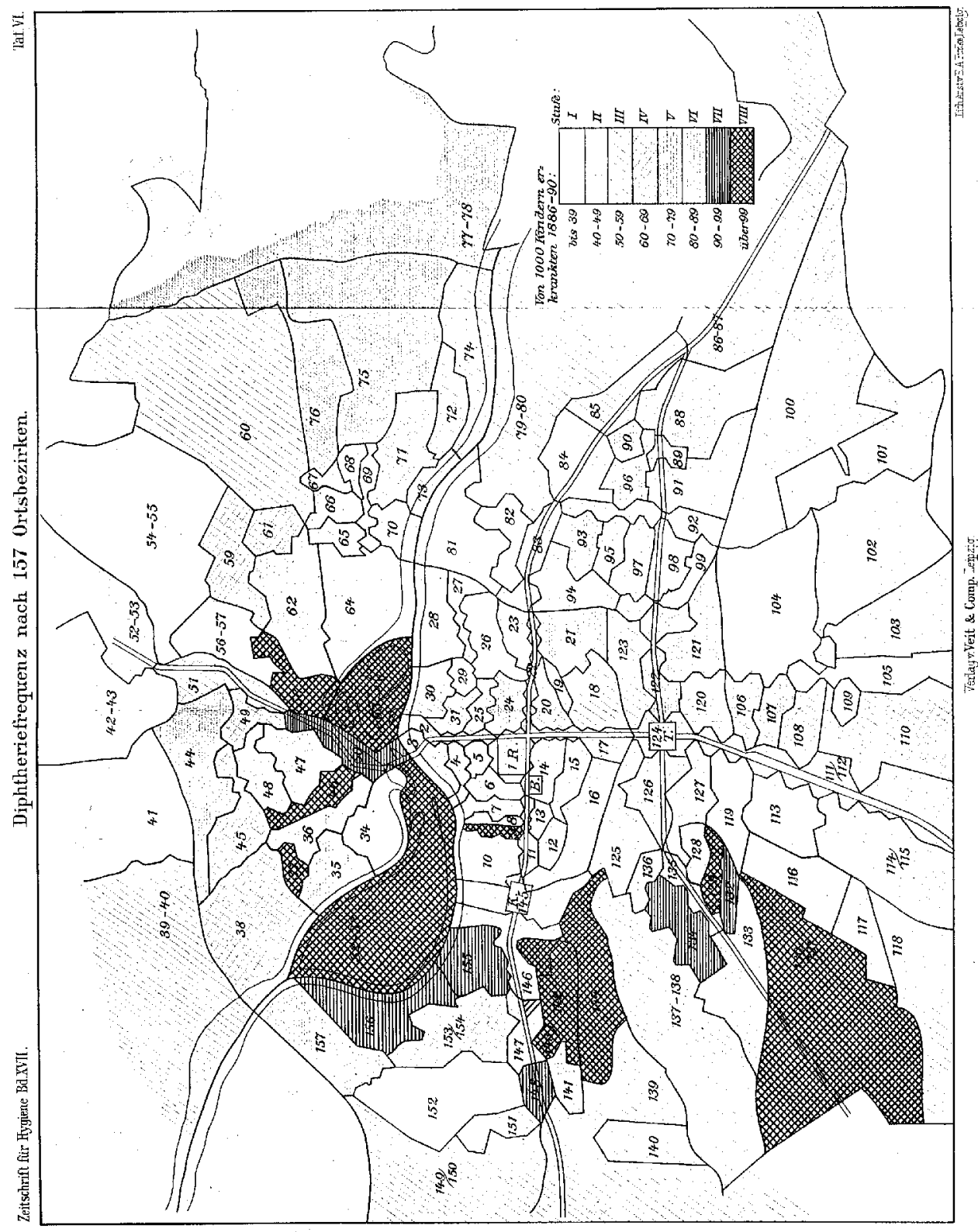




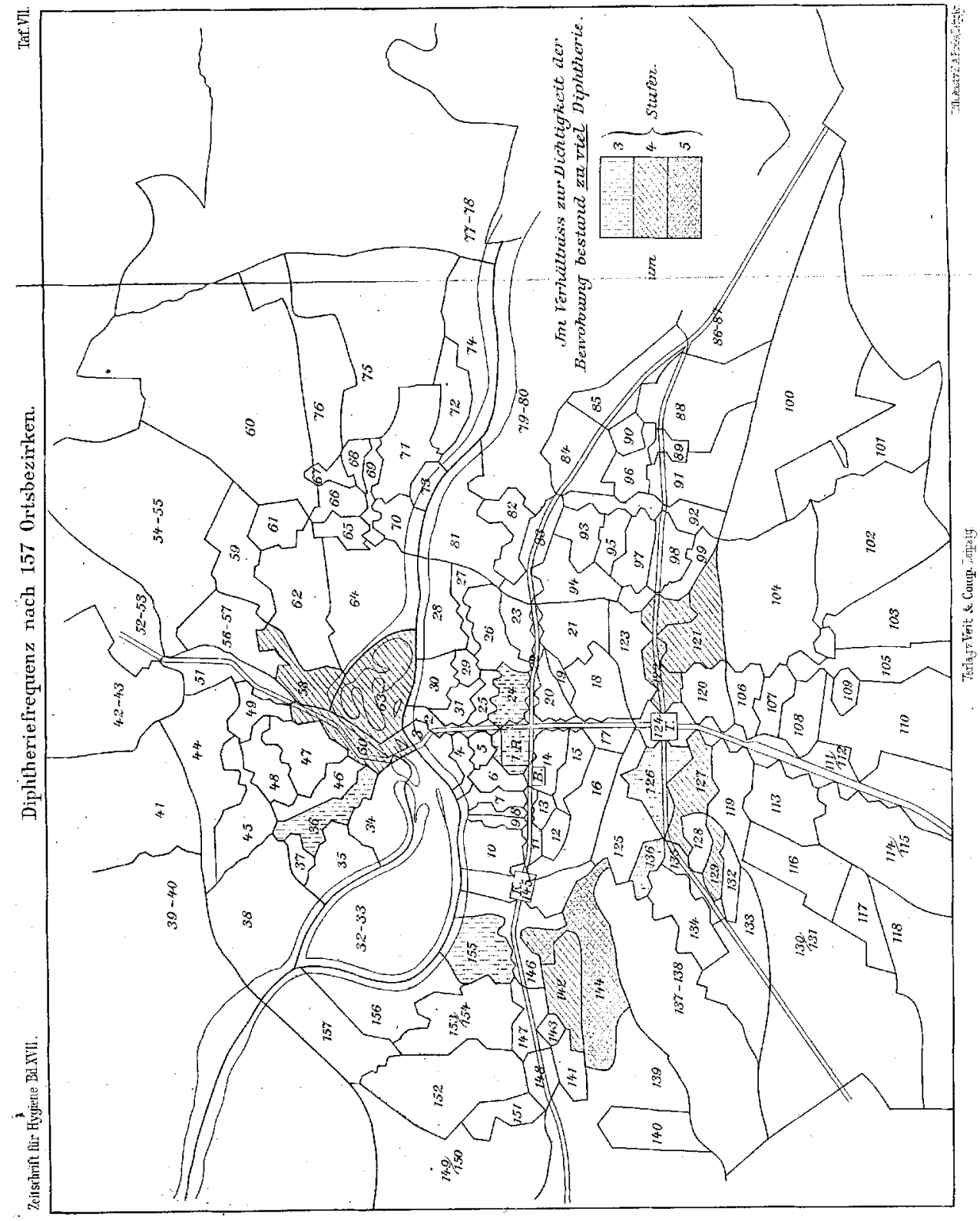




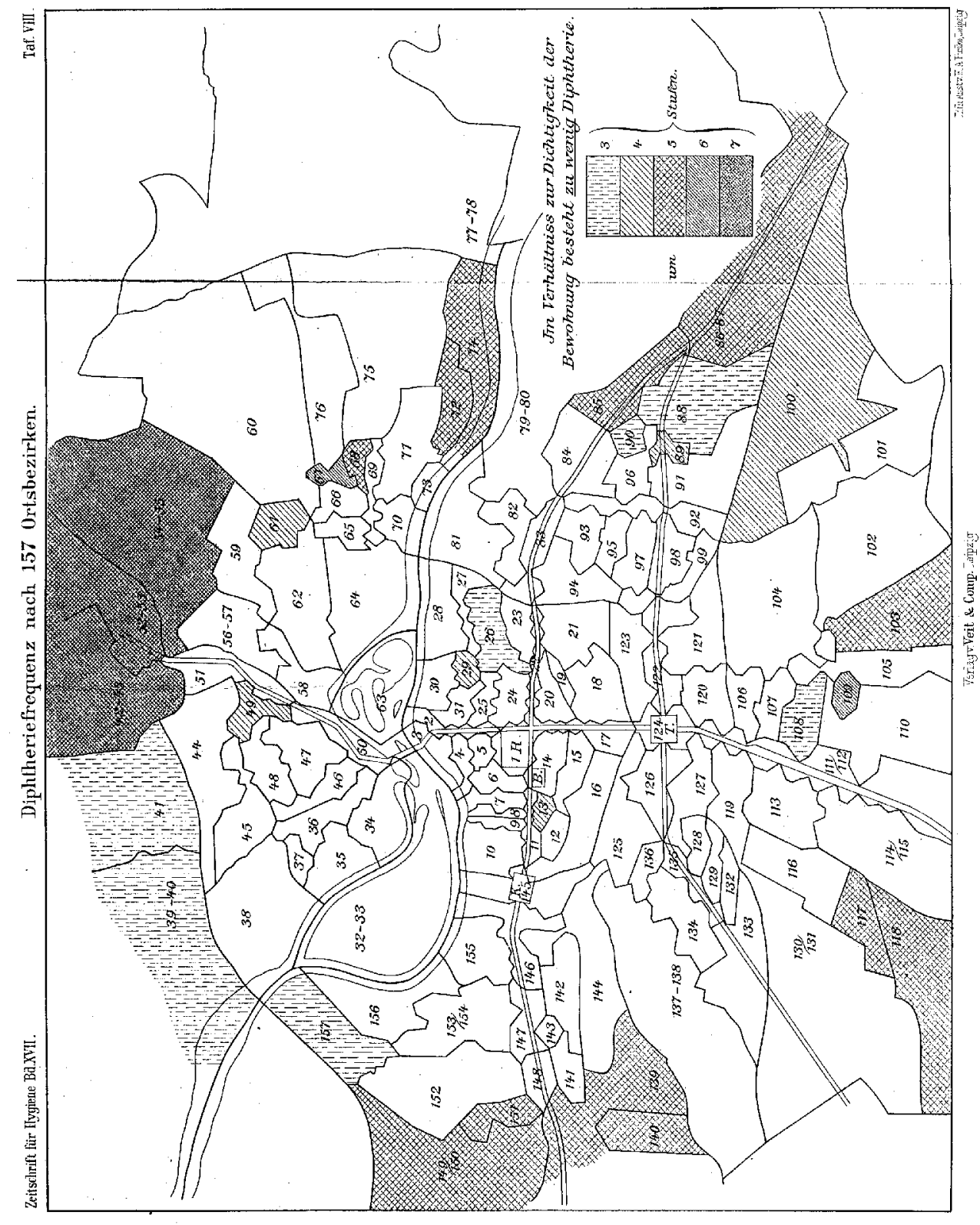



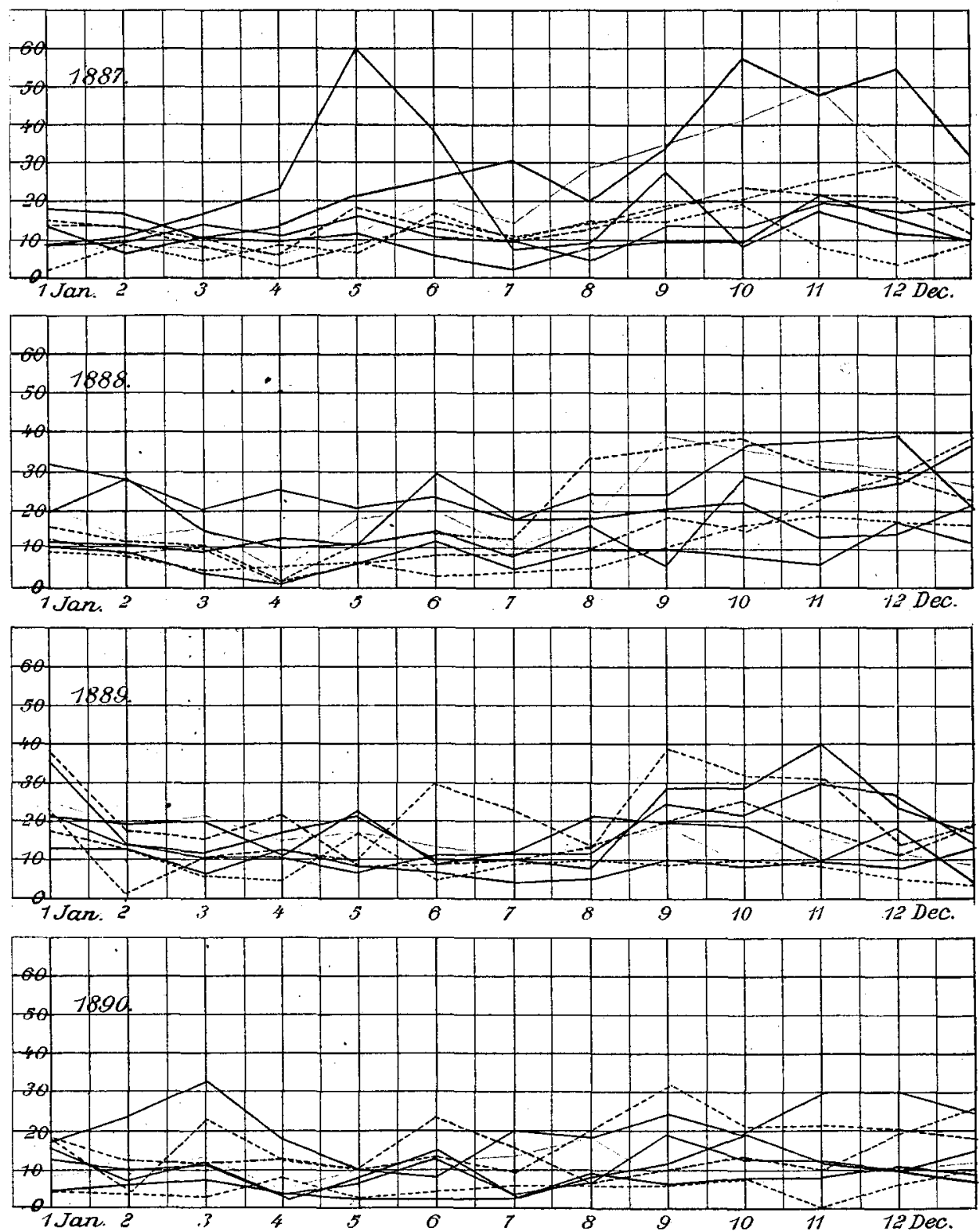

Jahreszeitliche Vertheilung der Diphtherieerkrankungen in den 8 Stadtteilen Breslaus in den Jahren 1887-1890 incl.
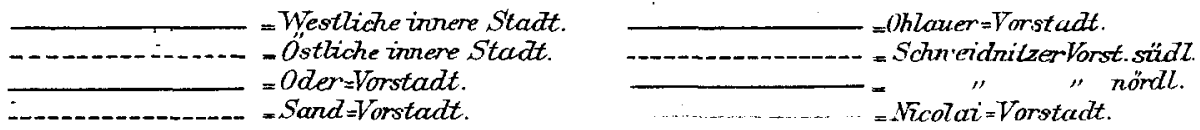